Estrutura de dados Mate Face e aplicações em geração e movimento de malhas 

SERVIÇO DE PÓS-GRADUAÇÃO DO ICMC-USP

Data de Depósito:

Assinatura:

\title{
Estrutura de dados Mate Face e aplicações em geração e movimento de malhas
}

\author{
Ícaro Lins Leitão da Cunha
}

Orientador: Prof. Dr. Antonio Castelo Filho

Dissertação apresentada ao Instituto de Ciências Matemáticas e de Computação - ICMC-USP, como parte dos requisitos para obtenção do título de Mestre em Ciências - Ciências de Computação e Matemática Computacional.

USP - São Carlos

Março/2009 

Aos meus pais. 



\section{Agradecimentos}

Agradeço primeiramente à Deus, acima de tudo e de todos.

Agradeço aos meus pais, que me serviram de grande exemplo de vida.

Às minhas irmãs e meus avôs.

Ao meu orientador e professor Antonio Castelo Filho.

Aos professores Luis Gustavo Nonato e Helio Vieira Lopes, pelo apoio, sugestões e críticas.

Aos demais professores e amigos do LCAD, com destaque para os co-autores de trabalhos: João Paulo Gois, Alexandre de Lacassa e Valdecir Polizelli. Gostaria de estender também meu agradecimento aos amigos Mario Liziér e Marcos Lage pelo apoio e sugestões.

Aos meus amigos de João Pessoa, em especial, às minhas amigas Thaíse Kelly Costa e Nathassia Guedes e minha namorada Rafaela Braga pela contribuição que deram durante a escrita dessa dissertação.

À FAPESP, pelo financiamento deste projeto. 



\section{Resumo}

Estruturas de dados (ED) topológicas oferecem diversas vantagens quando se deseja executar uma deformação sobre uma malha. Essas EDs permitem movimentar os nós da malha sem modificar sua topologia, são relativamente simples de serem implementadas e também são passíveis de serem incorporadas a um ciclo simulação/deformação de forma completamente automática e eficiente. O primeiro objetivo deste trabalho é a concepção de uma ED topológica para representação de malhas elásticas. Tais malhas podem ser do tipo superficial ou volumétrica, e ainda simples ou mista. Para melhor desempenho, confiabilidade e menor consumo de memória, deseja-se que a ED seja implícita quanto à representação de componentes incidentes e adjacentes dos elementos presentes na malha.

Outro objetivo deste trabalho é abordar o problema de geração de malhas em domínios arbitrários definidos por uma função implícita. O método proposto é uma extensão do algoritmo de Partição da Unidade Implícita (PUI). Para isso, o método proposto é baseado numa abordagem de preenchimento de superfícies. Este método proposto gera adaptativamente tetraedros em diferentes níveis de refinamento de acordo com o nível de detalhe presente na região do domínio. Diferentemente de trabalhos anteriores, esta característica é feita naturalmente sem necessitar de uma estrutura auxiliar. Para este fim, usa-se uma estrutura algébrica chamada de triangulação $J_{1}^{a}$ queé capaz de lidar com tais refinamentos. Além do mais, a triangulação $J_{1}^{a}$ permite que se percorra a estrutura simplesmente através de regras algébricas que é uma outra vantagem do método proposto. 



\section{Abstract}

Topological data Structures (DS) offer several advantages when performing a deformation on a mesh. These DSs allow movement throughout the mesh without modifying its topology, are relatively simple to implement, and there is always the possibility of merging it to simulation/deformation cycle on a completely automatic and efficient form. The main goal of this work is to design and implement a topological DS to represent elastic meshes. These meshes can be either of surface or volume kind, and even simple or mixed. For better performance, more reliability and lower memory consumption, it is necessary that the DSs allow the representation of incident and adjacent components of a given element to be implicit.

The second objective to this work is to tackle the problem of mesh generation on arbitrary domains defined by implicit functions. The proposed method is an extension to the algorithm of Partition of Unity Implicits (PUI). For this the proposed method is based on an isosurface stuffing approach. It adaptively generates the tetrahedra in different levels of refinement accordingly to the level of detail presented by the regions of the domain. Differently to previous work, this feature is done naturally without the aid of an auxiliary data structure. To this end, we use an algebraic structure, named $J_{1}^{a}$ triangulation, which is capable of dealing with such refinements. In addition, the $J_{1}^{a}$ triangulation permits traversing through the mesh by simply using algebraic rules which is another advantage to the proposed method. 



\section{Conteúdo}

Conteúdo $\quad$ i

Lista de Figuras $\quad$ v

Lista de Tabelas $\quad$ xi

1 Introdução 1

1.1 Contextualização e Motivação . . . . . . . . . . . . . . . . . . . . . 1

1.1.1 ED Topológica . . . . . . . . . . . . . . . . . 1

1.1.2 Geração de Malhas . . . . . . . . . . . . . . . . . . . 4

1.1.3 Plataforma ..................... 4

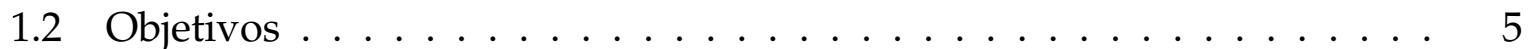

1.3 Organização da Dissertação . . . . . . . . . . . . . . . . . . 5

2 Conceitos Básicos $\quad 7$

2.1 Complexo Celular e Malhas . . . . . . . . . . . . . . . . 7

2.2 Malhas Elásticas . . . . . . . . . . . . . . . . . . . . 13

2.3 Considerações Finais . . . . . . . . . . . . . . . . . . . . 18

3 Estruturas de Dados Topológicas $\quad 19$

3.1 Estruturas de Dados 2D . . . . . . . . . . . . . . . . . . . 20

3.1.1 Winged-Edge ...................... 21

3.1 .2 Half-Edge........................ 22

3.1 .3 Handle-Edge . . . . . . . . . . . . . . . . . . 23

3.1.4 Corner-Table ....................... 24

3.1 .5 Compact Half-Edge . . . . . . . . . . . . . . . . . 24 
Conteúdo

3.2 Estruturas de Dados $3 \mathrm{D} \ldots \ldots \ldots \ldots$

3.2.1 Handle-Face . . . . . . . . . . . . . . . . . 27

3.2.2 Compact Half-Face . . . . . . . . . . . . . . . . . . . 28

3.3 Estrutura de Dados - Opposite Face . . . . . . . . . . . . . . . . . . . . 29

3.3 .1 A estrutura . . . . . . . . . . . . . . 30

3.3 .2 Perfil de malha . . . . . . . . . . . . . . . 31

3.3.3 Exemplo de aplicação usando a OF . . . . . . . . . . . . . . . . 31

3.4 Considerações Finais . . . . . . . . . . . . . . . . . 35

4 Mate Face $\quad 37$

4.1 Implementação . . . . . . . . . . . . . . . . . . . . 38

$4.1 .1 \quad$ Perfil de malha . . . . . . . . . . . . . . . . 38

4.1 .2 Vetor de elementos . . . . . . . . . . . . . . . 39

4.2 Composição da ED MF . . . . . . . . . . . . . . . . . . . . . . . . . . . 39

4.2 .1 Vértice . . . . . . . . . . . . . . . . . . 40

4.2 .2 Aresta ........................... 41

4.2 .3 Face . . . . . . . . . . . . . . . . . 42

4.2 .4 Célula . . . . . . . . . . . . . . . . . . . 42

4.2 .5 Malha ......................... 44

4.2 .6 Estruturas auxiliares . . . . . . . . . . . . . . . . 45

4.2 .7 Iteradores . . . . . . . . . . . . . . . . . 45

4.2 .8 Suporte a formatos de arquivos . . . . . . . . . . . . . . 46

4.2 .9 Cálculos geométricos . . . . . . . . . . . . . . . . 46

4.2 .10 Operações topológicas . . . . . . . . . . . . . . . 47

4.3 Adaptação da $\mathrm{OF} \ldots \ldots$. . . . . . . . . . . . . . . . . 47

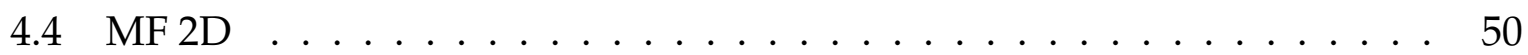

4.4.1 Malhas triangulares . . . . . . . . . . . . . . 51

4.4 .2 Malhas quadriláteras . . . . . . . . . . . . . . 53

4.4 .3 Malhas mistas . . . . . . . . . . . . . . . . . . . 54

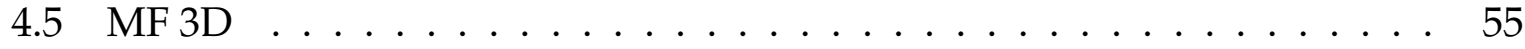

4.5.1 Malhas tetraédricas . . . . . . . . . . . . . . 57

4.5 .2 Malhas hexaédricas . . . . . . . . . . . . . . . . . . . 59

4.5.3 Malhas prismáticas e malhas piramidais . . . . . . . . . . 59

4.5 .4 Resultados . . . . . . . . . . . . . . 60

4.6 Considerações Finais . . . . . . . . . . . . . . . . . . 63 
5 Geração Algébrica de Malhas Adaptativas a partir de Funções Implícitas 65

5.1 Trabalhos Relacionados . . . . . . . . . . . . . . . . . . . . . . 67

$5.1 .1 \quad$ Isosurface Stuffing . . . . . . . . . . . . . . . . . . 68

5.2 Aproximação de Superfície Implícita a Partir de Nuvem de Pontos e a Triangulação $J_{1}^{a} \ldots \ldots \ldots \ldots \ldots$. . . . . . . . . . . . . . 69

5.2.1 Partição da Unidade Implícita em Multinível . . . . . . . . . . . . 69

5.2 .2 A Triangulação $J_{1}^{a} \ldots \ldots \ldots \ldots$. . . . . . . . . . . . . . . . . . . 70

5.3 Geração de Malhas Adaptativas Algébricas . . . . . . . . . . . . . . . 73

5.3.1 Avaliação de vértices, pontos de corte e Warping . . . . . . . . . 75

5.3 .2 Triangulação por estêncil . . . . . . . . . . . . . . 76

5.4 Prova de Qualidade dos Ângulos Diedrais . . . . . . . . . . . . . . 78

5.5 Resultados . . . . . . . . . . . . . . . . . . . . . 82

5.6 Considerações Finais . . . . . . . . . . . . . . . . . . . . . 86

6 Aplicações $\quad 91$

6.1 Execução de malha dinâmica . . . . . . . . . . . . . . . . . . . . . . 91

6.1.1 Vértices ativos . . . . . . . . . . . . . . . . . 92

6.1 .2 Passos de iteração . . . . . . . . . . . . . . . . . 93

6.2 Aplicação I - Movimento de malha triangular plana . . . . . . . . . . . . 94

6.3 Aplicação II - Movimento de malha mista plana . . . . . . . . . . . . . . 96

7 Conclusão $\quad 99$

7.1 Trabalhos Futuros . . . . . . . . . . . . . . . . . . 100

$\begin{array}{ll}\text { Referências Bibliográficas } & 103\end{array}$

$\begin{array}{ll}\text { A Códigos Exemplos } & 109\end{array}$ 
Conteúdo 


\section{Lista de Figuras}

1.1 Ilustração da composição da estrutura de dados topológica. . . . . . . . 3

2.1 Um exemplo que representa um complexo celular (esquerda) e um exemplo que não representa um complexo celular (direita). . . . . . . . 9

2.2 Adjacências entre células. . . . . . . . . . . . . . . . . . . 10

2.3 Complexo celular orientado no sentido anti-horário. . . . . . . . . . . 11

2.4 Operações de estrela e elo. . . . . . . . . . . . . . . . . . . . . . . 11

2.5 Variedades (a) e (b) e não-variedade (c). . . . . . . . . . . . . . . . 12

2.6 Tipos de células que são representadas dentro do escopo deste projeto. . 13

2.7 Exemplo de uma malha que não se caracteriza por ser um complexo celular, apesar de ser uma decomposição celular. Neste caso, a interseção entre as 2-células 1 e 2 não é uma face comum. . . . . . . . . . . . . . . 13

2.8 Tipos de molas usadas nas aplicações de malhas elásticas deste projeto. . 16

2.9 Ilustração da composição do coeficiente de rigidez total na aresta $e_{i j}$ formado por duas molas torcionais e sua mola longitudinal. . . . . . . . 17

3.1 Linha de tempo dos trabalhos anteriores para EDs 2D . . . . . . . . . . 21

3.2 Representação de informações de uma aresta armazenada por uma

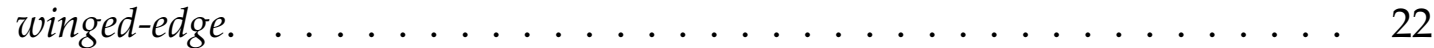

3.3 Uma half-edge com a associação de seus elementos incidentes. . . . . . . 23

3.4 Formas de composição de uma aresta de interior (esquerda) e uma aresta de bordo (direita). . . . . . . . . . . . . . . . . . . . 23

3.5 Vértices, corners e faces de um tetraedro aberto. . . . . . . . . . . . . 25

3.6 Ilustração da composição dos 4 níveis da estrutura CHE. . . . . . . . . 27

3.7 Linha de tempo dos trabalhos anteriores para EDs 3D . . . . . . . . . . 27 


\section{Lista de Figuras}

3.8 Ilustração da composição dos 4 níveis da estrutura CHF. . . . . . . . . . 29

3.9 Representação explícita básica de uma malha superficial 2D . . . . . . . . 31

3.10 Representação explícita básica de uma malha superficial 3D . . . . . . . . 32

3.11 Perfil de uma malha usada no sistema CyberMed. . . . . . . . . . . . . 33

3.12 Visualização do tórax humano com 3 camadas: sistema digestivo, esqueleto e pele. . . . . . . . . . . . . . . 34

3.13 Visualização de um estágio da simulação de coleta de medula óssea. 35

4.1 Vetor de alocação por blocos. . . . . . . . . . . . . . . . . . . . 40

4.2 Vértice singular com as células incidentes destacadas. . . . . . . . . . . 40

4.3 Composição básica do vértice de uma malha plana. . . . . . . . . . . . . 41

4.4 Composição básica da célula triangular. . . . . . . . . . . . . . . . . . . 42

4.5 Composição básica da célula tetraédrica. . . . . . . . . . . . . . . . . . 43

4.6 Tipos de células e indexação de seus vértices baseados no modelo padrão do formato VTK. . . . . . . . . . . . . . . . . . . . 43

4.7 Problema de indexação de vizinhança usando a idéia de corners opostos em células quadriláteras (a) e hexaédricas (b) . . . . . . . . . . . . . . 48

4.8 Abordagem de vizinhança por half-edge (he) em células quadriláteras (a) e por half-face (hf) em células tetraédricas (b) . . . . . . . . . . . . . . . . 48

4.9 Operação de estrela de um vértice na MF, onde a célula 0 é a célula inicial da busca da operação. . . . . . . . . . . . . . . . . . 50

4.10 Operação de estrela de um vértice de interior em uma malha superficial mista. . . . . . . . . . . . . . . . . . . . 50

4.11 Ilustração da MF 2D básica. . . . . . . . . . . . . . . . . . . 51

4.12 Indexação de elementos de uma célula triangular. . . . . . . . . . . . . . 51

4.13 Representação da malha do modelo Olivier Hand. Este modelo foi obtido do repositório Aim@Shape. . . . . . . . . . . . . . . . . . . . . . . 53

4.14 Representação em wireframe da malha de um elefante onde foi atribuído a cada vértice um valor de acordo com uma simulação de equação de calor. 53

4.15 Duas visualizações da malha do modelo de um busto, que foi obtido do repositório Aim@Shape.

4.16 Representação da malha superficial mista de um modelo CAD obtido do repositório Aim@Shape. . . . . . . . . . . . . . . . . . 56

4.17 Ilustração da MF 3D básica. . . . . . . . . . . . . . . . . . . . . 56

4.18 Ilustração das células resultantes da operação estrela da aresta em vermelho. 
4.19 Indexação de elementos de uma célula tetraédrica. . . . . . . . . . . . . 58

4.20 Visualização dos vértices internos (em amarelo) e de bordo (em vermelho) do modelo Stanford Bunny. . . . . . . . . . . . . . . . . 58

4.21 Visualização do resultado de uma simulação numérica de um modelo que representa parte de um reator nuclear. Este modelo em conjunto com os dados da simulação foi obtido do repositório Aim@Shape. . . . .

4.22 Visualização dos vértices internos (em amarelo) e de bordo (em vermelho) do modelo Bump. . . . . . . . . . . . . . . . . . . . 60

4.23 Visualização das arestas internas (em amarelo) e externas (em vermelho) do modelo Fru. . . . . . . . . . . . . . . . . . . . . . 60

5.1 Visualização da malha do Stanford Bunny. . . . . . . . . . . . . . . . . 67

5.2 Ilustração bidimensional do comportamento do refinamento dos blocos de uma triangulação $J_{1}^{a}$ induzidos pelo critério de erro da aproximação. . 71

5.3 Exemplo 2D de uma grade da triangulação $J_{1}^{a}$ (esquerda) e detalhes do bloco $g=(3,2), r=0$ onde é mostrado dois percursos para traçar os simplexos do bloco (direita). Esta figura foi adaptada do trabalho [19]. . 72

5.4 Ilustração do bloco de transição 3D onde são rotulados os tipos de tetraedros destacados na Figura 5.5 . . . . . . . . . . . . . . . 74

5.5 Ilustração dos 7 tipos de tetraedros existentes na triangulação $J_{1}^{a} 3 \mathrm{D}$. O tetraedro do canto superior esquerdo pertence ao bloco básico e os seis restantes pertencem ao bloco de transição. . . . . . . . . . . . . . . 75

5.6 Conjunto de estênceis para gerar a triangulação dos tetraedros. Os vértices dos tetraedros são rotulados com os sinais $(0,+,-)$, os pontos de corte estão em branco e a triangulação resultante está em azul. É fácil notar que os cinco estênceis de baixo geram de dois a três tetraedros. Mesmo que a triangulação $J_{1}^{a}$ apresente sete tipos de tetraedros, o tetraedro de bloco básico foi escolhido para representar o estêncil sem qualquer perda de generalidade. Esta figura foi adaptada do trabalho [19]. 77

5.7 Exemplo de duas faces quadriláteras vizinhas que precisam ser cortadas por uma mesma diagonal (em amarelo). Os tetraedros à esquerda (formado por $v_{0}, v_{1}, v_{2}$ e $v_{3^{\prime}}$ ) e à direita (formado por $v_{0}, v_{1}, v_{2}$ e $v_{3^{\prime \prime}}$ ) foram rotacionados em sentidos opostos em relação a aresta formada por $v_{0}$ e $v_{1}$ para melhor visualizar as faces vizinhas. . . . . . . . . . . . 78 
5.8 Ordem de construção dos vértices do tetraedro da triangulação $J_{1}^{a}$. Como ilustrado, o primeiro vértice localiza-se no centro do bloco; o segundo é o centro de face do bloco; o terceiro é o centro de uma aresta; e o quarto é um vértice do bloco. Esta figura foi obtida do trabalho [19]. . . . . . . . 79

5.9 Ilustração de um asterístico do vértice $v_{0} \ldots \ldots \ldots$. . . . . . . . . 81

5.10 Malhas do modelo de vaso, a primeira mala foi gerada sem o uso da regra de warping e a segunda foi gerada com o uso da regra de warping. .

5.11 Aproximação de regiões das malhas do vaso para melhor demonstrar a diferença do resultado sem o uso de warping (à esquerda) e com o uso de warping (à direita) . . . . . . . . . . . . . . . . . . 84

5.12 Malha do Dragão Chinês composta por 1053k tetraedros. . . . . . . . . . 85

5.13 Ilustração da relação de qualidade de tetraedros de algumas malhas geradas pelo método proposto. . . . . . . . . . . . . 86

5.14 Vaso sem warping, esta malha apresentou razão de aspecto médio de 3,61 com desvio padrão de 4,1706 e pior elemento com valor acima de 20 . . 87

5.15 Vaso com warping, esta malha apresentou razão de aspecto médio de 1,77 com desvio padrão de 0,2904 e pior elemento com valor de 15,5 . . . . . 87

5.16 Dragão chinês, esta malha apresentou razão de aspecto médio de 1,84 com desvio padrão de 0,36899 e pior elemento com valor de 19,9 . . . . . 87

5.17 Stanford Bunny, esta malha apresentou razão de aspecto médio de 1,86 com desvio padrão de 0,4032 e pior elemento com valor de 19,9 . . . . . 88

5.18 Duas Esferas, esta malha apresentou razão de aspecto médio de 1,8197 com desvio padrão de 0,3544 e pior elemento com valor de 4,9. . . . . . .

5.19 Elipse, esta malha apresentou razão de aspecto médio de 1,8019 com desvio padrão de 0,3277 e pior elemento com valor de 4,3 . . . . . . . 88

5.20 Coração, esta malha apresentou razão de aspecto médio de 1,7293 com desvio padrão de 0,2272 e pior elemento com valor de 4,2 . . . . . . . . .

5.21 Witch Hat, esta malha apresentou razão de aspecto médio de 1,807 com desvio padrão de 0,33128 e pior elemento com valor de 5,1 . . . . . . . .

6.1 Malha que representa a parte externa do aerofólio. O bordo interno da malha (que representa o aerofólio) está localizado no centro da malha. .

6.2 Execução do passos da Aplicação I e comparação entre a malha original e o resultado final. . . . . . . . . . . . . . . . . 95

6.3 Aproximação das regiões consideradas mais críticas após 60 passos. . . . 96 


\section{Lista de Figuras}

6.4 Malha da mão original formada por 6207 vértices e 4345 células. Esta malha foi gerada pelo algoritmo de geração de malhas proposto por Mario Augusto de Souza Liziér. . . . . . . . . . . . . . . . . . . . . 97

6.5 Execução do passos da Aplicação II e comparação entre a malha original e o resultado final. . . . . . . . . . . . . . . . . . . . . . . . 98 
Lista de Figuras 


\section{Lista de Tabelas}

2.1 Relação de elementos de célula . . . . . . . . . . . . . . . . . . . . 12

3.1 Dados armazenados referentes a aresta $a$ da Figura 3.2. . . . . . . . . 22

3.2 Lista de dados do tetraedro. . . . . . . . . . . . . . . . . . 25

3.3 Composição das camadas do tórax. . . . . . . . . . . . . . . . . . 33

3.4 Composição dos objetos usados na simulação de coleta de medula óssea. 34

4.1 Relação de malhas usadas nos testes. . . . . . . . . . . . . . . . . . . . 61

4.2 Comparação de tempo (em segundos) da execução de carga de malhas pelas EDs OF, MF e MF Implícita. . . . . . . . . . . . . . . . . . . . . . 62

4.3 Comparação de tempo (em segundos) da execução da estrela dos vértices das malhas pelas EDs OF e MF. . . . . . . . . . . . . . . . . 62

5.1 Relação de ângulos diedrais mínimos e máximos dos tetraedros (apresentados na Figura 5.5) que compõem a triangulação $J_{1}^{a}$. . . . . . . 79

5.2 Tempo de geração das malhas ilustradas na Figura 5.13 de acordo com a etapa. A unidade de tempo é dada em segundos. . . . . . . . . . . . . . . 84 
Lista de Tabelas 


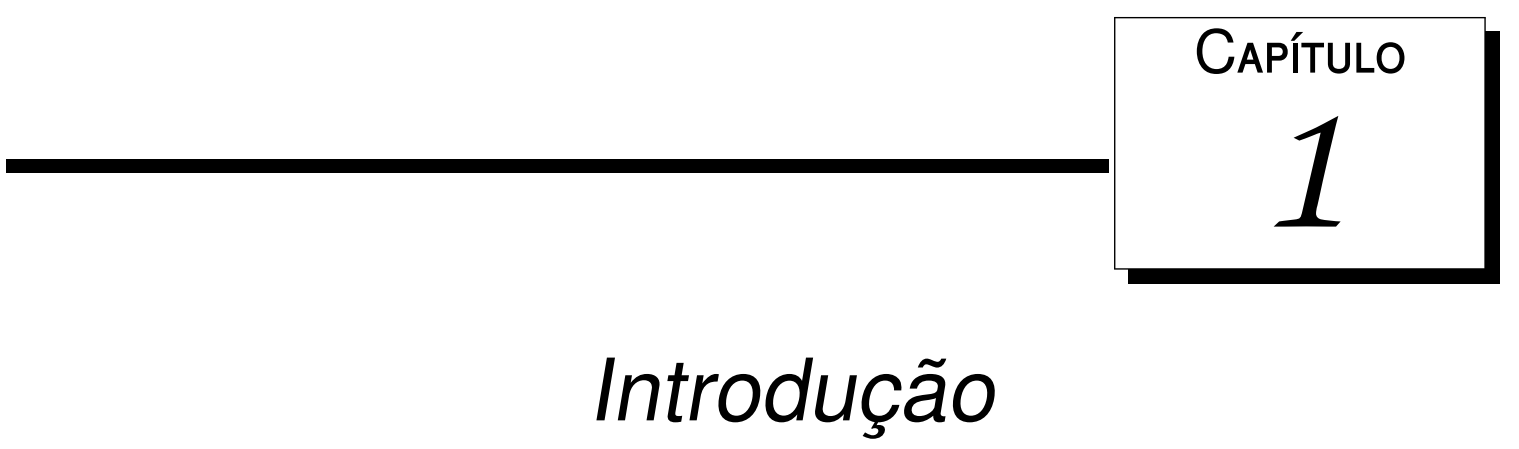

Neste capítulo, serão introduzidos os temas estudados neste trabalho: estrutura de dados (ED) topológica e geração de malhas tetraédricas. O primeiro tema envolve a implementação de uma ED capaz de representar malhas bidimensionais e tridimensionais a serem utilizadas em aplicações de malhas elásticas. O segundo problema envolve a implementação de um gerador de malhas tetraédricas com boa qualidade.

\subsection{Contextualização e Motivação}

\subsubsection{ED Topológica}

A simulação numérica pode, em poucas palavras, ser definida como a arte de reproduzir e prever fenômenos da natureza em um computador. Ao longo dos anos, a simulação numérica vem ganhando importância nas tentativas de compreensão desses fenômenos e tornou-se ferramenta fundamental no desenvolvimento de novas tecnologias empregadas nas mais diversas áreas do conhecimento.

A mecânica dos fluidos é uma disciplina onde os métodos numéricos e a simulação computacional vêm sendo aplicados há vários anos com muito sucesso. O progresso científico e tecnológico que adveio desse conhecimento culminou com o aparecimento de uma nova área do conhecimento, a Mecânica dos Fluidos Computacional (CFD).

Em muitas aplicações, um dos aspectos comuns aos problemas de CFD é sem dúvida a complexidade da geometria do domínio em que se dá o escoamento. A 


\section{Introdução}

representação computacional do domínio torna-se assim, um dos primeiros problemas a serem enfrentados. Neste contexto, a modelagem geométrica desempenha um papel primordial, uma vez que problemas inerentes dessa área de aplicação, como por exemplo, a representação de domínios complexos, decomposições espaciais, manipulação e movimento de malhas, são naturalmente tratados pelas ferramentas oriundas da modelagem geométrica.

A questão, portanto, é que em simulações numéricas de escoamento de fluidos, algumas superfícies não podem ser consideradas como corpos rígidos. Considere, por exemplo, a asa de um avião em vôo. A força originária do escoamento do ar pela asa pode ser intensa o suficiente para deformar sua estrutura. Essa deformação altera o escoamento de ar e, consequentemente, a configuração do campo de forças devido ao escoamento do fluido. Desta forma, um ciclo de simulação do escoamento de um fluido no entorno de uma estrutura elástica, como a asa de um avião, exige que simulações da deformação da estrutura sejam acopladas às simulações do escoamento do fluido $[23,35]$. Observe que neste ciclo fluido-estrutura, a malha fluídica (malha em torno da estrutura onde será efetuada a simulação) precisa se ajustar à nova descrição geométrica ditada pela deformação da estrutura, e aqui é justamente onde a modelagem geométrica pode contribuir.

Existem três formas de se realizar o ajuste de uma malha fluídica à nova descrição geométrica definida pela deformação de uma estrutura. A primeira é gerar uma nova malha a partir da nova geometria. Essa opção não é adequada, pois exige a intervenção do gerador de malhas durante o ciclo simulação/deformação, o que tornaria o processo inviável. Uma segunda opção é reaproveitar grande parte da malha original, alterando apenas as regiões afetadas pela deformação [58]. Muito embora esta seja uma opção robusta e possível de ser automatizada, ela é consideravelmente complexa de ser implementada e requer bons algoritmos de interpolação para transferir os dados da malha original à malha modificada. A terceira opção consiste em apenas movimentar os nós da malha original evitando qualquer alteração em sua conectividade (topologia). Essa última opção oferece diversas vantagens, pois além de sua implementação ser relativamente simples, ela também é passível de ser incorporada ao ciclo simulação/deformação de forma completamente automática e eficiente.

Portanto, além das questões relacionadas com a representação de malhas e domínios, problemas envolvendo movimento de malhas podem ser mais facilmente tratados com o uso de modelagem geométrica. O casamento entre modelos elásticos e estruturas de dados topológicas possibilita que inconsistências como sobreposição de 


\section{Introdução}

células e elementos com razão de aspecto ruim sejam detectados e tratados dentro de um contexto topológico, facilitando a implementação.

Estruturas de dados (ED) topológicas buscam indexar os elementos da malha de modo a representar as relações de incidência e adjacência entre tais elementos, garantindo ainda um acesso eficiente a suas informações [46, 9]. Muitas das estruturas topológicas descritas na literatura visam indexar os dados de modo a facilitar os mecanismos de acesso as relações de vizinhança e as buscas empregadas na construção ou leitura das malhas [36], viabilizando ainda o controle de procedimentos adaptativos.

Outro aspecto importante que merece ser discutido é a forma de armazenamento empregada por essas estruturas. Neste caso, podendo ser de forma explícita (onde dados como relações de adjacência podem ser armazenados em listas ou vetores), ou de forma implícita (onde as relações podem ser obtidas através de operações algébricas).

Vale ressaltar o interesse deste trabalho na concepção de uma ED topológica que possibilite obter as principais relações de incidência e adjacência de um dado elemento de uma malha. O acesso a essas relações deve ser em tempo constante ou proporcional ao número de elementos vizinhos do elemento em questão. Desta forma, a construção de uma estrutura implícita que possa ser empregada em qualquer tipo de decomposição celular (seja ela simples ou mista) ainda é um desafio.

Dividindo as malhas em bidimensionais e tridimensionais (de acordo com o seu elemento de maior dimensão), têm-se, para cada caso, diferentes tipos de elementos. No caso bidimensional, o domínio poderá ser composto por triângulos e quadriláteros. Já no contexto tridimensional, os elementos poderão ser tetraedros, prismas de base triangular, pirâmides de base quadrangular e hexaedros. A Figura 1.1 ilustra essa organização. O termo malha mista será utilizado para os casos em que a malha é composta por mais de um tipo de elemento.

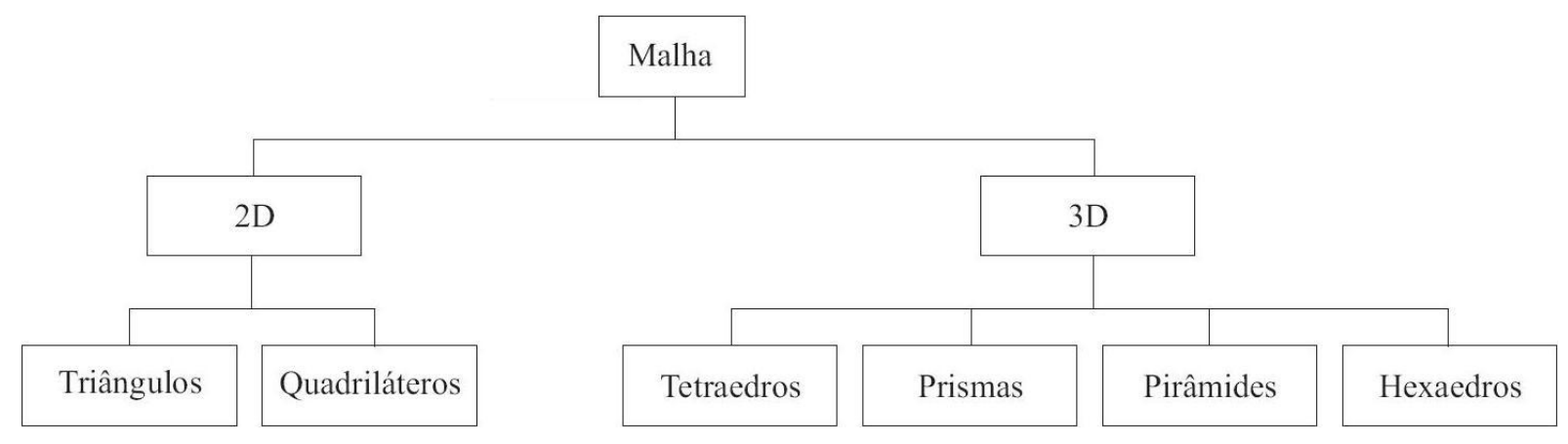

Figura 1.1: Ilustração da composição da estrutura de dados topológica.

Uma característica importante levada em consideração na concepção da ED é a de 
abstrair, o máximo possível, o conhecimento necessário sobre EDs topológicas. Para isso, é necessário que ela tenha uma interface simples e eficiente, além de ter uma documentação completa de toda sua estrutura (classes, atributos, métodos, etc.). Deste modo seus usuários poderão utilizá-la sem necessitar conhecer os mecanismos internos de funcionamento da ED.

\subsubsection{Geração de Malhas}

Outro foco deste trabalho foi abordar o problema de geração de malhas tetraédricas em domínios arbitrários definidos por funções implícitas. Foi proposta uma abordagem para esse problema baseada no método de Isosurface Stuffing proposto por Labelle e Shewchuk [37]. A abordagem, aqui proposta, gera malhas adaptativas em diferentes níveis de refinamento de acordo com os detalhes apresentados pelas regiões do domínio. Para tal propósito, a triangulação $J_{1}^{a}$ proposta por Castelo et al. [14] foi utilizada.

Para tal feito, o trabalho baseado na Partição da Unidade Implícita em Multi-nível (PUI) proposta por Gois et al. [30] foi estendido para um método de geração de malhas adaptativas tetraédricas que emprega o uso de estênceis tetraédricos e regras de warping de pontos apresentados em [37]. Este trabalho tem como foco gerar malhas volumétricas com boa qualidade de tetraedros.

A etapa inicial do método PUI é utilizada para obter uma malha tetraédrica inicial e também aproximar a função implícita de uma superfície. Esta função implícita determina a posição de um vértice relativa a superfície e permite calcular onde uma aresta transversal (arestas com um vértice dentro da superfície e com o outro fora da superfície) intersecta a superfície, este ponto será denominado de ponto de corte. A partir desta malha inicial, são empregadas as idéias apresentadas em [37].

Pelo fato da triangulação $J_{1}^{a}$ ser utilizada neste trabalho, a malha inicial é diferente daquela utilizada em [37], por isso, foram necessárias algumas adaptações às regras de warping e aos estênceis utilizados.

\subsubsection{Plataforma}

Todo o trabalho foi desenvolvido utilizando a linguagem de programação $C++$. Esta escolha foi feita levando-se em conta o desempenho que a linguagem oferece e a possibilidade de uso de templates para permitir a concepção de uma ED flexível. Além disso, a ED é portável com relação ao sistema operacional, ou seja, no seu modo básico pode ser utilizada em qualquer sistema operacional. 
O aplicativo Doxygen ${ }^{1}$ foi escolhido para criar uma documentação padrão do código da estrutura MF. Para exibição de resultados foi utilizada a biblioteca gráfica OpenGL. Todos os trabalhos foram feitos em um computador com processador Intel Core 2 Quad de $2.4 \mathrm{GHz}$ e 4 GB de memória Ram.

\subsection{Objetivos}

Este projeto de pesquisa teve como um de seus principais objetivos desenvolver atividades relacionadas às aplicações de modelagens geométricas em CFD. O primeiro objetivo deste projeto, que é de absoluta importância para o desenvolvimento de diversas ferramentas em CFD, é desenvolver uma estrutura de dados eficiente para representação e manipulação de malhas.

Tem-se o interesse em representar tanto malhas bidimensionais (planares ou superficiais) quanto tridimensionais (volumétricas) que podem ser compostas por elementos simpliciais ou mistos. A intenção é criar e implementar um modelo de representação implícita para que a estrutura seja ao mesmo tempo leve (reduzido consumo de memória) e eficiente (retornar rapidamente as relações de incidência e adjacência). Além disso, como foi dito na seção anterior, a estrutura conterá uma interface simples e eficiente, para torná-la fácil de ser integrada em diversas aplicações que envolvem o uso de malhas.

Outro objetivo deste projeto é o desenvolvimento de um gerador de malhas tetraédricas. As malhas resultantes devem ser adaptativas e com boa qualidade de ângulos diedrais.

\subsection{Organização da Dissertação}

Nesta dissertação serão detalhados os conceitos estudados e as atividades realizadas. Ela está organizada da seguinte forma:

- Capítulo 2: nesse capítulo são abordados os fundamentos ditos como necessários para o desenvolvimento da ED deste projeto;

- Capítulo 3: nesse capítulo é apresentada uma revisão bibliográfica sobre EDs topológicas, com o maior destaque para a ED Opposite Face (OF) proposta por Mario Lizier [41] que será a base para o desenvolvimento da estrutura do projeto;

- Capítulo 4: nesse capítulo é apresentada a ED Mate Face (MF) e os detalhes de sua implementação. Esta ED auxiliou o desenvolvimento do método de geração

\footnotetext{
${ }^{1}$ Doxygen - source code documentation generator tool - Site: http://www.stack.nl/ dimitri/doxygen/
} 
de malhas apresentado no Capítulo 5 e serviu de base para a implementação das aplicações apresentadas no Capítulo 6;

- Capítulo 5: nesse capítulo é apresentado o método de geração de malhas desenvolvido. Este método é a segunda contribuição desta dissertação;

- Capítulo 6: nesse capítulo são apresentadas algumas aplicações de movimento de malhas elásticas;

- Capítulo 7: nesse capítulo é feita uma apreciação sobre os resultados obtidos e serão detalhados alguns trabalhos futuros;

- Apêndice A: nesse apêndice são apresentados alguns códigos exemplos de uso da MF que serão referenciados no Capítulo 4. 


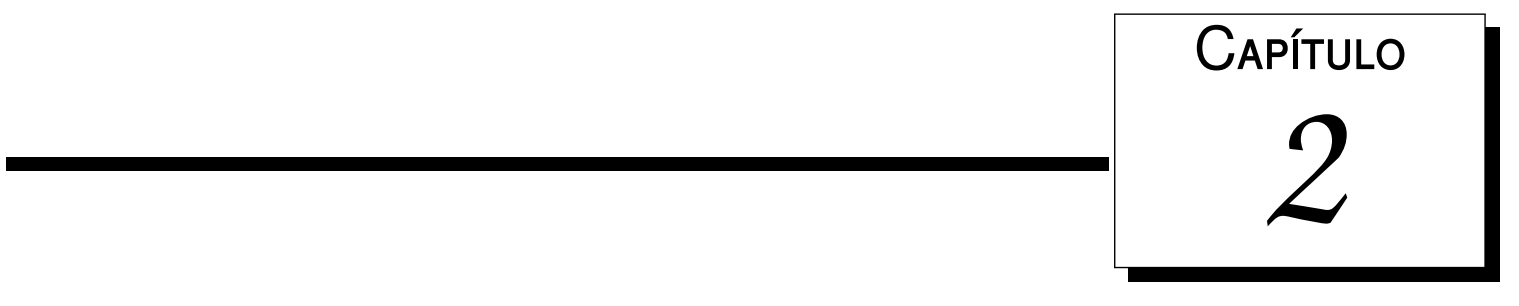

\section{Conceitos Básicos}

Neste capítulo serão revisados alguns conceitos básicos envolvendo complexos celulares. Serão introduzidos noções de células, de complexos celulares e de algumas relações topológicas. Estes conceitos foram obtidos de [12, 39]. Além disso, serão apresentados conceitos de malhas elásticas que foram utilizados na implementação das aplicações de movimento de malhas.

\subsection{Complexo Celular e Malhas}

Nesta seção apresenta-se a fundamentação teórica para contextualizar o tipo de malha estudada neste trabalho.

Definição 1 (Espaço afim) Dados $v_{0}, v_{1}, \ldots, v_{n} \in \mathbb{R}^{m}$, o espaço

$$
S=\operatorname{aff}\left\{v_{0}, \ldots, v_{n}\right\}=\left\{v \in \mathbb{R}^{m}: \sum_{i=0}^{n} \lambda_{i} v_{i}=v, e \sum_{i=0}^{n} \lambda_{i}=1\right\}
$$

é denominado espaço afim gerado por $v_{0}, v_{1}, \ldots, v_{n}$.

Definição 2 (Célula) Uma célula convexa afim gerada pelos pontos $v_{0}, v_{1}, \ldots, v_{n}$ é definida como sendo o conjunto:

$$
\sigma=\left[v_{0}, v_{1}, \ldots, v_{n}\right]=\left\{v \in \mathbb{R}^{m}: \sum_{i=0}^{n} \lambda_{i} v_{i}=v, \sum_{i=0}^{n} \lambda_{i}=1 e \lambda_{i} \geq 0\right\} .
$$


Em outra palavras, $\sigma$ é o menor conjunto convexo contendo os pontos $v_{0}, \ldots, v_{n}$.

Definição 3 (Dimensão de uma célula) A dimensão de uma célula convexa afim $\sigma=\left[v_{0}, v_{1}, \ldots, v_{n}\right]$ é definida como sendo a dimensão do espaço afim, ou seja, o menor número de vetores linearmente independentes entre $v_{1}-v_{0}, v_{2}-v_{0}, \ldots, v_{n}-v_{0}$.

Por convenção, as células de dimensão igual a 0 (0-célula) serão chamadas de vértices, as células de dimensão igual a 1 (1-célula) serão chamadas de arestas, e as células de dimensão igual a 2 (2-célula) serão chamadas de faces. Em caso geral, uma n-célula será tratada como sendo um elemento de uma malha.

Um caso particular de célula que é comumente tratado na literatura é o de simplexo.

Definição 4 (Simplexo) Um simplexo de dimensão d (d-simplexo) é uma célula convexa afim de dimensão d gerada por $d+1$ pontos.

Por convenção, o 0-simplexo é chamado de vértice, o 1-simplexo de aresta, o 2simplexo de triângulo e o 3-simplexo de tetraedro.

Definição 5 (Bordo de uma célula) O bordo de uma célula $\sigma$, denotado por $\partial(\sigma)$, éo conjunto de sub-células satisfazendo:

1. Se $\sigma^{\prime} \in \partial(\sigma)$, então $\sigma^{\prime}$ é gerado por um subconjunto de vértices de $\sigma$;

2. $\forall p \in \sigma^{\prime}$, onde $\sigma^{\prime} \in \partial(\sigma)$, não existe uma bola contendo $p$ em af $f(\sigma)$ inteiramente contida em $\sigma^{\prime}$;

3. Se $\sigma_{1}^{\prime}$ e $\sigma_{2}^{\prime}$ pertencem a $\partial(\sigma)$ e tem a mesma dimensão $\Rightarrow \sigma_{1}^{\prime} \nsubseteq \sigma_{2}^{\prime}$ e $\sigma_{2}^{\prime} \nsubseteq \sigma_{1}^{\prime}$.

Definição 6 (Face) Sejam $\gamma=\left[w_{0}, \ldots, w_{n}\right]$ uma $p$-célula convexa afim e $\sigma=\left[v_{0}, \ldots, v_{m}\right]$ uma $q$-célula. Então, se $\left\{w_{0}, \ldots, w_{n}\right\} \subset\left\{v_{0}, \ldots, v_{m}\right\}$, diz-se que $\gamma$ é uma face do bordo de $\sigma(\partial(\sigma))$ se:

1. $\gamma \subset \partial(\sigma)$;

2. Se existe alguma outra sub-célula $\eta$ cujo espaço afim é o mesmo que o de $\gamma$ (ou seja, $\operatorname{aff}(\gamma)=\operatorname{aff}(\eta))$, então $\eta \subset \gamma$.

Definição 7 (Decomposição celular) Uma coleção $C$ de células convexas afins é dita uma decomposição celular de um conjunto $K \subset \mathbb{R}^{m}$ se:

1. $K=\cup_{\sigma \in C} \sigma$; 
2. Se $\sigma_{1}, \sigma_{2} \in$ C então $\sigma_{1} \cap \sigma_{2}=\emptyset$ ou $\sigma_{1} \cap \sigma_{2} \in C$;

3. Todo subconjunto compacto de K intercepta um número finito de células de C.

Definição 8 (Triangulação) Uma decomposição celular $C$ de $K \subset \mathbb{R}^{m}$ é chamada de triangulação de $K$, se todas as células de $C$ são simplexos.

Definição 9 (Complexo celular) Um complexo celular $C$ é um conjunto finito de células convexas afins que satisfazem:

1. se $\sigma \in C$ e $\gamma$ é face de $\sigma$ então $\gamma \in C$;

2. se $\sigma_{1}$ e $\sigma_{2} \in$ C então $\sigma_{1} \cap \sigma_{2}=\emptyset$ ou $\sigma_{1} \cap \sigma_{2}$ é uma face comum de $\sigma_{1}$ e $\sigma_{2}$.

A condição 2 da Definição 9 garante que a interseção entre duas células quaisquer se dá somente por uma face em comum entre eles, impedindo assim interseções indesejadas. A Figura 2.1 à esquerda representa um exemplo de um complexo celular, e à direita, um exemplo que não representa um complexo celular.
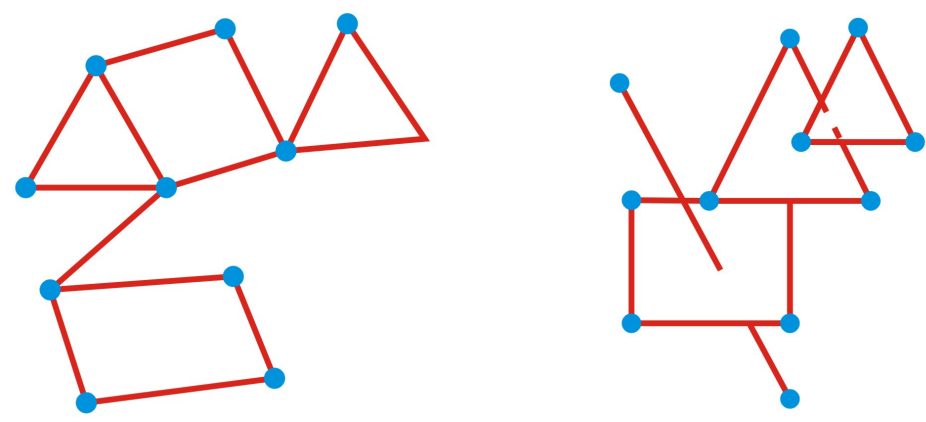

Figura 2.1: Um exemplo que representa um complexo celular (esquerda) e um exemplo que não representa um complexo celular (direita).

Neste trabalho, o conceito de adjacência entre elementos será importante para se percorrer entre elementos vizinhos de um complexo celular. Além disso, as relações topológicas tratadas são de fundamental importância para um bom desempenho de aplicativos. A seguir, serão apresentadas algumas definições relacionadas à vizinhança entre elementos.

Definição 10 (Células adjacentes) Uma célula $\sigma_{1}$ é dita adjacente (vizinha) a outra célula $\sigma_{2}$ se $\sigma_{1} \cap \sigma_{2}$ é uma face comum de $\sigma_{1}$ e $\sigma_{2}$. 
Observação 1 No caso de vértices, um vértice é dito vizinho do outro se existe uma aresta que contém os dois. Vale salientar, que esta definição de vizinho não se equivale à definição de adjacência.

A Figura 2.2 apresenta dois exemplos de adjacência entre células.

Quanto ao número máximo de vizinhos das 2-células é fácil notar que este valor se equivale ao número de arestas e, para o caso de 3-células, se equivale ao número de faces.

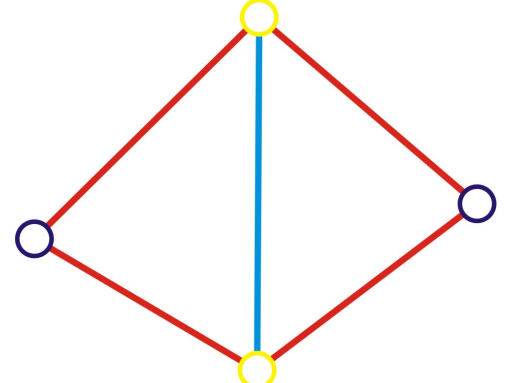

(a) Adjacência entre 2-células por uma aresta.

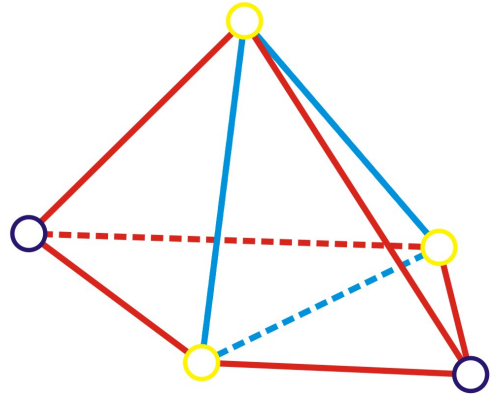

(b) Adjacência entre 3-células por uma face.

Figura 2.2: Adjacências entre células.

Definição 11 (Células incidentes) Dadas uma $p$-célula $\sigma$ e uma $k$-célula $\gamma$ onde $p>k$, estas células são ditas incidentes se $\gamma$ é uma face de $\sigma$.

Definição 12 (Orientação de células) Seja C um complexo celular de dimensão $p$, onde pé a maior dimensão de todas as suas células. A orientação de duas p-células adjacentes $\sigma$ e $\gamma$ pertencentes a $C$ é coerente se a $(p-1)$-face que compartilham tem orientação oposta em cada uma das células. O complexo celular C é orientável se uma orientação coerente pode ser escolhida para todas as suas células (Figura 2.3).

Definiçãa 13 (Ponto de acumulação) Se A é um conjunto de $\mathbb{R}^{m}$, então $x$ é um ponto de acumulação de A se qualquer aberto de $\mathbb{R}^{m}$ contendo $x$ também contém ponto de A.

Definição 14 (Fecho de conjunto) O fecho de um conjunto $A, F(A)$, é o conjunto de todos os pontos de acumulação de A.

Definição 15 (Estrela) Seja $C$ um complexo celular. A estrela (star) de um elemento $\sigma \subset C$, denotada por $S(\sigma)$ é o conjunto dos elementos de $C$ que contém $\sigma$, i.e., $S(\sigma)=\{\gamma \in C: \sigma \subseteq \gamma\}$. 


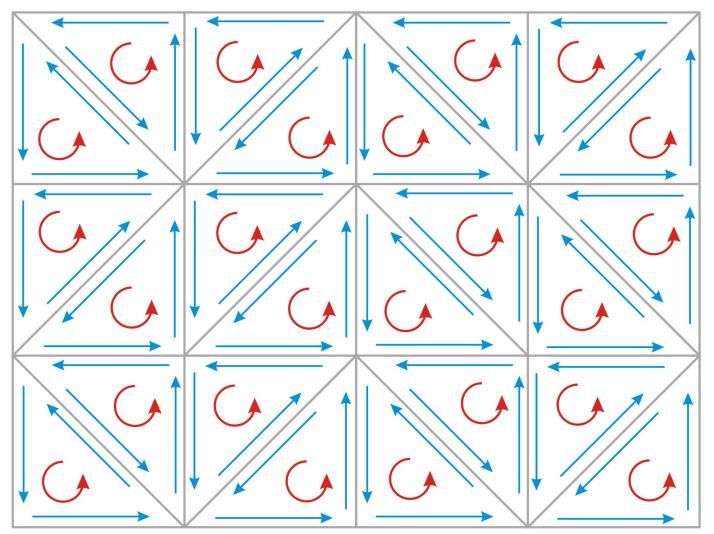

Figura 2.3: Complexo celular orientado no sentido anti-horário.

A Figura 2.4(a) ilustra um exemplo da estrela de um vértice central. As arestas em preto e as faces em laranja pertencem à estrela do vértice em azul.

Definição 16 (Elo) $O$ elo (link) de um elemento $\sigma \subset C$ denotado por $L(\sigma)$, é o conjunto $L(\sigma)=\{\gamma \in F(S(\sigma)): \gamma \cap \sigma=\emptyset\}$, onde $F(S(\sigma))$ é o fecho da estrela de $\sigma$.

A Figura 2.4(b) ilustra um exemplo de elo de um vértice central. As arestas em preto e os vértices em vermelho pertencem ao elo do vértice em azul.

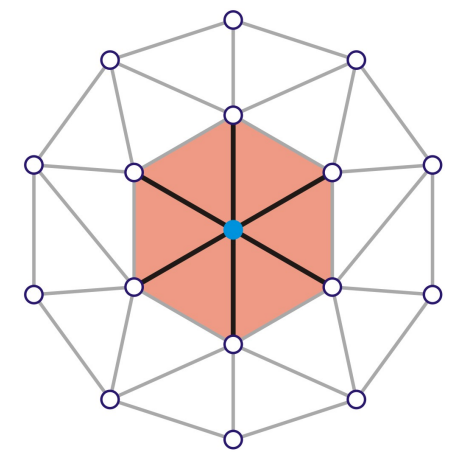

(a) Estrela do vértice central (azul)

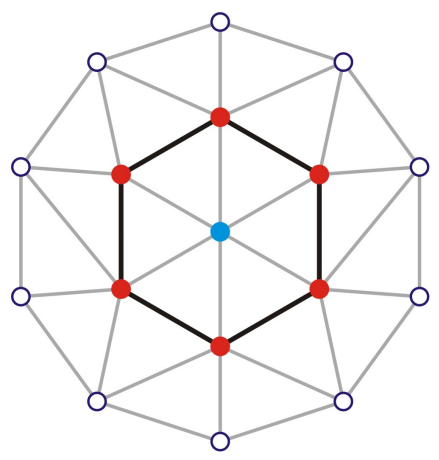

(b) Elo do vértice central (azul)

Figura 2.4: Operações de estrela e elo.

Definição 17 (Homeomorfismo) Sejam dois conjuntos $U$ e V e uma aplicação, $f: U \rightarrow V . f$ é chamada de homeomorfismo se $f$ éinversível e, $f e f^{-1}$ são contínuas. Se féum homeomorfismo então os conjuntos $V$ e $U$ são ditos homeomorfos.

Definição 18 (Variedade) Um complexo celular $C$ de dimensão $n$ é dito uma variedade linear por partes de dimensão $n$, se, para todo $\sigma$ de $C$, ou $L(\sigma)$ é homeomorfo a uma esfera de dimensão 
n-1 (Figura 2.5(a)), ou é homeomorfo a um disco de dimensão $n-1$ (Figura 2.5(b)). Caso contrário Cé dito uma não-variedade (Figura 2.5(c)).

Caso o elo de uma célula seja homeomorfo a uma esfera de dimensão $n-1$, esta célula é dita como sendo uma célula de interior. E caso seu elo seja homeomorfo a um disco de dimensão $n-1$, esta célula é dita como sendo uma célula de bordo.

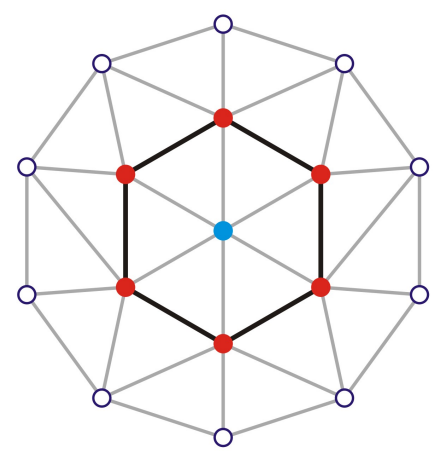

(a) Ponto de interior

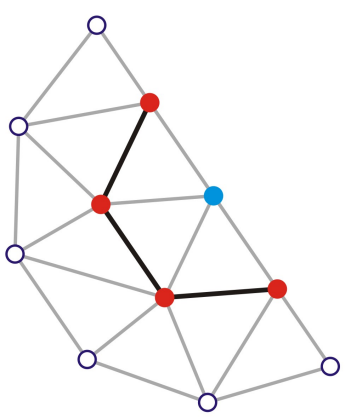

(b) Ponto de Bordo

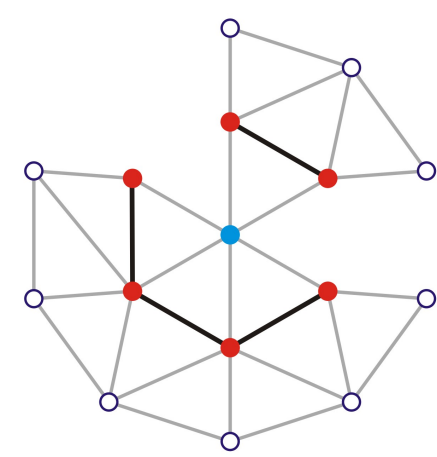

(c) Não-variedade

Figura 2.5: Variedades (a) e (b) e não-variedade (c).

No contexto deste trabalho, o maior elemento que formar um complexo celular será tratado simplesmente como célula. Como foi dito anteriormente, neste trabalho tem-se o interesse em representar tanto malhas bidimensionais quanto tridimensionais que podem ser compostas por complexos simples ou mistos (híbridos). A Figura 2.6 apresenta os diferentes tipos de células dentro do escopo deste projeto. As células de dimensão 2 são as células de maior dimensão no contexto de malhas superficiais e são representadas por triângulos e quadriláteros. E as células de dimensão 3 são as de maior dimensão no contexto de malhas volumétricas. Estas células são representadas por tetraedros, prismas (com base triangular), pirâmides (com base quadrada) e hexaedros. A Tabela 2.1 apresenta a composição de cada tipo de célula de interesse deste projeto.

Tabela 2.1: Relação de elementos de célula

\begin{tabular}{|c||c|c|c|}
\hline Tipo & Número de Vértices & Número de Arestas & Número de Faces \\
\hline \hline Triângulos & 3 & 3 & - \\
\hline Quadriláteros & 4 & 4 & - \\
\hline Tetraedros & 4 & 6 & 5 \\
\hline Pirâmides & 5 & 8 & 5 \\
\hline Prismas & 6 & 9 & 6 \\
\hline Hexaedros & 8 & 12 & \\
\hline
\end{tabular}


<smiles>[Na][Hg]</smiles>

0-Célula

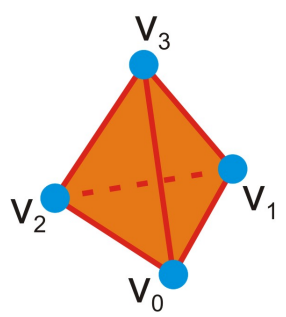

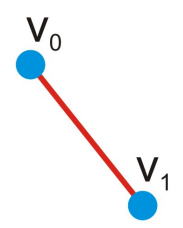

1-Célula

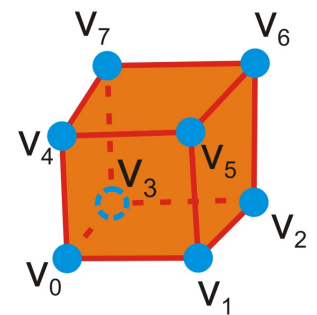

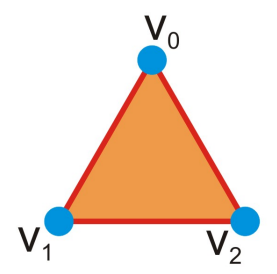

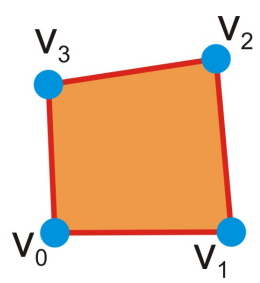

2-Célula
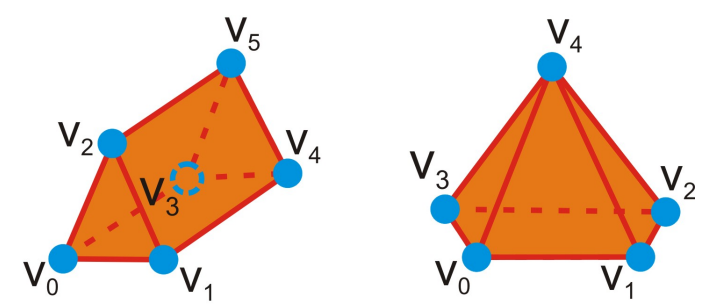

3-Célula

Figura 2.6: Tipos de células que são representadas dentro do escopo deste projeto.

A definição de uma malha é mais flexível que a de um complexo celular pois às vezes é interessante tratar malhas que seja do tipo ilustrado na Figura 2.7. No contexto deste trabalho, quando se fala em malha faz-se referência a um complexo celular.

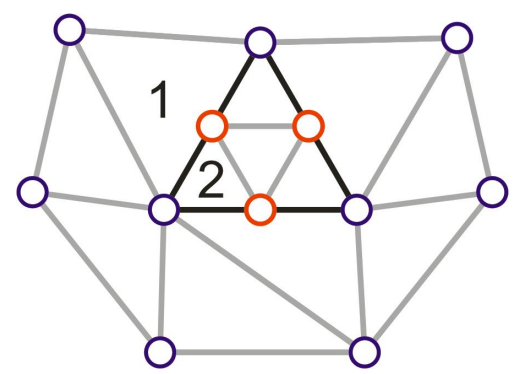

Figura 2.7: Exemplo de uma malha que não se caracteriza por ser um complexo celular, apesar de ser uma decomposição celular. Neste caso, a interseção entre as 2-células 1 e 2 não é uma face comum.

\subsection{Malhas Elásticas}

Malhas elásticas são métodos que buscam reposicionar os vértices de uma malha por meio de simulações de forças físicas de atração e repulsão. Nesse caso, a malha é vista como um domínio onde os vértices (vistos como partículas) se movimentam até encontrarem alguma configuração de equilíbrio de forças. Em geral, tais métodos trabalham como um sistema de molas onde cada aresta conectando dois vértices é vista como uma mola que tem um comprimento de equilíbrio. As molas contribuem no 


\section{Conceitos Básicos}

movimento dos vértices para se chegar na configuração de equilíbrio $[2,21]$.

Assumindo que as forças atuantes em um vértice tenham sido computadas, é necessário formular alguma equação de movimento que possa reger o comportamento dinâmico dos vértices. Pela segunda lei de Newton, tem-se a seguinte equação:

$$
m \ddot{x}=\vec{F}
$$

onde $x$ é o vetor de posições dos vértices da malha, $m$ é a massa associada aos vértices

e $\vec{F}$ são as forças atuando nos vértices. Este modelo pode ser estendido para o caso massa-mola-amortecimento, onde a força $\vec{F}$ é computada a partir das forças que agem nos vértices:

- $\vec{f}$ : força entre-vértices, análoga a uma mola e age apenas entre vértices adjacentes.

- $\vec{f}_{d}$ : força de amortecimento, contrária ao movimento e contribui para convergência do sistema.

Cada vértice $i$ possui três variáveis de estado - posição $x_{i}$, velocidade $\dot{x}_{i}$ e aceleração $\ddot{x}_{i}$ - e dois atributos - massa $m_{i}$ e coeficiente de amortecimento $d_{i}$. Para simplificar o sistema, é assumido que todos os vértices possuem a mesma massa e o mesmo coeficiente de amortecimento.

A força de amortecimento, $\vec{f}_{d}$, contribui para a convergência dos vértices para uma configuração estável. Essa força é contrária ao movimento, proporcional à velocidade do vértice e é definida por $\vec{f}_{d}=-d \dot{x}$.

A força total $\vec{F}$ agindo nos vértices é então dada por:

$$
\begin{aligned}
\vec{F} & =\vec{f}+\vec{f}_{d} \\
& =\vec{f}-d \dot{x}
\end{aligned}
$$

Desta forma, a equação final do sistema pode ser descrita pela seguinte equação diferencial ordinária de segunda ordem:

$$
m \ddot{x}+d \dot{x}=\vec{f}
$$

Uma equação diferencial de primeira ordem também pode ser utilizada para formular o problema $[8,58]$. Embora tenha mais chances de estacionar em um mínimo 


\section{Conceitos Básicos}

local, esta formulação tem maior estabilidade numérica. O movimento dos vértices passa a ser expresso pela seguinte equação:

$$
\vec{f}-d \dot{x}=0
$$

O problema pode ser ainda mais simplificado em um sistema conhecido como quase-estático $[6,26,21]$ da forma $\vec{f}=0$.

A formulação de $\vec{f}$ é determinante para a solução do sistema. Considere $\vec{f}_{i}$ como a força resultante em um vértice $v_{i}$ devido a influência de outros vértices $v_{j}$. Existem várias formas de se calcular tal força, sendo a analogia com molas uma das mais conhecidas e empregadas em CFD.

$\mathrm{Na}$ analogia com molas, estas sendo fictícias, são atribuídas entre os vértices e determina-se a força pela aplicação da lei de Hook:

$$
\vec{f}=-k \vec{\delta}
$$

onde $k$ é o coeficiente de resistividade da mola e $\vec{\delta}$ é o deslocamento.

Cada aresta da malha é tratada como sendo uma mola possuindo um coeficiente de rigidez. Tais molas são chamadas longitudinais. Considerando que a força resultante em um vértice é calculada apenas para as molas que incidem nele, a própria conectividade da malha determina quais vértices influenciam no cálculo das forças atuantes no vértice $v_{i}$ devido aos vértices vizinhos $v_{j}$, como mostra a Equação 2.6:

$$
\vec{f}_{i}=\sum_{j \in V\left(x_{i}\right)} k_{i j}\left(\vec{x}_{j}-\vec{x}_{i}-\vec{l}_{i j}\right)
$$

onde $\vec{l}_{i j}$ é o vetor de equilíbrio entre os vértices $v_{i}$ e $v_{j}, V\left(x_{i}\right)$ representa o conjunto de vértices adjacentes ao vértice $v_{i}$.

Tal abordagem tem sido empregada em problemas de simulações físicas onde a fronteira da malha se move com o tempo, como será mostrado nas aplicações do Capítulo 6.

Nesse tipo de problema é interessante preservar algumas propriedades da malha original. Por exemplo, a proporção entre os comprimentos das arestas. Assim, a proporção de tamanho entre os elementos tende a ser mantida depois da suavização. Nesse caso o vetor $\vec{l}_{i j}$ da Equação 2.6 é definido a partir da aresta entre os vértices $v_{i} \mathrm{e}$ $v_{j}$ na malha original [6] e a equação da força pode ser escrita como: 


$$
\vec{f}_{i}=\sum_{j \in V\left(x_{i}\right)} k_{i j}\left(\vec{\delta}_{j}-\vec{\delta}_{i}\right)
$$

onde $\vec{\delta}_{i}$ é o deslocamento do vértice $v_{i}$.

Para preservar a proporção de tamanho entre os elementos, o coeficiente da mola pode ser calculado como [2]:

$$
k_{i j}=\frac{1}{\left(l_{i j}^{0}\right)^{2}}
$$

onde $l_{i j}^{0}$ é o comprimento da aresta entre os vértices $v_{i}$ e $v_{j}$ na malha inicial, ou seja, antes da deformação no bordo. A Figura 2.8(a) apresenta uma representação da mola longitudinal sobre a aresta $e_{i j}$.

Uma limitação desse tipo de modelagem é que não se pode garantir que um vértice não atravesse uma aresta, o que causa elementos inconsistentes (ou elementos sobrepostos). A principal causa da deficiência das molas longitudinais é que elas não levam em consideração a área do triângulo ou o ângulo entre as arestas. Uma solução para este problema consiste em agregar molas torcionais [26] ao sistema. As molas torcionais têm seus coeficientes de rigidez $C^{i j m}$ calculados a partir da equação:

$$
C_{m}^{i j m}=\frac{1}{1+\cos \left(\theta_{i}^{i j m}\right)} \frac{1}{1-\cos \left(\theta_{i}^{i j m}\right)}=\frac{1}{\sin ^{2}\left(\theta_{i}^{i j m}\right)}=\frac{\left(e_{i j}\right)^{2}\left(e_{i m}\right)^{2}}{4 A\left(t_{i j m}\right)^{2}},
$$

onde $\theta_{i}^{i j m}$ é o ângulo entre as arestas $e_{i m}$ e $e_{j m}, A\left(t_{i j m}\right)$ é a área do triângulo $t_{i j m}$ e $C_{i}^{i j m}$ é o coeficiente de rigidez da mola torcional situada no vértice $v_{i}$ do triângulo $t_{i j m}$ (ver Figura 2.8(b)). Observe que o coeficiente tende a infinito quando o ângulo tende a $0^{\circ}$ ou $180^{\circ}$.

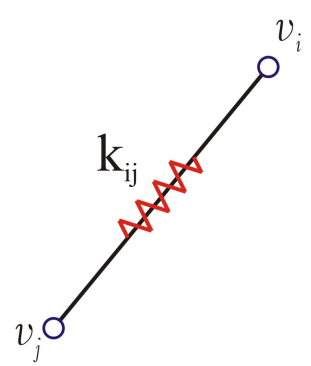

(a) Mola longitudinal

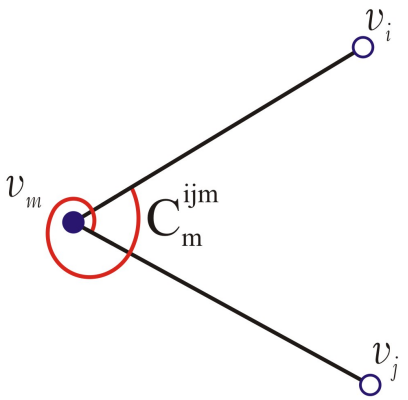

(b) Mola torcional

Figura 2.8: Tipos de molas usadas nas aplicações de malhas elásticas deste projeto.

As molas torcionais estão situadas nos vértices enquanto as molas longitudinais 


\section{Conceitos Básicos}

estão nas arestas.

Baseado no trabalho de Farhat et al. [26], Blom [6] propôs uma abordagem simplificada para agregar a informação dos ângulos num sistema composto por molas longitudinais. Ele denominou essa mola simplificada como semi-torcional cuja idéia principal é fazer com que os ângulos influenciem os coeficientes de molas longitudinais. A proposta de Blom baseava-se simplesmente em dividir o coeficiente da mola longitudinal na aresta $e_{i j}$ pelo valor do ângulo interno do triângulo $t_{i j m}$ em $v_{m}\left(\theta_{m}^{i j m}\right)$.

Além de algumas indefinições quanto ao cálculo do coeficiente para arestas internas, a proposta de Blom tem algumas características indesejadas quando o ângulo fica muito obtuso. Uma melhoria na abordagem de molas semi-torcionais foi introduzida por Zeng e Ethier [64]. A idéia consiste em basicamente adicionar o coeficiente de mola torcional ao coeficiente de mola longitudinal oposta. Assim, o coeficiente de resistividade total na aresta $e_{i j}\left(\alpha_{i j}\right)$ é dado por:

$$
\alpha_{i j}=k_{i j}+C_{m}^{i j m}+C_{n}^{i j n}
$$

onde $v_{m}$ e $v_{n}$ são vértices presentes na estrela da aresta $e_{i j}$. A Figura 2.9 representa como é formado o coeficiente $\alpha_{i j}$ na aresta $e_{i j}$.

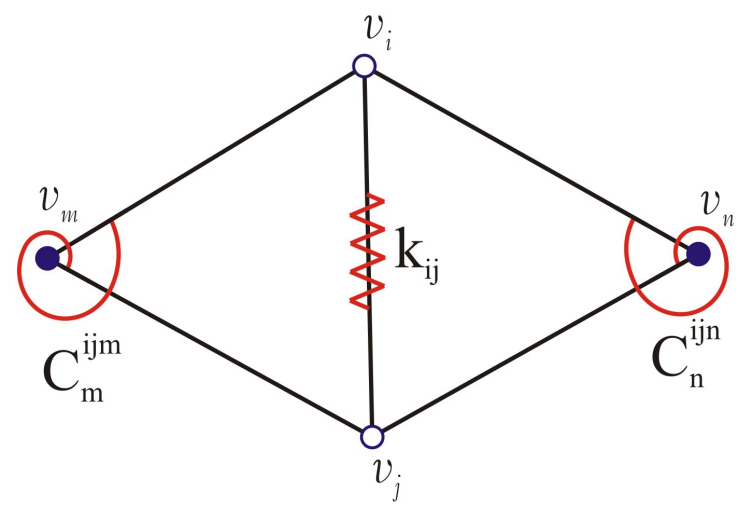

Figura 2.9: Ilustração da composição do coeficiente de rigidez total na aresta $e_{i j}$ formado por duas molas torcionais e sua mola longitudinal.

A equação geral da força no vértice $v_{i}$ considerando também molas torcionais pode então ser descrita como:

$$
\vec{f}_{i}=\sum_{j \in V\left(x_{i}\right)}\left(k_{i j}+C_{m}^{i j m}+C_{n}^{i j n}\right) \cdot\left[\vec{\delta}_{j}-\vec{\delta}_{i}\right]
$$

Além de malhas bidimensionais (planares), para muitas aplicações é necessário movimentar malhas superficiais. Isto é, malhas compostas por elementos 
bidimensionais representando a superfície de um modelo tridimensional. Soares et. al [59] desenvolveu um método para aplicação de malhas elásticas em triangulações sobre superfícies de tal modo a preservar a geometria da superfície original.

\subsection{Considerações Finais}

Os fundamentos apresentados neste capítulo foram de grande importância para o desenvolvimento deste projeto. Os conceitos sobre os tipos de elementos existentes em uma malha e a relação entre eles permitiram um melhor entendimento para a modelagem da ED, além de se poder padronizar os tipos de dados representados por ela.

Quanto ao conceito de malha elástica, este permitiu entender mais o funcionamento dessas malhas e assim poder elaborar aplicações de movimento de malhas. Estas aplicações serão apresentadas no Capítulo 6. 


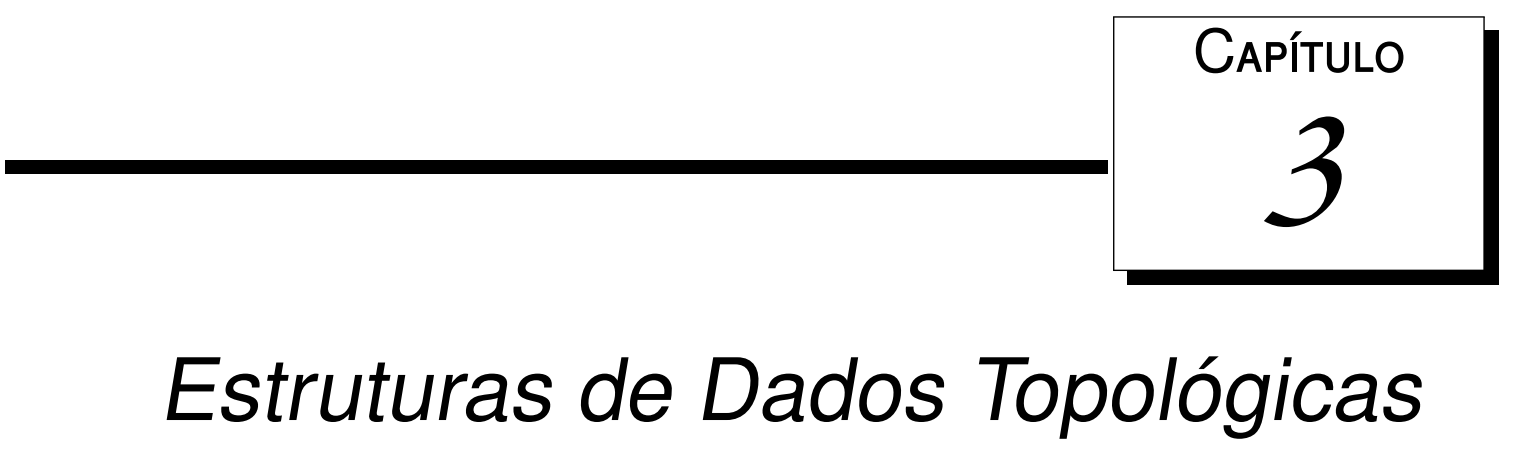

Decomposições celulares, comumente empregadas em simulação numérica de fenômenos físicos e usualmente chamadas de malhas ou grades, podem ser agrupadas em duas grandes categorias: regulares (ou estruturadas) e não-estruturadas.

Malhas regulares são caracterizadas por uma indexação dos elementos por meio de estruturas de dados simples, como por exemplo, matrizes. No caso de malhas nãoestruturadas, a não uniformidade da decomposição celular requer uma estratégia de representação mais sofisticada, que são as estruturas de dados (ED) topológicas [4].

Como foi dito anteriormente, EDs topológicas buscam indexar os elementos da malha de modo a representar as relações entre eles, garantindo assim um acesso eficiente a tais informações [46, 9]. A representação das relações de incidência e adjacência entre os elementos de uma malha é de extrema importância no contexto de simulações numéricas de fenômenos físicos, uma vez que métodos numéricos como volumes finitos, elementos finitos e diferenças finitas generalizadas fazem uso extensivo de tais relações.

A grande maioria das EDs topológicas descritas na literatura visa indexar os dados de modo a facilitar os mecanismos de acesso às relações de vizinhança e as buscas empregadas na construção ou leitura das malhas [36] viabilizando ainda o controle de procedimentos adaptativos [9]. Outro aspecto bastante importante destas estruturas são os operadores topológicos utilizados na construção e manutenção das mesmas [48].

Os dados topológicos das malhas podem ser armazenados de duas formas: por representação explícita ou por representação implícita. A forma explícita faz o uso 


\section{Estruturas de Dados Topológicas}

de listas ou vetores para armazenar tanto os elementos que constituem a malha quanto suas relações de incidência e adjacência [50]. E a forma implícita representa apenas os elementos da malha, mantendo as relações entre os elementos implicitamente representadas, podendo ser recuperadas via operações algébricas [55, 33].

As representações implícitas têm várias vantagens sobre a explícita, entre elas as de menor consumo de memória e de maior simplicidade na implementação dos operadores topológicos, aumentando assim a confiabilidade e a robustez de tais estruturas. A principal desvantagem da representação implícita é a dificuldade de empregá-la em decomposições celulares com diferentes tipos de células. $\mathrm{Na}$ verdade, a literatura apresenta representações implícitas com mecanismos eficientes de recuperação das relações de incidência e adjacência apenas para decomposições simpliciais, isto é, malhas triangulares [55] ou tetraedrais [7].

Este capítulo apresenta os estudos de algumas EDs Topológicas presentes na literatura que são de maior interesse para este projeto. Entre as EDs de maior interesse estão aquelas que são capazes de representar complexos celulares. Pretende-se aqui fazer um estudo sobre EDs semelhantes à ED proposta neste projeto, ED esta que será uma expansão da Opposite Face proposta por Mario Lizier [41]. A apresentação destas EDs foi dividida de acordo com a dimensão da malha que representam: superficiais (2D) ou volumétricas (3D).

Vale ressaltar que o maior interesse desse trabalho está voltado para estruturas do tipo implícitas que possibilitam obter as principais relações de incidência e adjacência de um dado elemento em tempo constante ou proporcional ao número de elementos vizinhos deste elemento. O diferencial deste trabalho, quanto as EDs topológicas, está no fato de além dela ser implícita, ela pode ser empregada em decomposições 2D ou 3D simples ou mistas.

\subsection{Estruturas de Dados 2D}

EDs 2D são do tipo que representam decomposições celulares de superfície e, dependendo do espaço onde a decomposição é representada, seu sistema de coordenadas pode ser do tipo 2D ou 3D. As malhas destas decomposições são do tipo poligonais, sendo triângulos e quadriláteros os mais comuns entre os polígonos utilizados.

A Figura 3.1 representa uma linha de tempo de trabalhos voltados a EDs 2D ao longo dos anos.

Proposta por Guibas e Stolfi [32], a ED Quad-Edge é uma variante da Winged- 


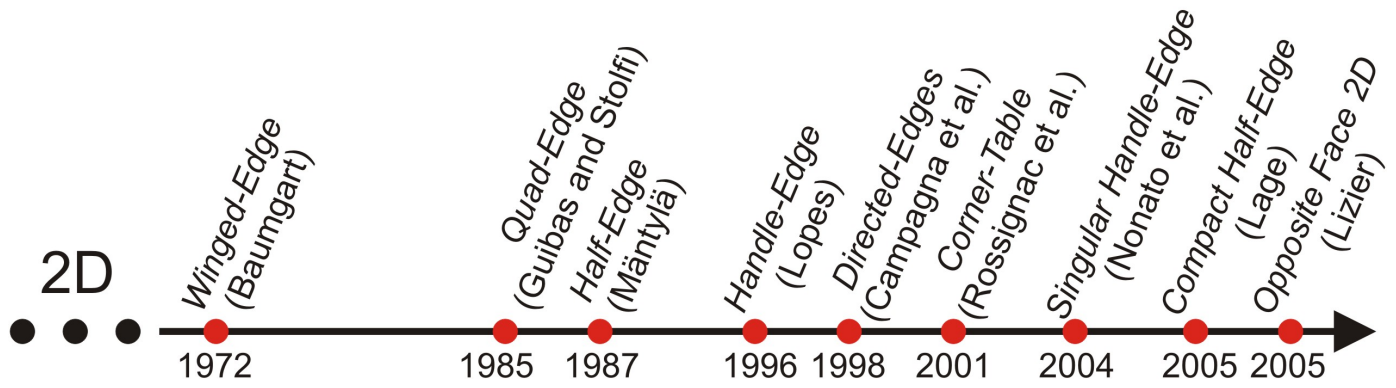

Figura 3.1: Linha de tempo dos trabalhos anteriores para EDs 2D.

Edge capaz de tratar variedades de dimensão 2 não orientáveis. Pelo fato de poder representar variedades não orientáveis, esta ED necessita de uma categoria de operações diferente do interesse deste trabalho, por isso não será mais detalhada.

A estrutura Singular Handle-Edge (SHE) proposta por Nonato et al. [49, 51], assim como a Handle-Edge [42, 13], é capaz de representar explicitamente o bordo de uma superfície combinatória. Porém, o que diferencia a SHE é que ela é capaz de tratar singularidades. Devido a essa semelhança e ao fato que a Handle-Edge serviu de base para a Compact Half-Edge (CHE), escolheu-se somente detalhar a Handle-Edge no decorrer desta seção.

Campagna et al. [11] propuseram uma extensão escalonável da Half-Edge chamada de Directed-Edges. Essa estrutura pode ser representada em três níveis de acordo com o tipo de representação (implícita ou explícita) dos elementos da malha. Este tipo de abordagem se faz interessante quando se deseja balancear entre o consumo de memória e a necessidade de bom processamento. Como a CHE apresenta esse mesmo tipo de abordagem escolheu-se somente detalhá-lo quando for apresentada a CHE.

Devido às suas características, as EDs 2D de maior interesse para esse projeto (com exceção da Opposite Face 2D que será apresentada na Seção 3.3) serão detalhadas a seguir.

\subsubsection{Winged-Edge}

A Winged-Edge proposta por Baumgart [3] é um dos primeiros trabalhos propostos para a representação de superfícies em $\mathbb{R}^{3}$. Esta ED utiliza arestas para poder acessar os dados necessários de uma malha. Nesta ED, as seguintes informações são necessárias para cada aresta da malha:

- Os vértices de suas extremidades;

- As faces à esquerda e à direita dela;

- A aresta antecessora e sucessora desta aresta em relação à face da esquerda; 
- A aresta antecessora e sucessora desta aresta em relação à face da direita.

A tabela 3.1 demonstra os dados armazenados referentes à aresta a presente na Figura 3.2.

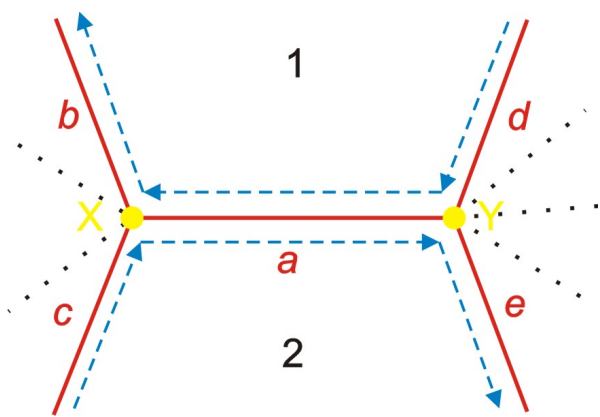

Figura 3.2: Representação de informações de uma aresta armazenada por uma wingededge.

Tabela 3.1: Dados armazenados referentes a aresta $a$ da Figura 3.2.

\begin{tabular}{|c|c|c|c|c|c|c|c|c|}
\hline Aresta & \multicolumn{2}{|c|}{ Vértice } & \multicolumn{2}{c|}{ Faces } & \multicolumn{2}{c|}{ Esquerda } & \multicolumn{2}{c|}{ Direita } \\
\hline \hline Nome & Inicio & Final & Esquerda & Direita & Pred & Suc & Pred & Suc \\
\hline$a$ & $\mathrm{X}$ & $\mathrm{Y}$ & 1 & 2 & $d$ & $b$ & $c$ & $e$ \\
\hline
\end{tabular}

Além da tabela 3.1, a Winged-Edge necessita de mais duas tabelas: uma tabela de vértices, onde, além do identificador do vértice, o indicador de uma aresta incidente a este vértice é armazenado; e uma tabela de faces, onde, além do identificador da face, o indicador de uma aresta pertencente ao bordo dessa face é armazenado.

\subsubsection{Half-Edge}

A Half-Edge é uma ED proposta por Mäntylä [46] centrada em uma aresta capaz de manter informação de incidência de vértices, arestas e faces. Cada aresta é decomposta em duas half-edges com orientação induzida por sua célula incidente (Figura 3.3).

Uma face incidente e um vértice incidente são armazenados em cada half-edge, e, para cada face e vértice, uma half-edge é armazenada. A Figura 3.3 representa a associação da half-edge $\left(H E_{i}\right)$ com os seus elementos adjacentes. Nota-se que o vértice incidente a $H E_{i}$ está de vermelho, e sua face incidente induz sua orientação no sentido anti-horário. A half-edge oposta $\left(O\left(H E_{i}\right)\right)$ de $H E_{i}$ tem orientação invertida induzida pela face oposta a face de $H E_{i}$. 


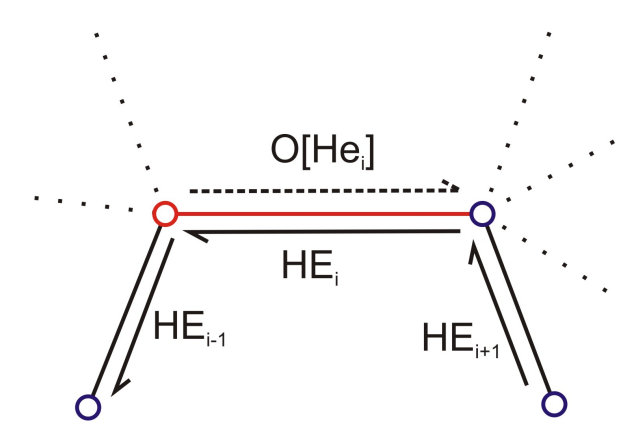

Figura 3.3: Uma half-edge com a associação de seus elementos incidentes.

Assim como a Winged-Edge, algumas modificações feitas à Half-Edge podem tornar possível a omissão de algumas das informações fazendo com que ambas as estruturas utilizem menos memória.

\subsubsection{Handle-Edge}

A Handle-Edge é uma versão estendida da Half-Edge proposta por Lopes [42], cujo propósito é a representação eficiente para uso de operadores de alça. Deste modo, a Handle-Edge necessita representar explicitamente as curvas de bordo da superfície. A ED utiliza ponteiros para representar os tipos de nós de cada elemento da malha.

Entre os nós da estrutura tem-se: o nó face que representa o triângulo que compõe a superfície; o nó vértice que representa tanto os nós internos quantos os nós de bordo; o nó half-edge $H E_{i}$ que representa a orientação da aresta na sua face incidente; o nó curva de bordo que representa uma componente do bordo através de uma aresta pertencente uma de suas arestas incidentes; o nó aresta que representa tanto as arestas internas quanto as arestas de bordo, cada aresta é composta pelo trio $\left(H E_{i}, H E_{j}, \partial S\right)$ onde $i \neq j$ e $\partial S$ representa a curva de bordo a quem a aresta possa pertencer.

Note que a representação da aresta só pode ser feita da forma $\left(H E_{i}, H E_{j}, \emptyset\right)$, $\left(H E_{i}, \emptyset, \partial S\right)$ ou $\left(\emptyset, H E_{j}, \partial S\right)$ como mostra a Figura 3.4. Para cada aresta se uma de suas $H E$ é vazia a aresta é dita como sendo aresta de bordo da superfície, caso contrário, a aresta é dita como sendo aresta de interior.
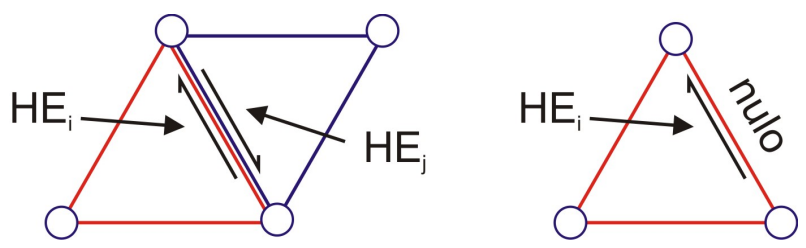

Figura 3.4: Formas de composição de uma aresta de interior (esquerda) e uma aresta de bordo (direita). 


\subsubsection{Corner-Table}

Uma Corner-Table é uma ED concisa para representar malhas triangulares. Nela é usado o conceito de corners para representar a associação de um triângulo a um de seus vértices ou, equivalentemente, associar um triângulo ao bordo oposto de uma corner $[55,62]$.

Nesta ED, as corners, os vértices e os triângulos são indexados por números não negativos. Cada triângulo é definido por três corners consecutivos que definem sua orientação. A indexação das corners é diferente para cada triângulo. Por exemplo, na Figura 3.5, as corners 0,1 e 2 correspondem ao primeiro triângulo (triângulo 0), as corners 3,4 e 5 correspondem ao segundo triângulo (triângulo 1) e assim sucessivamente. Como consequência disso, uma corner $c$ é associada ao seu triângulo $t$ por $t=c \% 3$ (onde $c \% 3$ é uma operação que retorna o resto da divisão de $c$ por 3). A corner-table representa a geometria de uma superfície por associar cada corner ao seu índice de vértice geométrico.

Assumindo a orientação anti-horária de representação dos triângulos, para cada corner c, o prox (c) e o ante(c) são corners de seu triângulo obtidos através do uso de das seguintes equações: $\operatorname{prox}(c)=(c+1) \% 3$ e ante $(c)=(c+2) \% 3$. Estas equações tornam-se importantes na obtenção de dados dos vértices vizinhos dentro de um mesmo triângulo. Pelo fato do armazenamento dos pontos seguirem o sentido de construção do triângulo, pode-se saber qual vértice vizinho está sendo acessado.

A adjacência de bordos entre triângulos vizinhos é representada por associar a cada corner $c$ sua corner oposta $O[c]$ que tem a mesma aresta oposta. A Figura 3.5 demonstra os elementos (vértices, corners e triângulos) para o caso de um tetraedro e a tabela 3.2 uma lista dos dados deste tetraedro. É importante destacar que como o tetraedro é um objeto gráfico sólido definido por uma malha triangular, toda corner tem associado a ela três faces triangulares e consequentemente três corners opostos.

Levando em consideração a equação $t(c)=c / 3$ pode-se fazer a representação dos triângulos $t(c)$ da malha de forma implícita.

\subsubsection{Compact Half-Edge}

A ED Compact Half-Edge (CHE) proposta por Lage [39] apresenta características semelhantes às apresentadas nas estruturas Handle-Edge, Corner-Table e Direct-Edges. Inicialmente, essa ED foi criada para representar malhas triangulares, mas recentemente foram incorporadas algumas extensões para representar malhas de quadriláteros e a até mesmo malhas mistas (triângulos+quadriláteros). 


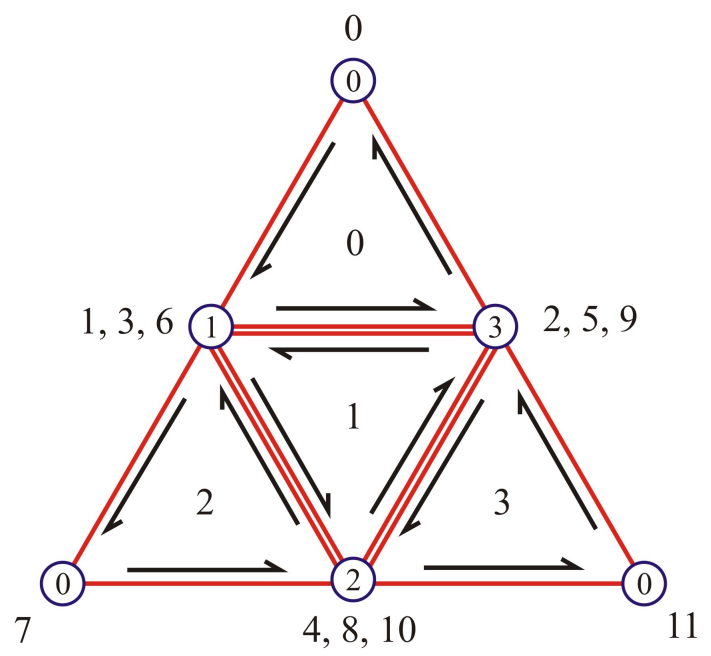

Figura 3.5: Vértices, corners e faces de um tetraedro aberto.

Tabela 3.2: Lista de dados do tetraedro.

\begin{tabular}{|c|c|c|c|}
\hline Corner & Vértice & Triângulo & Oposto \\
\hline \hline 0 & 0 & 0 & 2 \\
\hline 1 & 1 & 0 & 2 \\
\hline 2 & 3 & 0 & 2 \\
\hline 3 & 1 & 1 & 0 \\
\hline 4 & 2 & 1 & 0 \\
\hline 5 & 3 & 1 & 0 \\
\hline 6 & 1 & 2 & 3 \\
\hline 7 & 0 & 2 & 3 \\
\hline 8 & 2 & 2 & 3 \\
\hline 9 & 3 & 3 & 1 \\
\hline 10 & 2 & 3 & 1 \\
\hline 11 & 0 & 3 & 1 \\
\hline
\end{tabular}

Baseada na Direct-Edges, essa ED tem a característica de ser escalonável por fazer um balanceamento entre o consumo de memória e a necessidade de bom processamento da aplicação onde a ED é usada. Para isso, a ED é composta por 4 níveis de escalabilidade, sendo o nível 0 o com menor uso de memória e o nível 3 o de maior uso de memória mas de melhor desempenho de processamento para dados topológicos. A seguir, serão detalhadas algumas características dos níveis de escalabilidade:

- Nível 0

Neste nível, só são armazenadas as informações essenciais para representar uma malha de triângulos. Aqui não se tem o interesse de representar relações de 
incidências e adjacências entre os elementos da malha. Serve basicamente para aplicações de visualização da mesma. Porém, assim como na Corner-Table, existem algumas relações de adjacências internas às células entre os vértices.

- Nível 1

A partir deste nível, as relações de adjacências entre células são armazenadas. Assim como na Half-Edge esta relação é obtida através das relações entre as halfedges opostas de duas células vizinhas.

- Nível 2

Até o momento, as células não foram representadas explicitamente, pois os seus dados foram armazenados em suas respectivas listas em ordem de acordo com suas células e orientação e, assim, a célula a quem estes dados pertencem pode ser determinada a partir de uma simples operação algébrica. Neste nível, as células passam a ser representadas explicitamente e, deste modo, pode-se associar atributos a determinados elementos.

- Nível 3

Finalmente, neste nível é adicionada uma representação explícita para curvas de bordo.

A Figura 3.6 representa como cada nível desta ED é formado.

\subsection{Estruturas de Dados 3D}

As EDs 3D representam decomposições celulares volumétricas e, devido a este fato, o seu sistema de coordenadas é do tipo 3D. As malhas destas decomposições são do tipo poliedral, sendo os tetraedros os mais comuns entre os poliedros utilizados na literatura.

A Figura 3.7 representa uma linha de tempo de trabalhos voltados a EDs 3D ao longo dos anos.

Dobkin e Lazslo [22] estenderam a ED Quad-Edge para propor uma nova estrutura chamada Facet-Edge que é capaz de representar complexos celulares que são subdivisões de uma esfera tridimensional. Porém, além da dimensão da malha representada, a Facet-Edge se diferencia por tratar somente complexos celulares orientáveis.

A estrutura Non-Manifold Indexed Data Structure with Adjacencies foi proposta por De Floriani e Hui [27]. Esta ED apresenta uma abordagem interessante para tratar 
Nível 3

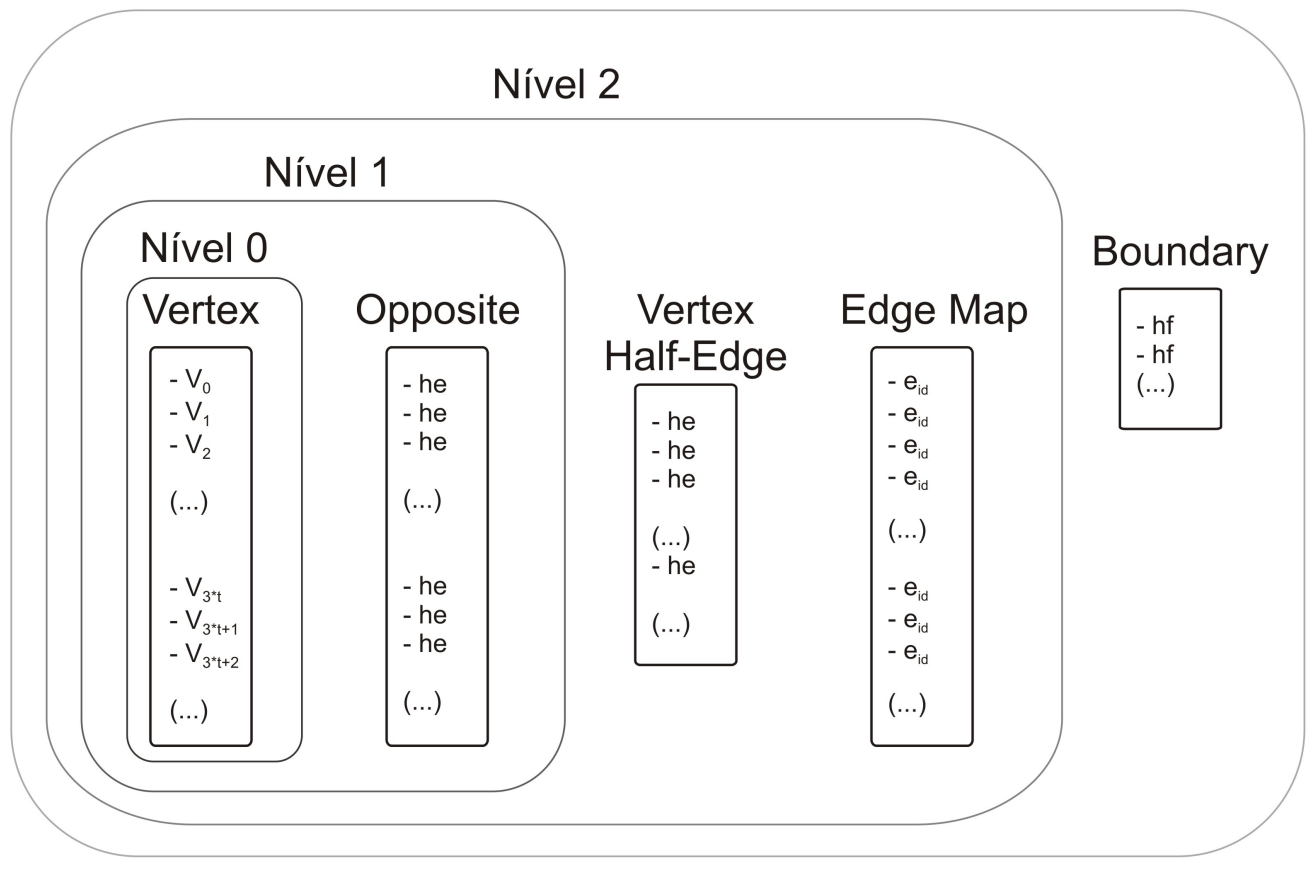

Figura 3.6: Ilustração da composição dos 4 níveis da estrutura CHE.

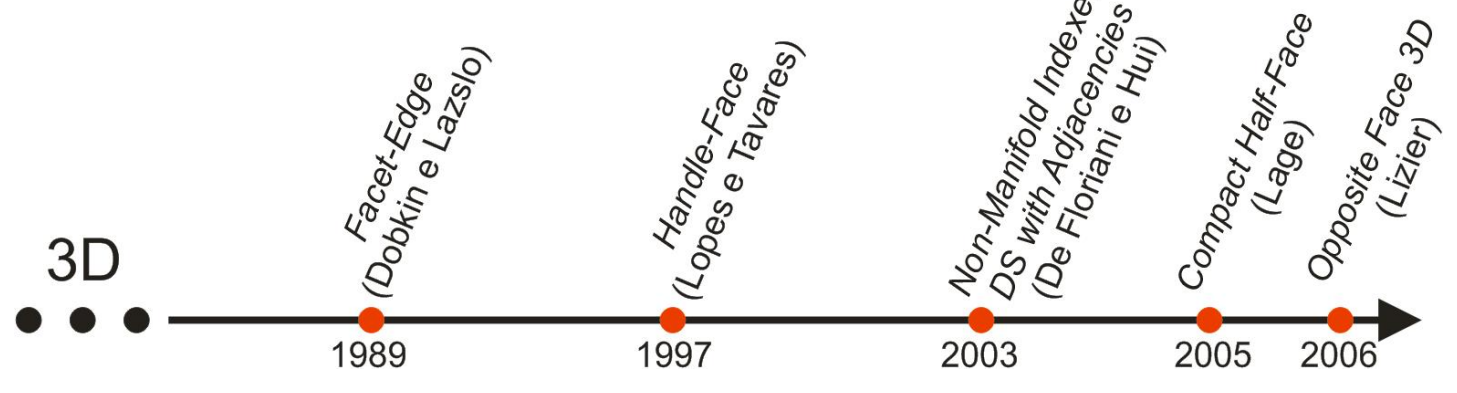

Figura 3.7: Linha de tempo dos trabalhos anteriores para EDs 3D.

operações de estrelas de seus componentes, entretanto por se tratar de uma ED que representa não-variedades, optou-se por não detalhá-la.

Devido às suas características, as EDs 3D de maior interesse para esse projeto (com exceção da Opposite Face 3D que será apresentada na Seção 3.3) serão detalhadas a seguir:

\subsubsection{Handle-Face}

A Handle-Face é uma versão estendida da Handle-Edge proposta por Lopes e Tavares [43] para representação de malhas volumétricas formadas por tetraedros. Esta ED utiliza o conceito de half-face representada por um triângulo, cuja orientação é induzida 


\section{Estruturas de Dados Topológicas}

pelo tetraedro a que ela pertence. Assim como a Handle-Edge, esta ED utiliza ponteiros para representar os tipos de nós de cada elemento da malha.

Entre os nós da estrutura tem-se: o nó 3-manifold que é representado por uma lista de superfícies (que formam o bordo do volume), por uma lista de faces internas, por uma lista de arestas internas e finalmente uma lista de vértices internos; o nó superfície que corresponde ao tetraedro tem uma lista de suas half-faces, de arestas e de vértices; o nó face que pode representar tanto a face de bordo quanto a face interna. As faces representadas aqui são do tipo triangulares, caso seja interna é conectada a suas duas half-faces e, caso contrário, é conectado a uma única half-face e a superfície que a contém; o nó half-face que representa uma half-face da célula (tetraedro) através de seu ciclo de half-edges; entre outros, têm-se ainda os nós de arestas, os nós de half-edges e os nós de vértices.

\subsubsection{Compact Half-Face}

A ED Compact Half-Face (CHF) proposta por Lage [38, 39] apresenta características semelhantes Às apresentadas na estrutura Handle-Face. Esta ED foi criada para representar malhas tetraédricas e, assim como a CHE usa, a característica de escalabilidade de estruturas.

A CHF é composta por 4 níveis de escalabilidade, sendo o nível 0 o com menor uso de memória e o nível 3 o de maior uso de memória, mas de melhor desempenho de processamento para dados topológicos. A seguir, serão detalhadas algumas características dos níveis de escalabilidade:

- Nível 0

Neste nível, só são armazenadas as informações essenciais para representar uma malha de tetraedros. São armazenadas somente as informações de geometria e os tetraedros para gerar uma visualização da malha.

- Nível 1

Neste nível, as relações de adjacências entre os tetraedros são armazenadas. Assim como na Handle-Face esta relação obtida através das relações entre uma half-face e a sua half-face oposta.

- Nível 2

Neste nível, as células passam a ser representada explicitamente e, deste modo, pode-se associar atributos a determinados elementos. Novos contêineres são adicionados a estrutura para armazenar tais atributos. 
- Nível 3

Finalmente, neste nível é adicionada uma representação explícita da superfície de bordo para representar explicitamente as relações de incidência e adjacência entre as células de bordo.

A Figura 3.8 representa como cada nível desta ED é formado.

Nível 3

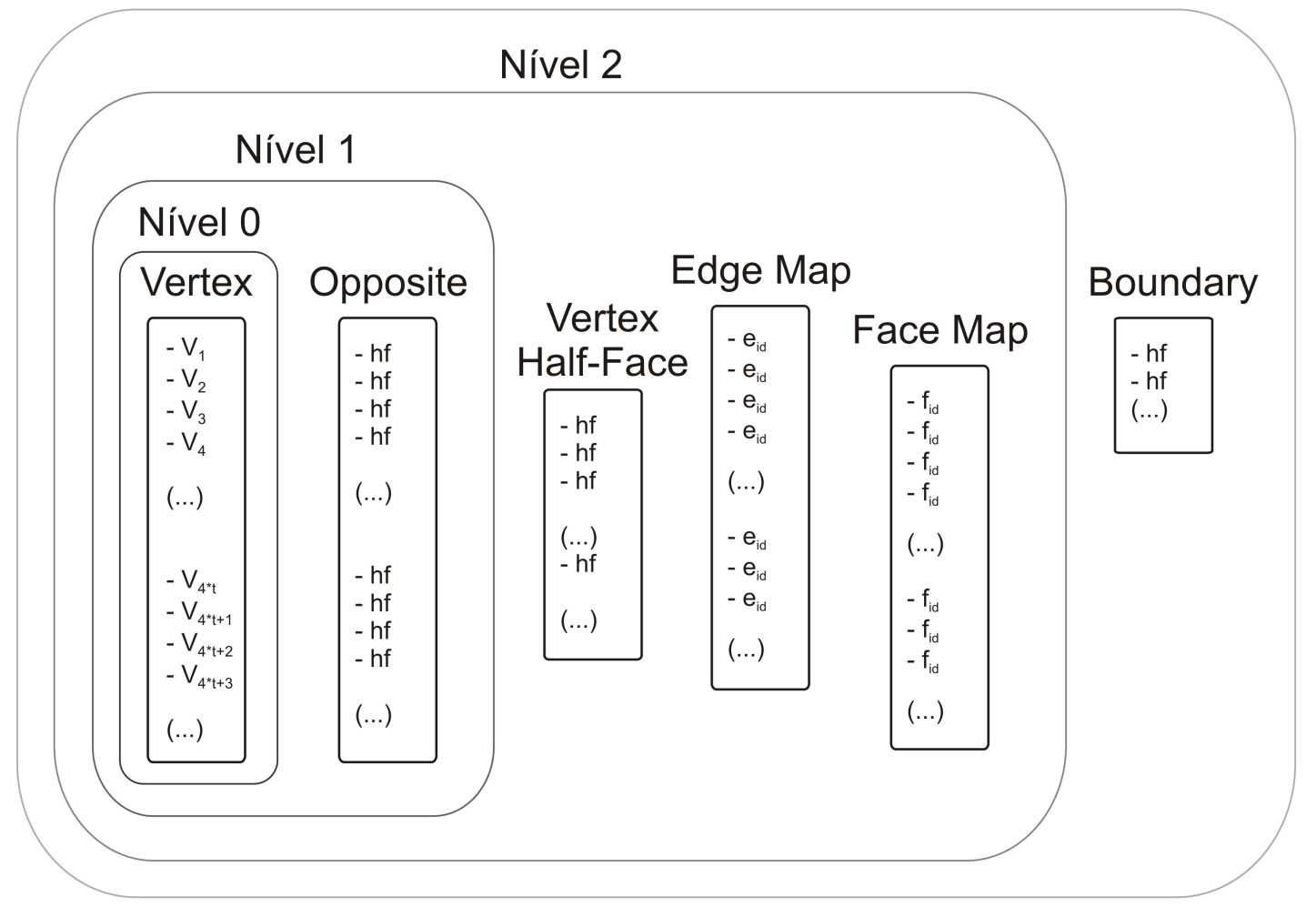

Figura 3.8: Ilustração da composição dos 4 níveis da estrutura CHF.

\subsection{Estrutura de Dados - Opposite Face}

Nesta seção, será apresentada a ED Opposite Face (OF) que foi proposta por Mario Lizier [41]. Esta ED servirá de base para a implementação da ED Mate Face (MF). Alguns detalhes de implementação serão omitidos neste capítulo devido à semelhança entre as duas EDs, estes detalhes serão apresentados no capítulo seguinte para apresentar semelhanças e comparações.

O objetivo do desenvolvimento de uma nova estrutura para o armazenamento e manipulação de malhas é o de otimizar o processo de geração de malha, priorizando os procedimentos mais requisitados. Inicialmente, a OF foi baseada nos trabalhos 


\section{Estruturas de Dados Topológicas}

realizados na estrutura Corner-Table. Uma das preocupações para a definição da estrutura foi a minimização do consumo de memória necessário para a representação da malha. Outro ponto observado foi prover facilidade de utilização e flexibilidade.

A ED representa explicitamente os vértices e células (triângulos ou tetraedros) de uma malha simplicial. Foi desenvolvida para ser flexível quanto aos tipos de malhas que ela armazena, ou seja, dependendo onde a ED é usada, os dados contidos nela podem ser 2D ou 3D. Além disso, podem ser acrescentados mais dados que caracterizam a malha. Uma das suas principais características é fornecer o rápido acesso a dados topológicos e disponibilizar funções para execução de cálculos para malha. Esta ED foi implementada em $\mathrm{C}++$ para usufruir da vantagem que a linguagem apresenta quanto à programação de estruturas flexíveis.

\subsubsection{A estrutura}

A ED armazena os componentes básicos de uma malha e quanto a representação desses componentes da malha, a OF faz uso dos dois tipos de representação: os dados de vértice, de triângulos (célula 2D) e de tetraedros (célula 3D) são representados explicitamente, e os dados de arestas e faces são representados implicitamente.

$\mathrm{Na} E D$, os vértice e células são armazenados em vetores separados e identificados por um número inteiro, positivo e único para cada elemento presente em seu respectivo vetor. Esse identificador único permite acesso direto a qualquer um desses elementos, pois há uma associação entre a posição da memória deste elemento e seu identificador.

A Figura 3.9 ilustra como é feito o armazenamento dos dados de uma malha superficial. A malha é formada por referências dos seus vetores de células e vértices, e, como foi dito anteriormente, cada vetor armazena seu respectivo dado usando um identificador único. Os vértices são formados pelas suas coordenadas geométricas (no espaço 2D ou 3D, dependendo do perfil da malha no caso dessa Figura o espaço é 2D). E, por sua vez, a célula armazena os identificadores dos vértices que a formam além de suas células vizinhas. Assim como ocorre na Corner-Table, a relação de vizinhança é obtida a partir da relação entre um vértice de uma célula e uma outra célula oposta a esse vértice. No caso de malhas 3D formadas por tetraedros, essa idéia pode ser estendida facilmente, já que células vizinhas compartilham uma face entre si e os vértices opostos a essas faces são únicos para cada célula.

Mesmo armazenando somente as relações de adjacências, pode-se obter, com acesso direto, a maioria das informações necessárias de uma malha com bom desempenho. Desse modo, é possível a representação implícita de certas informações da malha 
reduzindo assim o consumo de memória.

\subsubsection{Perfil de malha}

Para tornar a ED flexível, foi proposta a idéia de associar perfis às malhas de acordo com suas características e tipos de componentes. Assim, caso necessite, um usuário poderá criar um perfil próprio além dos perfis básicos já existentes na OF.

O que diferencia cada perfil básico da OF é o tipo de identificador que indexa os elementos da malha (int ou long), além disso, para o espaço métrico do elemento, podese utilizar os tipos de ponto flutuante (float, double e long double). Também é necessário definir os tipos de vértices (2D ou 3D), de células (triângulo ou tetraedro) e o tipo de classe de manipulação de malha (planar, superficial ou volumétrica; orientada ou não orientada). As Figuras 3.9 e 3.10 apresentam dois tipos de perfis básicos o ofDefault2D (para representação de malhas triangulares planas) e o ofDefault3D (para representação de malhas tetraédricas), onde space é do tipo ponto flutuante e ids é do tipo inteiro não negativo. Nota-se que há pouca diferença entre tais perfis (somente no tipo de classe de manipulação de malha, vértice e célula), isso demonstra a facilidade de uso da OF.

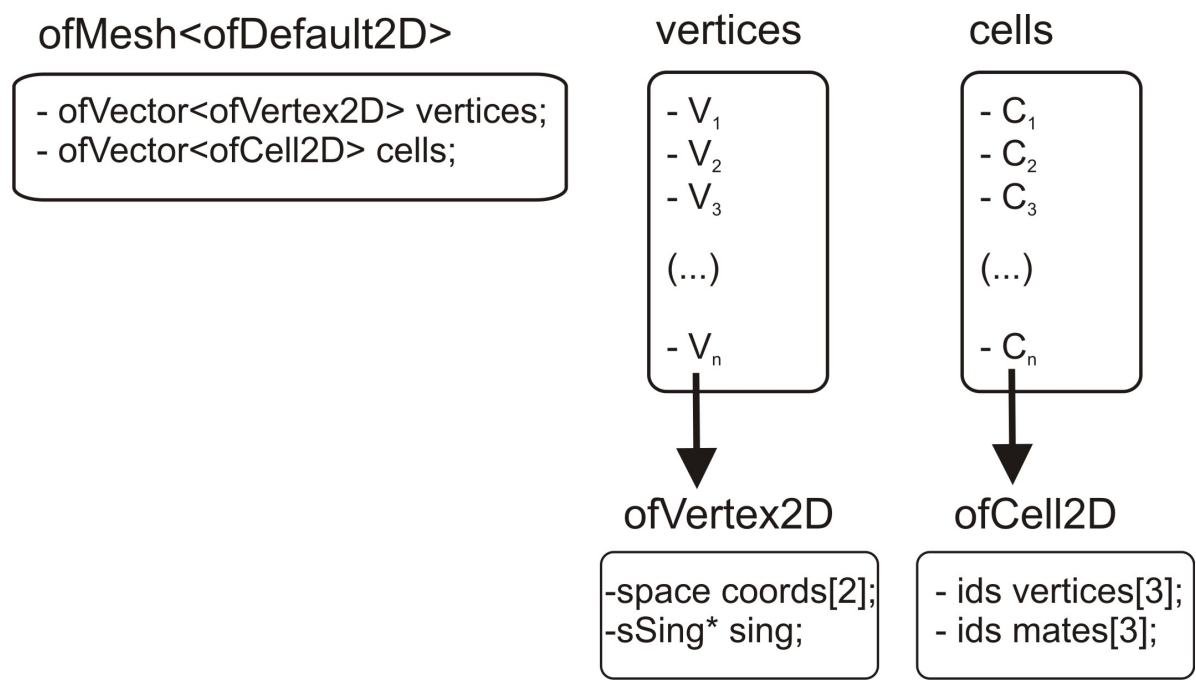

Figura 3.9: Representação explícita básica de uma malha superficial 2D.

\subsubsection{Exemplo de aplicação usando a OF}

A OF vem sendo utilizada em diversas aplicações do LCAD e em outros laboratórios. Aqui, será apresentado o uso desta ED em um sistema baseado em realidade virtual para simulação de procedimentos médicos. Este sistema é chamado de CyberMed [24, 25] e 


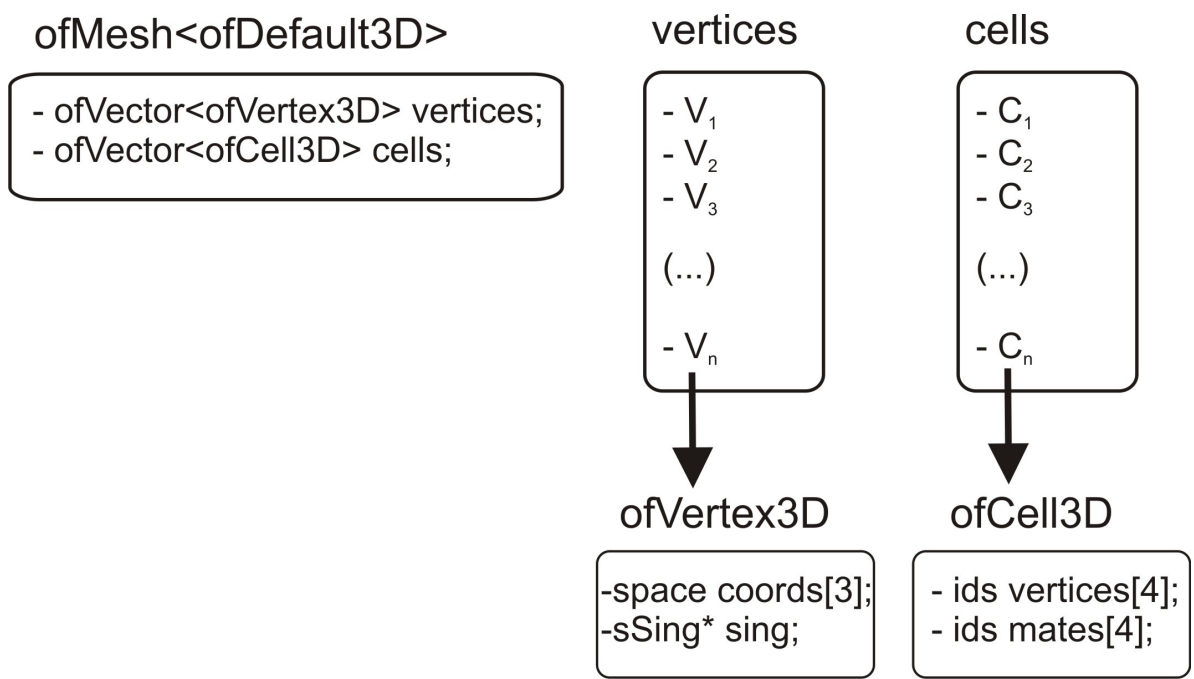

Figura 3.10: Representação explícita básica de uma malha superficial 3D.

foi desenvolvido em conjunto com o Laboratório de Tecnologias para Ensino Virtual e Estatística da Universidade Federal da Paraíba (LabTEVE-UFPB) e o Laboratório de Computação de Alto Desempenho da Universidade de São Paulo (LCAD-USP). A OF foi responsável em armazenar dados geométricos e topológicos dos objetos a serem visualizados e/ou interagidos. Em cada simulação estes objetos podem representar tanto órgãos humanos quanto objetos de interação, além disso, podem ser compostos por mais de uma camada, ou seja, mais de uma malha superficial com dados independentes [61,20].

Além dos dados básicos já tratados na OF, a aplicação necessita de outros dados (do tipo normais de faces e vértices, coeficientes de elasticidade, etc.) para tornar possível um bom nível de realismo. Por isso a característica de flexibilidade da ED foi bastante útil, pois não só permitiu acesso eficiente a esses dados, como também só foram necessárias implementações de classes que herdam as classes base da ED e de um novo perfil para os objetos gráficos usados. Entre as classes básicas estão as de malha, de vértice e de célula. Para caracterizar as classes que pertencem ao CyberMed todas elas foram nomeadas com o prefixo $c y b$ como mostra o perfil da malha detalhado na Figura 3.11.

Neste perfil (traits), nota-se que as representações do espaço são do tipo double e dos identificadores dos elementos são do tipo inteiro. Entre as classes, vale a pena citar a classe cybVertex que representa os vértices no espaço 3D e armazena suas coordenadas e normais; a classe cybCell que representa as células triangulares com sua normal de superfície e os vértices pertencentes a cada célula; e a classe cybMesh que representa 


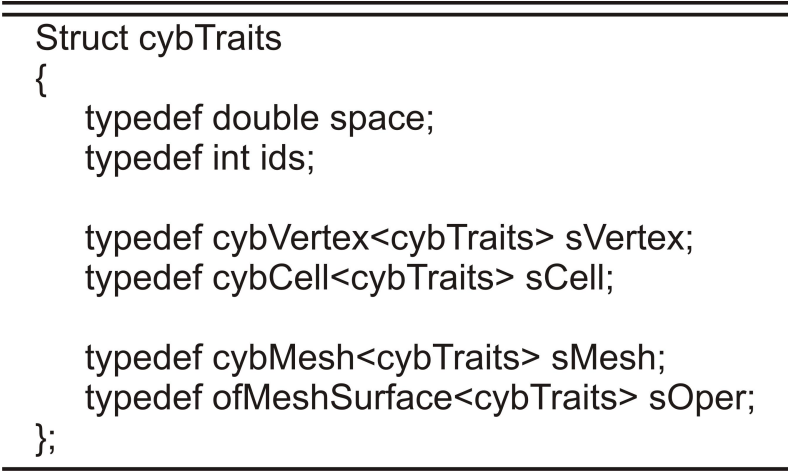

Figura 3.11: Perfil de uma malha usada no sistema CyberMed.

a malha em geral com o vetor de células e vértices. Cada uma dessas classes criadas para o CyberMed herdam características de suas respectivas super-classes originais da ED OF.

Os exemplos 1 e 2 demonstram duas aplicações do CyberMed. Em cada exemplo é detalhada a composição dos objetos gráficos representados quanto ao nome da camada, número de vértices e número de células.

Exemplo 1 (Visualização da anatomia humana) Em caráter geral, a visualização desse sistema pode ser de três maneiras (normal, anaglifo ou obturação) [20]. Como aplicação de visualizador da anatomia humana é interessante dividir em camadas simples (ou até mesmo múltiplas) cada órgão presente na região do corpo sendo visualizada. A Figura 3.12 representa um modelo que é composto por 3 camadas, onde cada uma tem seus dados armazenados separadamente, o que é possível observar durante a visualização através das características de transparência e cor atribuídas individualmente. A tabela 3.3 apresenta a composição de cada camada, no total, o objeto é composto por 43359 vértices e 83654 células.

Tabela 3.3: Composição das camadas do tórax.

\begin{tabular}{|c|c|c|}
\hline Camada & Número de Células & Número de Vértices \\
\hline \hline Sistema digestivo & 53418 & 27276 \\
\hline Esqueleto & 24702 & 12716 \\
\hline Pele & 5534 & 3367 \\
\hline Total & $\mathbf{8 3 6 5 4}$ & $\mathbf{4 3 3 5 9}$ \\
\hline
\end{tabular}

Exemplo 2 (Simulação do procedimento de coleta de medula óssea) $A$ aplicação de coleta de medula óssea envolve uma simulação do procedimento onde uma agulha coleta medula 


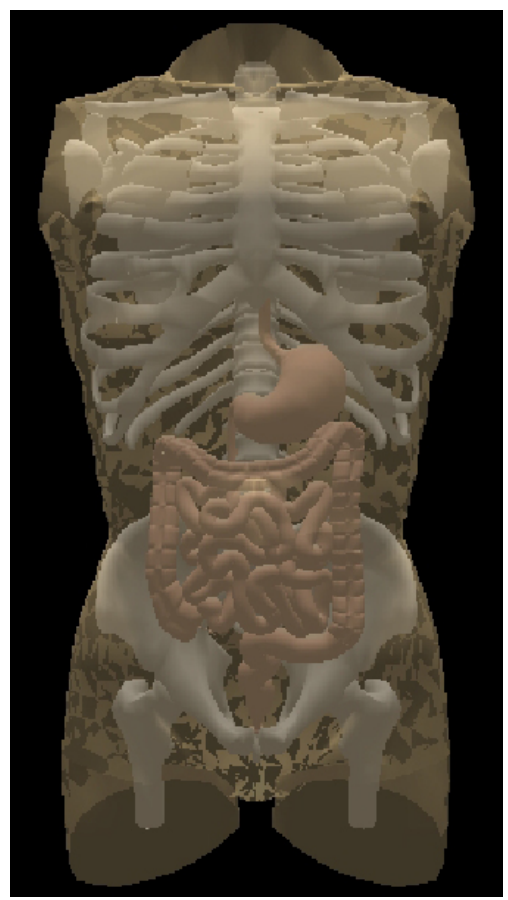

Figura 3.12: Visualização do tórax humano com 3 camadas: sistema digestivo, esqueleto e pele.

a partir do osso pélvico humano. Para tal aplicação dois tipos de objetos gráficos são necessários: uma representação da área da bacia humana formada por três camadas (pele, osso e medula) e uma representação da agulha que efetuará a coleta formada por uma única camada. Nessa simulação, a bacia é o objeto estático e a agulha é o objeto de interação do usuário que efetuará a simulação [61].

A Figura 3.13 representa um estágio da simulação, nela estão representados o objeto estático (onde só se vê a pele da bacia) e a agulha. A pele é a única parte visível da bacia para dar um caráter de realismo à simulação, já que em uma coleta de medula real a pele também é a única parte visível. A tabela 3.4 apresenta a composição de cada camada, no total, a bacia é composta por 20930 vértices e 41873 células.

Tabela 3.4: Composição dos objetos usados na simulação de coleta de medula óssea.

\begin{tabular}{|c|c|c|}
\hline Camada & Número de Células & Número de Vértices \\
\hline \hline Medula & 16072 & 8036 \\
\hline Osso & 24164 & 12070 \\
\hline Pele & 1637 & 824 \\
\hline Total Bacia & $\mathbf{4 1 8 7 3}$ & $\mathbf{2 0 9 3 0}$ \\
\hline Agulha & $\mathbf{2 5 6}$ & $\mathbf{4 6 0}$ \\
\hline
\end{tabular}




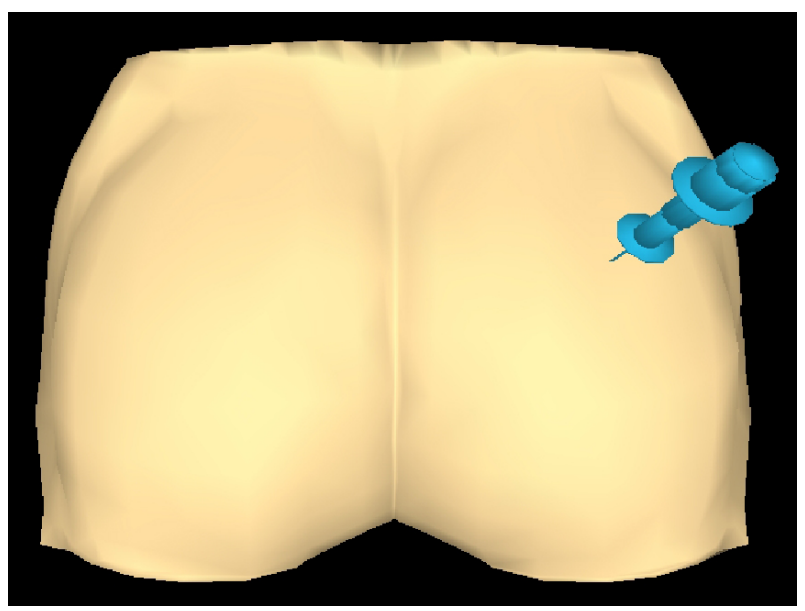

Figura 3.13: Visualização de um estágio da simulação de coleta de medula óssea.

\subsection{Considerações Finais}

O estudo das estruturas apresentadas neste capítulo serviu de grande valia para o desenvolvimento do projeto. Junto com os conceitos apresentados no Capítulo 2, as idéias aqui apresentadas auxiliaram na modelagem e implementação da ED deste projeto.

Mesmo que a estrutura MF seja uma extensão da OF, foram necessárias algumas adaptações em certas abordagens da OF. Estas adaptações serão apresentadas no decorrer do próximo capítulo. 
Estruturas de Dados Topológicas 


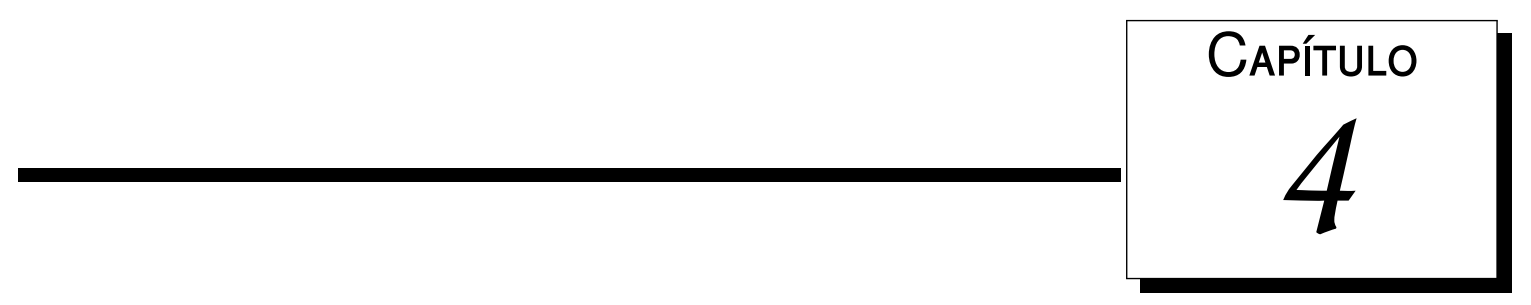

\section{Mate Face}

Neste capítulo serão apresentados detalhes de modelagem e implementação da ED topológica chamada Mate Face (MF).

Assim como na OF, o desenvolvimento desta ED se focou em as duas características: a facilidade de uso e flexibilidade. Devido a isso e para apoiar usuários, o uso de uma documentação padrão de seu código se fez necessário, tornando a ED mais compreensível.

Um dos principais objetivos da estrutura MF é poder representar tanto malhas bidimensionais (planares ou superficiais) quanto tridimensionais (volumétricas), além disso, essas malhas podem ser simples ou mistas. Porém, devido ao interesse em implementar a ED seguindo a forma de representação implícita, ainda não foi possível representar malhas volumétricas mistas. A implementação desta foi proposta como sendo um dos trabalhos futuros da ED.

A seguir, serão apresentados alguns detalhes de implementação da MF de acordo com as características herdadas da OF. Nas seções posteriores, será detalhada a composição da estrutura, além de serem apresentados alguns exemplos de aplicação de visualização de malhas. Finalmente, serão apresentados alguns resultados comparativos com a OF e as considerações finais. 


\subsection{Implementação}

A estrutura $\mathrm{OF}$ foi implementada usando a linguagem $\mathrm{C}++$. Originalmente, esta linguagem foi adotada para se manter a compatibilidade com os demais projetos desenvolvidos no Laboratório LCAD. Além disso, foram levados em conta o desempenho que a linguagem oferece e a possibilidade de uso de templates[41].

A MF foi proposta para estender a OF quanto aos tipos de elementos que seja capaz de representar. Uma das principais diferenças entre a OF e a MF é que esta representa as arestas e faces explicitamente. Outra diferença está no fato que a MF representa malhas mistas e, devido a isto, foram necessárias algumas adaptações. Uma das adaptações que se destacam é a da operação de determinação de vizinhança de uma célula, que originalmente (pela OF) era feita usando o conceito de corners opostos. Este conceito, porém não é adequado para malhas com faces com mais de três vértices. Conceitos como half-edges e half-faces permitem o uso de uma abordagem diferente mais adequada para os novos tipos de dados acrescentados na extensão. As operações de determinação de vizinhança serão demonstradas ao longo deste capítulo.

Mesmo havendo algumas modificações, a MF herdou muitas de suas características da OF. Algumas destas características herdadas serão apresentadas a seguir:

\subsubsection{Perfil de malha}

Assim como na OF, todas as classes da ED MF dependem de parâmetros templates que precisam ser definidos no momento de sua declaração. Com isso, é possível tornar a ED flexível podendo representar tipos de malhas diferentes, com dados associados em elementos distintos, bastando apenas alterar a definição do parâmetro template. Desta maneira, não são realizados testes de verificação de tipos durante a execução do algoritmo sobre a estrutura, pois esta tarefa é realizada durante a compilação.

Cada classe que representa um determinado componente da malha necessita de um conjunto de parâmetros templates diferente. O uso de perfil foi então escolhido para tornar mais prático o uso de templates, pois assim pode-se agrupar num único conjunto todos os parâmetros necessários para todas as classes da estrutura. Este perfil deve conter todos os tipos utilizados em todas as classes, desta maneira, fica cada classe responsável por escolher os tipos que utiliza.

A MF adota a mesma estrutura de perfil que a OF utiliza para definição de uma malha. A única diferença é que, devido à extensão, foram adicionados os tipos de arestas e de faces, além de serem acrescentados novos tipos de células e classes manipuladoras de malhas. 
Vale salientar, mais uma vez, que o uso de perfis é bastante importante para tornar a ED flexível. Já que permite a um usuário criar novos perfis caso deseje associar dados a elementos da malha. Tudo o que o usuário precisa fazer é criar uma nova classe (onde o dado vai ser atribuído) que herde da sua respectiva classe base da MF. Um exemplo desta flexibilidade foi apresentado na Subseção 3.3.3.

\subsubsection{Vetor de elementos}

Uma das vantagens em utilizar um identificador para referenciar cada elemento de uma malha é poder associá-lo com a posição de memória do elemento. Por exemplo, se todos os vértices forem alocados em um vetor, pode-se enumerá-los de acordo com a posição de cada vértice no vetor. Porém, essa abordagem tem alguns problemas, como exemplo, o limite imposto pelo tamanho de espaço de memória alocado a um vetor. Outro problema pode ser observado quando se deseja remover algum elemento deste vetor. Para contornar estes problemas e ainda poder tirar proveito do acesso direto à memória, Lizier [41] propôs o uso de um vetor alocado em partes com gerenciamento de posições vazias. Assim, blocos de memória são alocados dinamicamente, na medida em que novos elementos são inseridos em seus respectivos vetores.

Estes blocos são indexados em um vetor de ponteiros, onde a posição de um bloco nesse vetor é a divisão inteira do identificador do elemento pelo tamanho do bloco. A posição do elemento no bloco é dada pelo resto dessa divisão. Desta maneira, o limite ainda é estabelecido no momento em que o vetor de ponteiros é alocado, mas pode-se definir uma ordem de grandeza maior do número de elementos de uma malha.

A MF herda a classe deste vetor de elementos da OF e, como na OF, todo elemento inserido neste vetor deve herdar da classe base da estrutura (mfBase), pois nesta classe se encontra a estrutura necessária para realizar o gerenciamento de posições vazias. A classe do vetor de elementos é chamada de mfVector.

A Figura 4.1 ilustra o esquema de alocação deste vetor.

Vale salientar que na MF cada vértice, aresta ou face podem ser representados de duas formas: por um único identificador que representa sua posição em seu respectivo vetor de elementos ou por um índice que indica sua posição em sua célula incidente. A questão de indexação de elementos é tratada na seção 4.2.4.

\subsection{Composição da ED MF}

Todas as malhas representadas pela MF tem associado a elas um tipo de perfil. Este perfil indica a dimensão da malha e que tipos de dados e operações que a compõem. 


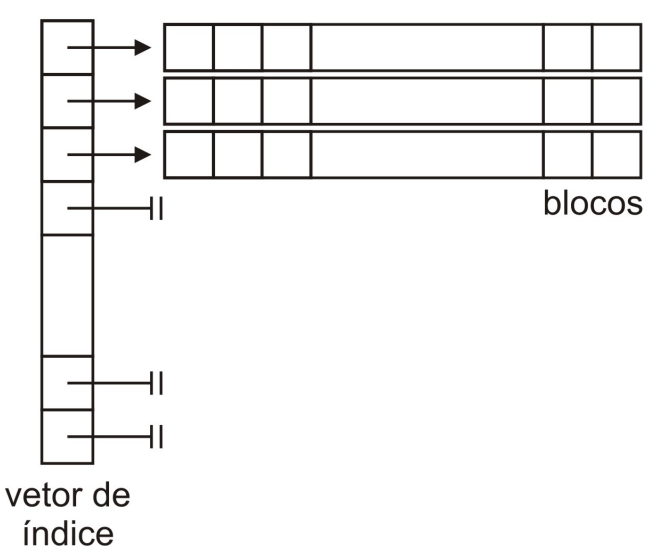

Figura 4.1: Vetor de alocação por blocos.

Os códigos exemplos A.1 e A.2 demonstram dois tipos de perfis, o primeiro representa uma malha superficial triangular dentro de um espaço 2D, e o segundo representa uma malha volumétrica padrão formada por tetraedros.

A seguir, serão detalhados alguns dos tipos de classes bases da MF.

\subsubsection{Vértice}

As informações geométricas básicas da malha são armazenadas nos seus vértices. Cada vértice está associado a uma posição (por um vetor de coordenadas) no espaço, que é base da maioria das operações geométricas. Além do vetor de coordenadas, o vértice armazena uma referência (por meio de um identificador) para uma célula incidente. Caso o vértice seja singular, será armazenado um identificador para uma célula de cada componente que constitui a singularidade a ser armazenada. A figura 4.2 ilustra o caso de um vértice singular que pertence a dois componentes diferentes.

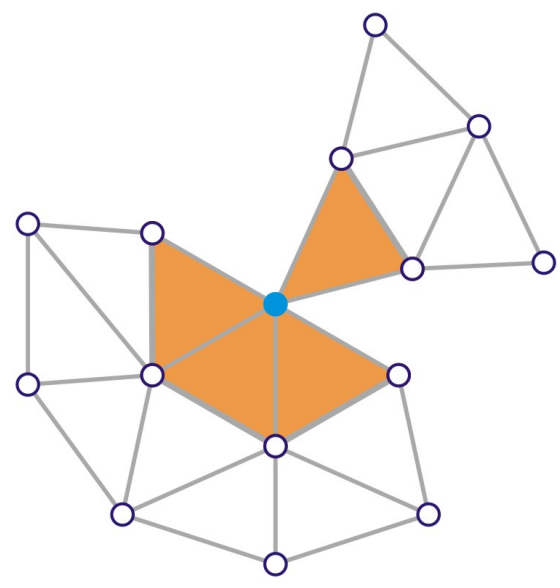

Figura 4.2: Vértice singular com as células incidentes destacadas. 
Nesta ED escolheu-se representar singularidade de vértices pois o tratamento destas singularidades se demonstra bastante útil em aplicações de geração de malhas. Além disso, este tipo de relação torna mais eficiente a determinação de vizinhança entre células durante o processo de carga de malha como é demonstrado na seção 4.4.

A classe base dos vértices é a mfVertex. Os templates do perfil necessários para a definição desta classe são a dimensão do espaço do vértice, que corresponde ao tamanho do vetor que armazenará as coordenadas, e os tipos que definirão o tipo de dado da coordenada e o tipo de identificador.

Para tratar malhas com singularidade nos vértices, é necessário utilizar como vértice base a classe mfSingularVertex, na qual uma lista de singularidade é associada ao vértice. A partir desta lista, é possível percorrer, de forma direta, todas as células incidentes a um determinado vértice. Para definir a classe mfSingularVertex são necessários os mesmos parâmetros da classe mfVertex.

Para simplificar o uso dos vértices, foram implementadas as classes mfVertex $2 D$ e mfVertex $3 D$, que correspondem respectivamente a vértices no espaço bidimensional e tridimensional. Estas classes só precisam do parâmetro de tipos. A Figura 4.3 ilustra uma malha planar e a composição de seus vértices.

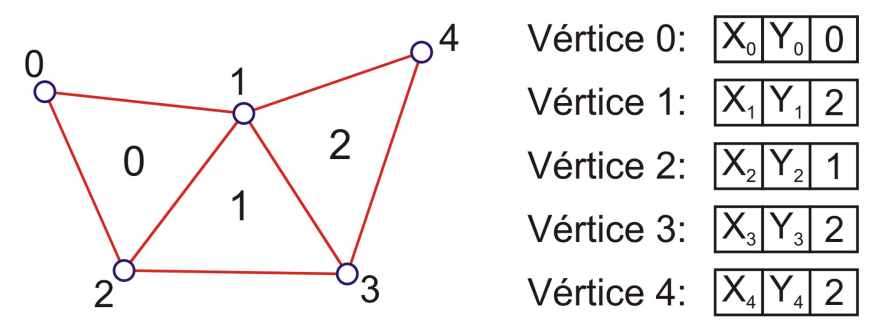

Figura 4.3: Composição básica do vértice de uma malha plana.

\subsubsection{Aresta}

A componente aresta é representada explicitamente, e tem como classe base a $m f E d g e$. Foi necessário este tipo de representação para poder associar informações à esta componente. Porém, devido a flexibilidade da ED, é possível representá-la implicitamente, caso não seja necessário atribuí-la alguma informação. Deste modo, a flexibilidade permite o consumo menor de memória.

Por armazenar uma informação em uma única instância de aresta, também é possível reduzir o consumo de memória. Além do mais atribuir uma informação a uma única aresta consome menos tempo que atribuí-la as representações implícitas em duas ou mais células. De certo modo, nesses casos, representar uma aresta explicitamente é 
tão necessário quanto representar um vértice unicamente.

Diferentemente do vértice, nesta ED não serão tratadas arestas singulares ou faces singulares.

\subsubsection{Face}

Assim como a aresta, a face é representada explicitamente, podendo também ser representada implicitamente caso não seja necessário atribuir informação a este componente de malha. A componente face tem como classe base a mfFace. Esta classe só está presente na representação de malhas volumétricas. Na estrutura, a face assume a forma ou de um triângulo ou de um quadrilátero.

\subsubsection{Célula}

Em cada célula, são armazenadas referências aos seus vértices, arestas e faces (estas no caso de malhas 3D), e também são armazenadas as referências às células vizinhas determinadas através de arestas ou faces incidentes. A classe base para definição da célula é a mfCell.

Dependendo do tipo de malha, a célula pode representar no caso 2D: um triângulo e um quadrilátero (através das classes mfTriCell e mfQuadCell respectivamente); e no caso 3D: um tetraedro, um hexaedro, um prisma e uma pirâmide (através das classes mfTetraCell, mfHexaCell, mfPrismCell e mfPiramidCell respectivamente). As Figuras $4.4 \mathrm{e}$ 4.5 ilustram respectivamente exemplos da composição básica das células triangulares e tetraédricas.

Célula 0:

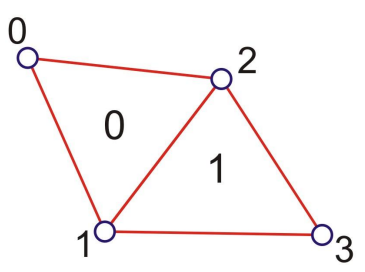

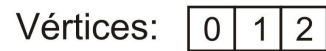

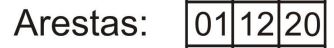

Vizinhos:

Célula 1:

Vértices: 112302

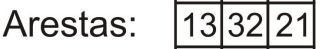

Vizinhos: \begin{tabular}{r|r|l|}
\hline & - & 0 \\
\hline
\end{tabular}

Figura 4.4: Composição básica da célula triangular.

A ordem de indexação dos componentes desta célula é um fator muito importante para simplificar e padronizar a concepção das operações da ED. Para isso, resolveuse adotar o modelo do formato VTK - Visualization ToolKit [34] como padrão desta estrutura. A Figura 4.6 ilustra o modelo para os variados tipos de células. 


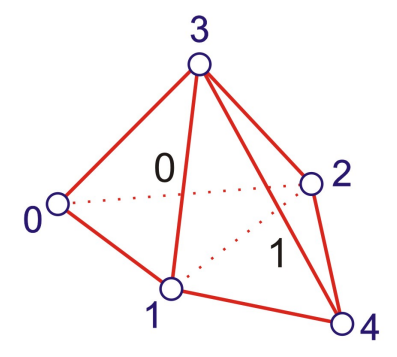

Célula 0:

\begin{tabular}{|c|c|c|c|c|c|}
\hline \multirow{4}{*}{$\begin{array}{l}\text { Vértices: } \\
\text { Arestas: } \\
\text { Faces: } \\
\text { Vizinhos: }\end{array}$} & \begin{tabular}{|l|}
0 \\
\end{tabular} & 1 & 2 & 3 & \\
\hline & 01 & 02 & 03 & 12 & \begin{tabular}{l|l|l}
13 & 23 \\
\end{tabular} \\
\hline & 132 & 023 & 031 & 012 & \\
\hline & \begin{tabular}{|l}
1 \\
\end{tabular} & - & - & - & \\
\hline
\end{tabular}

Célula 1:

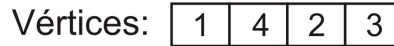

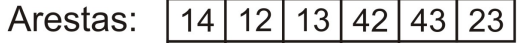

Faces: $\quad 432$ 123 134 | 142

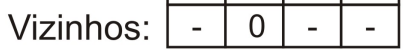

Figura 4.5: Composição básica da célula tetraédrica.

2D

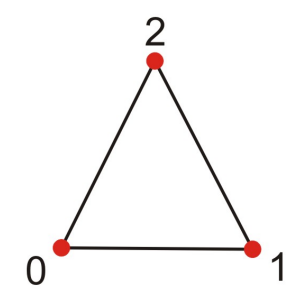

Triângulo

3D

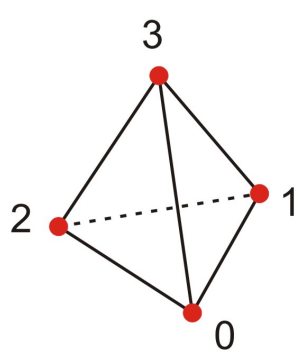

Tetraedro

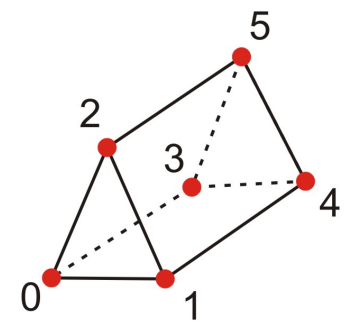

Prisma

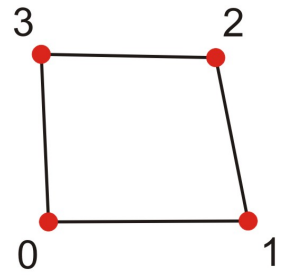

Quadrilátero

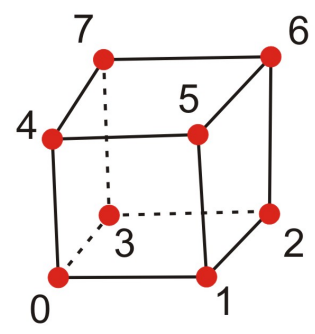

Hexaedro

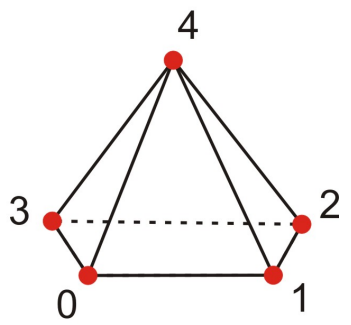

Pirâmide

Figura 4.6: Tipos de células e indexação de seus vértices baseados no modelo padrão do formato VTK. 


\section{Mate Face}

No caso das células 2D, a indexação é simples, pois não há necessidade de referenciar a face (já que a própria célula é a face) e o número dos vértices da célula é igual ao número das suas arestas e vizinhos. Então, a partir daí, a indexação dos dois componentes segue a orientação da célula (sentido anti-horário) e, no caso da aresta, a sua indexação é igual ao índice do seu primeiro vértice. No caso da célula vizinha, o problema de sua indexação será tratado na Seção 4.3.

Já as células 3D são mais complexas que as 2D, devido aos seguintes fatores:

- A presença de face e, como a vizinhança entre essas células é determinada através de faces incidentes, o fato do número de vértices não ser igual ao número de faces torna inviável a operação de vizinhança por vértice oposto (com exceção do tetraedro);

- O número de arestas é diferente do número de vértices (também impossibilitando a representação de arestas por um único vértice);

- No caso dos prismas e das pirâmides, há a presença de dois tipos de faces nas suas células.

Com estes fatores em mente, foi proposto que, além dos atributos que compõem a célula (vetores dos vértices, das arestas, das faces e dos vizinhos), sejam implementadas funções especiais para mapear/identificar elementos a partir de um conjunto de outros elementos.

\subsubsection{Malha}

Todas as malhas suportadas pela MF são representadas pela classe base mfMesh. A especificação do tipo de malha é definida pelo tipo de vértice, aresta, face e célula que serão alocados em seus respectivos vetores da malha.

O tipo de malha alocada só pode ser alterado pela mudança no perfil atribuído à classe $m f M e s h$; por isso, foi necessário definir uma classe responsável por manutenção e manipulação da malha. Este tipo de classe tem como classe base a mfOper e tem como função principal executar as rotinas necessárias quando se adiciona e remove algum vértice, aresta, face ou célula.

Com a representação explícita das arestas e faces, as operações de adição e remoção de células presentes na ED OF foram modificadas. Essas mudanças foram feitas para tratar a adição/remoção destes componentes à medida que as células forem adicionadas/removidas. 
O código exemplo A.4 demonstra a construção de uma malha. Neste exemplo, cada vértice é primeiro adicionado ao vetor de vértices da malha e referenciado às suas respectivas células. Quando uma célula obtém as referências de todos os seus vértices, ela é então adicionada ao vetor de células da malha. Por padrão da estrutura, para o caso de malha $2 \mathrm{D}$, a função de adição da célula na malha também executa a determinação de células vizinhas e a alocação de arestas pertencentes a esta célula e suas vizinhas.

\subsubsection{Estruturas auxiliares}

As estruturas auxiliares presentes na MF são estruturas simples que seguem o mesmo padrão de programação, onde precisam ser instanciadas com o tipo de objeto que será armazenado.

Atualmente, são três as estruturas disponíveis: lista de elementos (mfList), vetor de elementos (a classe mfVector que foi detalhada na Subseção 4.1.2) e árvore binária $k d$-tree (mfKdTree).

\subsubsection{Iteradores}

Seguindo o requisito de se ter uma interface simples, uma classe base de iteradores (mflterator) foi criada não só para simplificar o acesso a dados que possuem alguma relação entre si, como também para padronizar tal acesso. Os iteradores percorrem os elementos da malha de acordo com a necessidade específica do seu tipo, podendo ser um simples iterador para percorrer células da malha, como também, um que percorre as células do bordo da malha. Na MF foram implementados os seguintes iteradores:

- mfVerticesIterator, mfCellsIterator, mfEdgesIterator e mfFacesIterator: percorrem respectivamente todos os vértices, células, arestas e faces da malha;

- mfVertexStarIterator: percorre todas as células que contém um determinado vértice (estrela do vértice). Os nomes das classes deste tipo de iterador terminam com o sufixo relacionado ao tipo de célula da malha;

- mfEdgeStarIterator: percorre todas as células que contém uma determinada aresta (estrela da aresta). Os nomes das classes deste tipo de iterador terminam com o sufixo relacionado ao tipo de célula da malha 3D;

- mfMateCelliteratorTri, mfMateCelliteratorQuad, mfMateCelliteratorHybrid2D: percorre todas as células vizinhas de uma determinada célula (vizinhas por vértice(s) comuns e não apenas por aresta ou face comuns); 
- mfBoundaryCelliterator: percorre todas as células que possuem ao menos um vértice no bordo. Os nomes das classes deste iterador terminam com o sufixo relacionado ao tipo de célula da malha $2 \mathrm{D}$.

Estes iteradores exigem na sua declaração apenas o perfil de tipos como parâmetro template. No construtor, é necessário informar o endereço da malha que terá seus elementos percorridos. Nos iteradores de vetor de elementos é necessário iniciar a iteração com a posição inicial do iterador no vetor, por padrão esta posição inicial é a do primeiro item do vetor. Nos casos de iteradores que envolvem vizinhança, é necessário iniciar a iteração com o identificador do elemento cuja vizinhança se deseja percorrer.

O código exemplo A.5 demonstra o uso de três tipos de iteradores: de lista vértices, de estrela de um vértice (neste caso, o vértice 10 da malha) e de bordo de malha.

\subsubsection{Suporte a formatos de arquivos}

Em certas aplicações, se deseja carregar malhas a partir de arquivos e, também, salvar os resultados em outros arquivos. Com isso em mente, as classes de leitura presentes na OF foram adaptadas para a MF usá-las além de serem acrescentadas outras classes. Atualmente, a MF dá suporte à leitura de arquivo dos formatos VTK [34], OFF ${ }^{1}$, VRML [1], PLY² e HEX ${ }^{3}$. O código A.6 apresenta um exemplo onde uma malha é carregada a partir de um arquivo no formato VTK, e depois é salva em outro arquivo no formato VRML (com extensão WRL).

\subsubsection{Cálculos geométricos}

A MF concentra todas as suas operações de cálculos geométricos na classe mfGeometric. O propósito desta classe é de disponibilizar operações geométricas básicas, além de tornar flexível as alterações destas operações realizadas pela ED e seus algoritmos. Para acessar suas operações, é necessário especificá-la no perfil de tipos da malha, podendo até ser substituída por outra classe com a mesma interface.

Vale ressaltar que a grande maioria das operações realizadas pela mfGeometric exige que as malhas tenham suas células orientadas.

Dentre as operações disponíveis na mfGeometric estão:

- dist: Calcula a distância entre dois pontos (no espaço 2D ou 3D);

\footnotetext{
${ }^{1}$ Geomview - Site: http://www.geom.uiuc.edu/software/geomview

${ }^{2}$ PLY - Polygon File Format - Site: http://local.wasp.uwa.edu.au/ pbourke/dataformats/ply/

${ }^{3}$ Unstructured Hexahedral Meshes - Site: http://www.cc.gatech.edu/ lindstro/data/hexzip/
} 
- orientation2D: Verifica a orientação de células 2D no espaço bidimensional;

- orientation3D: Verifica a orientação de células tetraédricas;

- inCircle: Verifica se um ponto está dentro ou fora de um círculo definido pelo vértices de um triângulo;

- getCircuncircle: Retorna as coordenadas do centro do circuncírculo de um triângulo;

- inDiametralCircle: Verifica se um ponto está dentro ou fora do círculo diametral de uma aresta;

- inTetrahedron: Verifica se um ponto está dentro ou fora de um tetraedro.

\subsubsection{Operações topológicas}

A MF disponibiliza duas classes para realização de operações topológicas: a mfOper e a mfTopology. Como foi dito na Seção 4.2.5, a mfOper e suas sub-classes são responsáveis pelas operações de adição e remoção de células. O objetivo da classe mfTopology é de permitir a fácil substituição destes tipos de algoritmos na estrutura, visto que a classe é um dos parâmetros (representado por sTopology) do perfil de malhas.

Dentre as operações disponíveis na mfTopology estão:

- flip2D: Realiza a operação de flip em uma malha triangular;

- addOnEdge: Adiciona uma aresta diagonal em um par de triângulos adjacentes. Substituindo os dois triângulos originais por quatro novos triângulos;

- collapseEdge: Executa um colapso em uma aresta ao fundir seus dois vértice incidentes em um só.

\subsection{Adaptação da OF}

Para tornar possível a representação dos variados tipos propostos pelo projeto, além da OF ser estendida, parte de sua estruturação teve que ser adaptada. Entre as adaptações necessárias se destacam:

\section{Representação de vizinhança de células}

Como foi dito na Seção 4.2.4, a presença de novos elementos na malha e o fator de meios de indexações diferentes destes, tornou necessário uma adaptação quanto ao meio de representar vizinhos de células. Assim, o método de uso de corners opostos utilizado na OF não é conveniente como mostra a Figura 4.7 para os casos de quadriláteros (a) e hexaedros (b). 


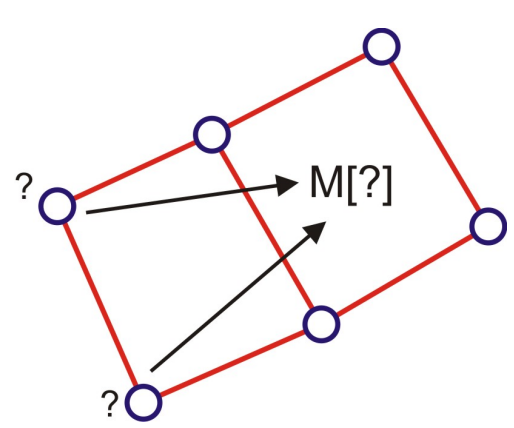

(a)

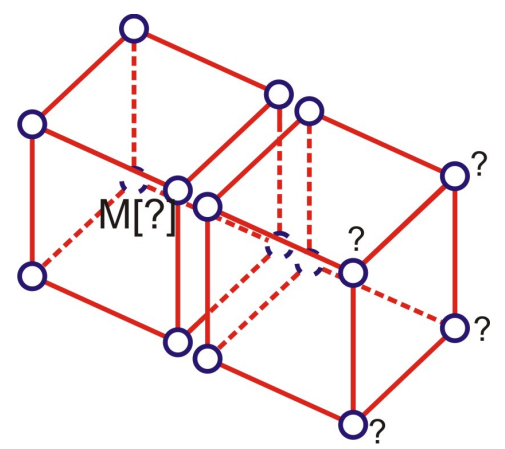

(b)

Figura 4.7: Problema de indexação de vizinhança usando a idéia de corners opostos em células quadriláteras (a) e hexaédricas (b).

A abordagem escolhida para solucionar tal problema é a que utiliza half-edges em malhas superficiais e half-faces em malhas volumétricas. Neste caso, as arestas ou faces incidentes comuns são os elementos que indicam tal vizinhança. A Figura 4.8 demonstra essa nova representação para o caso de malhas formadas por quadriláteros e tetraedros.

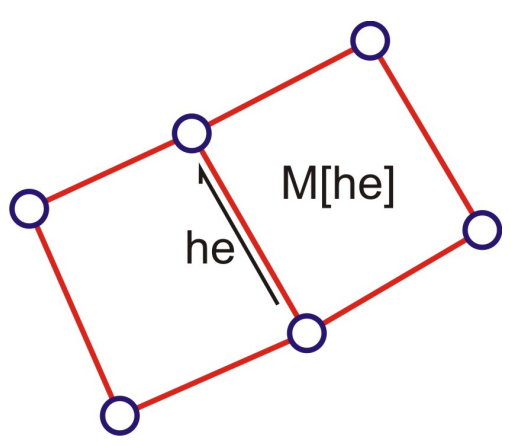

(a)

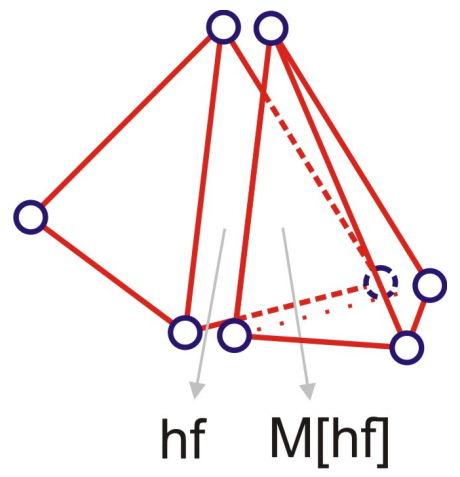

(b)

Figura 4.8: Abordagem de vizinhança por half-edge (he) em células quadriláteras (a) e por half-face (hf) em células tetraédricas (b).

\section{Mapeamento de elementos de malha}

Devido a maior complexidade na representação de componentes de malhas volumétricas, foram propostos métodos de mapeamento de elementos. Estes métodos utilizam relações de vizinhança entre vértices e orientação para melhor acessar os seus elementos incidentes. Entre os métodos implementados, destacam-se:

- getEdgeIndex: determina o índice de uma aresta a partir dos vértices incidentes; 
- getFaceIndex: determina o índice de uma face representada por três de seus vértices. É evidente que, mesmo que uma face seja quadrangular, é possível determinar seu índice com apenas três de seus vértices, já que a MF só representa complexos celulares;

- getRightFaceIndex, getLeftFaceIndex: que obtém respectivamente as faces a direita e a esquerda de uma aresta definida pelos seus vértices extremos, além disso a orientação da aresta é definida pela ordem dos vértices.

Estes métodos de mapeamento foram implementados seguindo a estrutura de suas respectivas classes de célula: $m f$ TetraCell, mfHexaCell, mfPrismCell e mfPiramidCell.

\section{Estrela de vértices em malhas superficiais}

Como foi dito anteriormente, esta operação percorre todas as células incidentes a um dado vértice, para isso usa-se a referência de vizinhança entre as células. A seguir, serão apresentadas duas abordagens para a execução das estrelas. A primeira é utilizada na OF e a segunda foi proposta para melhorar o desempenho de execução da operação.

- A operação na estrutura OF

A operação estrela de um vértice é executada a partir de uma célula inicial, desta célula as duas células vizinhas que contém o vértice são buscadas e armazenadas em uma lista de busca e uma lista flag. A lista de busca serve para indicar quais células podem ter vizinhos que ainda não foram visitados, e a lista flag verifica se uma nova célula já foi achada e, caso não seja, adiciona esta célula nas duas listas.

- A operação na estrutura MF

A operação proposta na MF faz uma abordagem diferente da OF. O acesso a célula vizinha ainda é feito pela referência de vizinhos, porém, a operação de estrela inicialmente faz o acesso seguindo um ciclo com orientação no sentido antihorário, como mostra a Figura 4.9(a). Esta figura apresenta o cálculo de estrela de um vértice de interior. No caso de vértice de bordo (ilustrado nas Figuras 4.9(b) e 4.9(c)), uma vez que uma referência vazia for achada (ou seja, uma vez que uma das células não tenha vizinho quando se percorre no sentido anti-horário), a busca volta para a célula inicial e faz a busca no sentido horário até achar a referência vazia indicando que todas as células da estrela foram determinadas. 


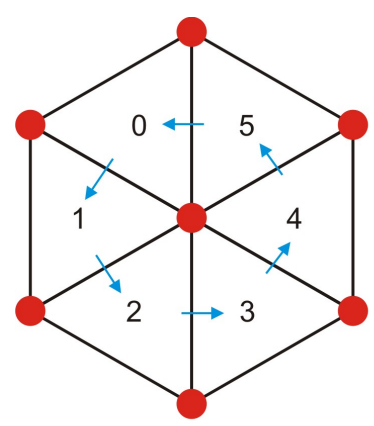

a) Ciclo completo

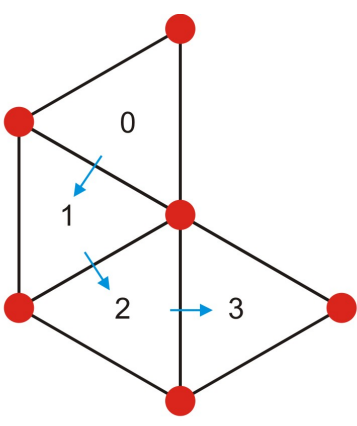

b) Ciclo incompleto com um sentido de busca

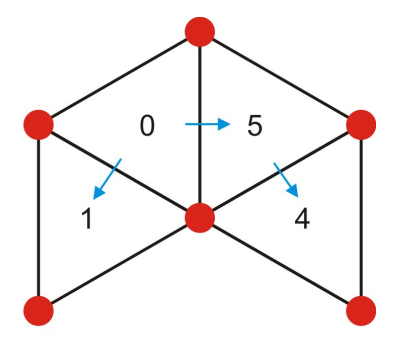

c) Ciclo incompleto com dois sentidos de busca

Figura 4.9: Operação de estrela de um vértice na $\mathrm{MF}$, onde a célula 0 é a célula inicial da busca da operação.

A comparação de desempenho de execução das duas abordagens será apresentada na Seção 4.5.4.

As adaptações permitiram que a implementação da representação de malhas quadriláteras seja semelhante à representação de malhas triangulares. Tal semelhança levou a possibilidade de se implementar representações para malhas mistas, neste caso, formadas por triângulos e quadriláteros. A Figura 4.10 demonstra a operação estrela de um vértice de uma malha mista, onde a transição de uma célula para outra é feita a partir da operação de transição da célula de origem.

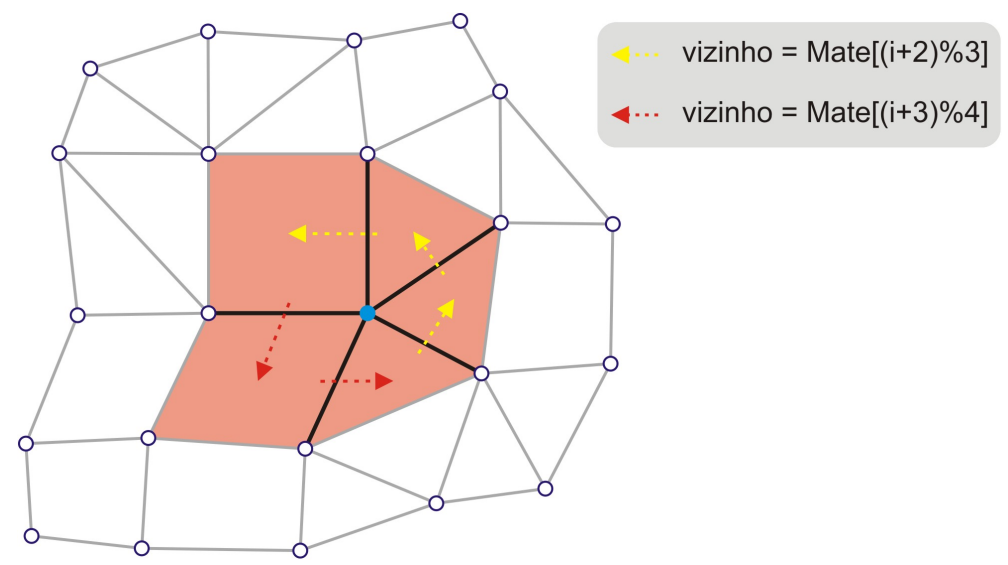

Figura 4.10: Operação de estrela de um vértice de interior em uma malha superficial mista.

\subsection{MF 2D}

Como foi dito anteriormente, a representação das malhas bidimensionais é mais simples que a tridimensionais. Nesta seção, serão apresentadas alguns detalhes de 


\section{Mate Face}

indexação de elementos de malhas 2D.

A Figura 4.11 representa a composição básica da MF 2D, onde sTrait2D, sVertex, sEdge e $s C e l l 3 D$ são respectivamente os tipos perfil, vértices, arestas e células da malha $3 \mathrm{D}, i$ é a dimensão no espaço e $j$ é a quantidade de vértices, aresta e vizinhos pertencentes a célula do tipo sCell3D.

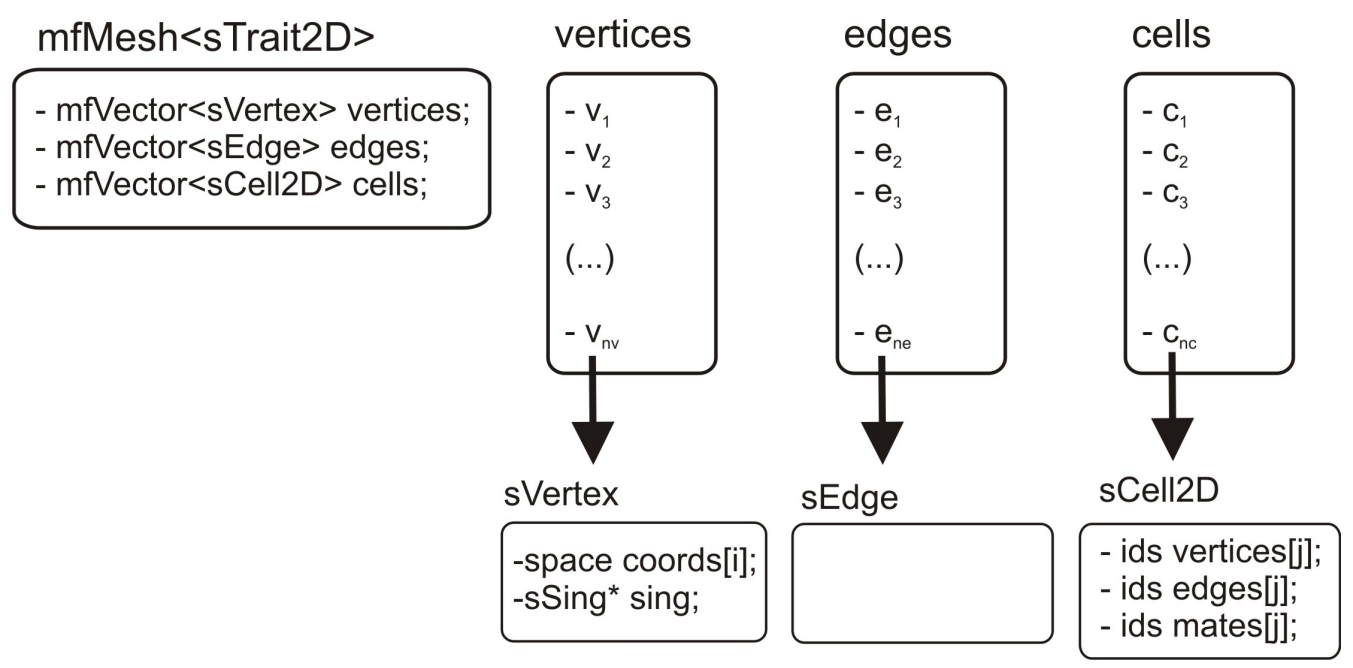

Figura 4.11: Ilustração da MF 2D básica.

A seguir, serão apresentados os tipos de malhas 2D de acordo com a célula que as compõem que são suportados pela MF.

\subsubsection{Malhas triangulares}

As células triangulares apresentam a indexação de seus elementos bastante simples, como mostra a Figura 4.12.

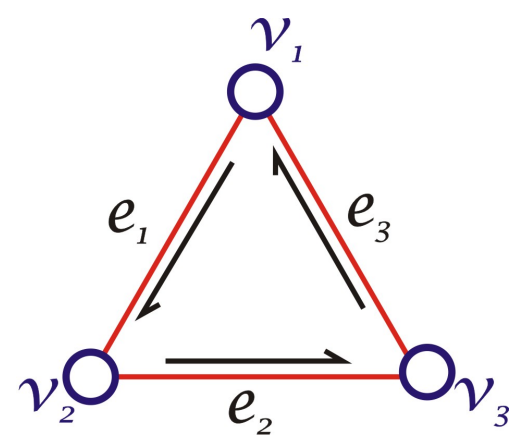

Figura 4.12: Indexação de elementos de uma célula triangular.

A determinação e indexação das células vizinhas é feita a partir de arestas em comum. A classe de operações de manipulação da malha triangulares (mfMeshTri) determina as células vizinhas à medida que células são adicionadas à malha. 
Assim como na Corner-Table, dado um elemento da célula indexado por $i$ e a orientação da célula no sentido anti-horário, pode-se obter os índices do próximo elemento $(\operatorname{prox}(i))$ e do elemento anterior (ante $(i))$ usando as equações:

$$
\begin{aligned}
& \operatorname{prox}(i)=(i+1) \% 3 \\
& \operatorname{ante}(i)=(i+2) \% 3
\end{aligned}
$$

Essas equações serviram de base à determinação de células vizinhas, como é mostrado no Algoritmo 4.1.

\section{Algoritmo 4.1}

Entrada: Seja $V$ o vetor de vértices de uma célula $c_{n}$

1. para $\mathrm{i} \leftarrow 1$ até 3 faça

2. $\quad$ para $\mathrm{j} \leftarrow 1$ até número_de_singulares[i] faça

3. $\quad c_{\text {aux }} \leftarrow V[\mathrm{i}]->\operatorname{singular}[\mathrm{j}]$

4. $\quad$ indice $_{\text {aux }} \leftarrow c_{\text {aux }}->$ indice_do_vertice $(V[\mathrm{i}])$

5. $\quad$ se $c_{n}->i d \_d o \_v e ́ r t i c e(\operatorname{prox}(i))=c_{a u x}->$ id_do_vértice $\left(\right.$ ante $\left(\right.$ indice $\left.\left.e_{\text {aux }}\right)\right)$ então

6. $\quad c_{n^{-}}>$Vizinho[i] $\leftarrow c_{\text {aux }}$

7. $\quad c_{\text {aux }}->$ Vizinho[ indice $\left._{\text {aux }}\right] \leftarrow c_{n}$

8. $\quad$ se número_de_singulares[i] $>1$

9. $\quad$ delete $V[\mathrm{i}]->$ singular[j]

10. $\quad$ vá para linha 1.

A operação de estrela de um vértice de uma malha triangular foi tratada na Seção 4.3, a operação ante(i) serviu de base para obtenção de células vizinhas no sentido anti-horário.

Um exemplo de representação de uma malha triangular é ilustrado na Figura 4.13 que mostra a visualização da malha do modelo Olivier Hand composto por 53054 vértices e 105860 triângulos.

Outro exemplo é ilustrado na figura 4.14, onde é visualizada em wireframe uma malha de um elefante (composta por 2688 vértice e 5384 triângulos) cujos vértices tem associado a eles um valor equivalente a temperatura obtido por uma simulação de equação de calor. Cada valor é representado por uma cor de acordo com a escala apresentada ao lado da malha. Esta simulação foi realizada pela aluna de mestrado do LCAD,amor Larissa Alves Petri. 
Mate Face

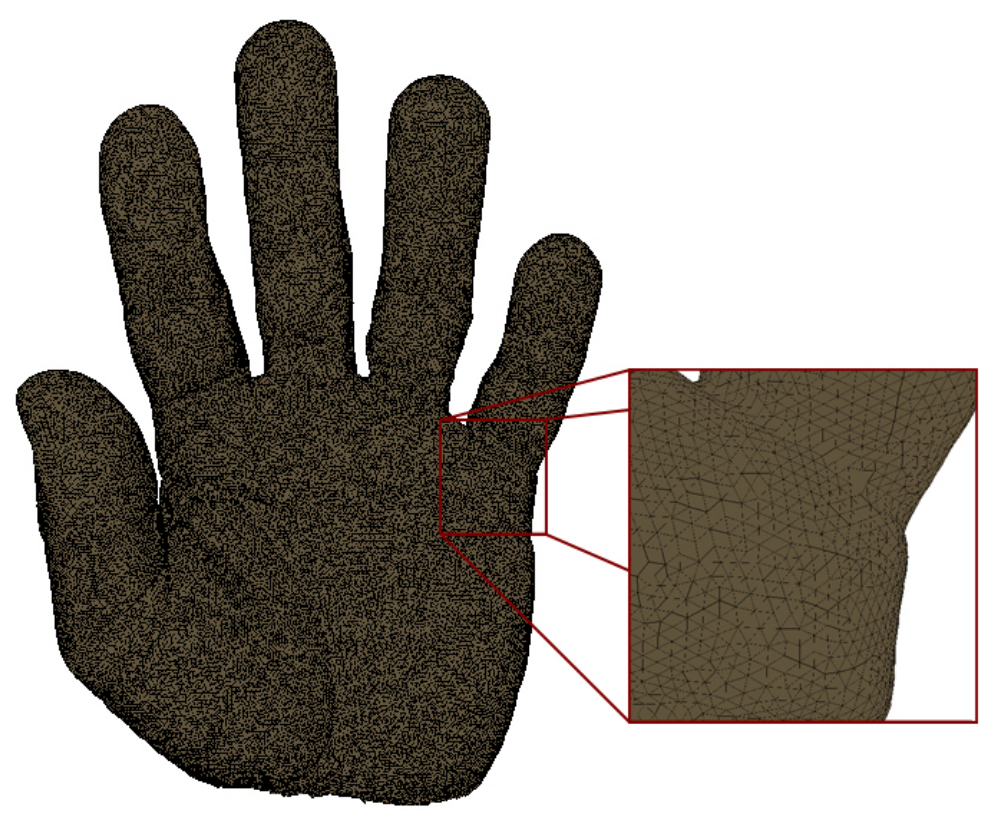

Figura 4.13: Representação da malha do modelo Olivier Hand. Este modelo foi obtido do repositório Aim@Shape.

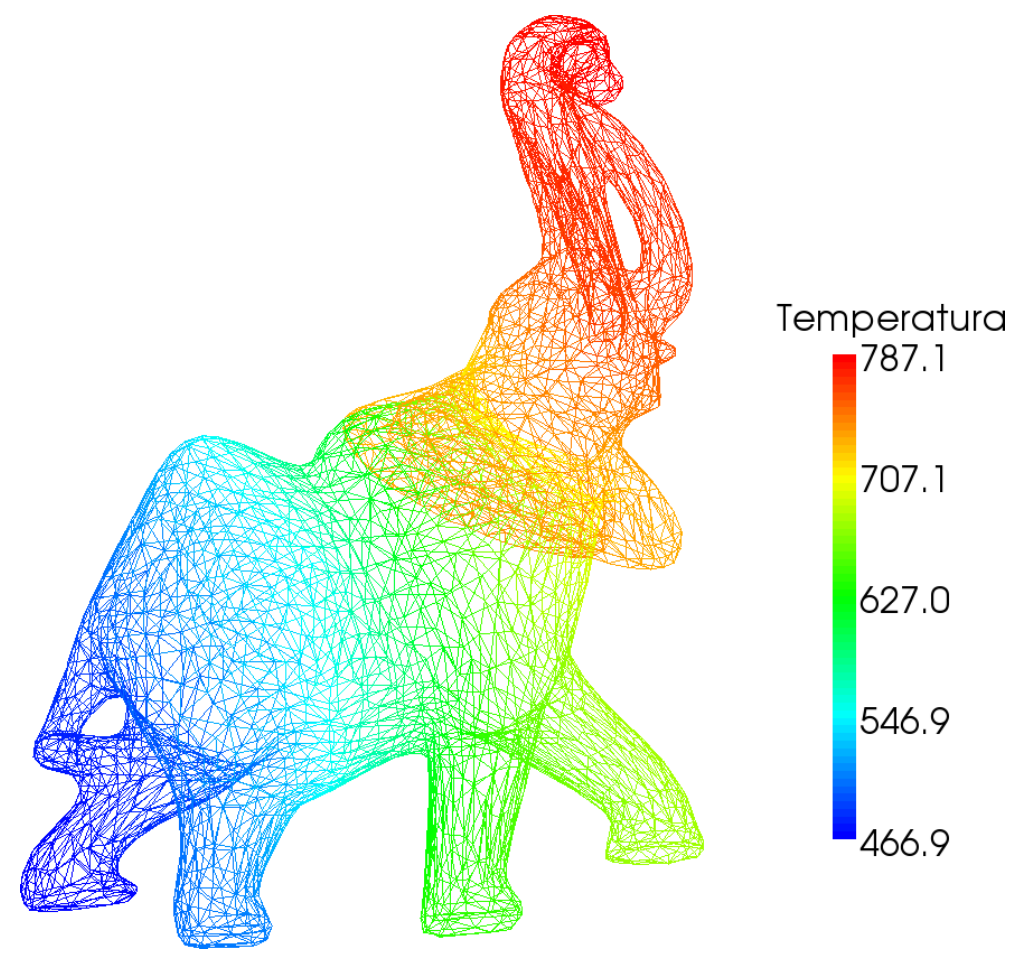

Figura 4.14: Representação em wireframe da malha de um elefante onde foi atribuído a cada vértice um valor de acordo com uma simulação de equação de calor.

\subsubsection{Malhas quadriláteras}

A representação de malhas quadriláteras segue analogamente à representação de malhas triangulares. Os índices que representam os vértices, as arestas e os vizinhos 
seguem a orientação da face. Além disso, o índice da aresta (e consequentemente do vizinho) é obtido pelo primeiro vértice que segue da sua orientação.

Semelhante às células triangulares, a obtenção do próximo elemento $(\operatorname{prox}(i))$ e do elemento anterior (ante(i)) de um elemento $i$ são feitas a partir das equações:

$$
\begin{aligned}
& \operatorname{prox}(i)=(i+1) \% 4 \\
& \operatorname{ante}(i)=(i+3) \% 4
\end{aligned}
$$

A classe de operações de manipulação da malha de quadriláteros é a mfMeshQuad. Nela são determinadas as relações de vizinhança entre células usando um algoritmo análogo ao Algoritmo 1.

A Figura 4.15 ilustra dois modos de visualização da malha do modelo de um busto composto 196761 vértices e 183552 quadriláteros. A malha é composta por múltiplos componentes. À esquerda, é demonstrada a capacidade de atribuir valores às células da malha, onde todas as células pertencentes a um mesmo componente tem atribuída a mesma cor. À direita, é apresentada uma visualização normal da malha com suas arestas em preto.

\subsubsection{Malhas mistas}

Assim como as malhas triangulares e quadriláteras, a indexação dos componentes das malhas mistas segue a orientação da célula. A diferença é que nas malhas mistas são representados os dois tipos de células 2D. A classe base de células mistas 2D é a classe $m f H y b r i d 2 D C e l l$ e a classe de operações de manipulação de malhas superficiais mistas é a mfMeshHybridSurface.

Para poder representar ambas as células da malha na classe mfHybrid2DCell, foi escolhido manter o vetor de índices de vértices, arestas e vizinhos com o tamanho 4, podendo assim armazenar todos os componentes de ambas as células. No caso da célula triangular, o quarto elemento de cada vetor de índice recebe o valor de -1 , a partir desse valor é possível determinar que tipo de célula é representada e quais tipos de equações $\operatorname{prox}(i)$ e ante( $i$ ) devem ser escolhidas.

A Figura 4.10 ilustra os tipos de equações a serem usadas para percorrer o ciclo (no sentido anti-horário) de uma estrela de um vértice de interior.

Um exemplo de representação de malha superficial mista é ilustrado na Figura 4.16, a malha em questão é um modelo CAD (Computer Aided Design) de uma peça de automóvel composto por 5215 vértices e 8432 células (sendo 6418 triângulos e 2014 

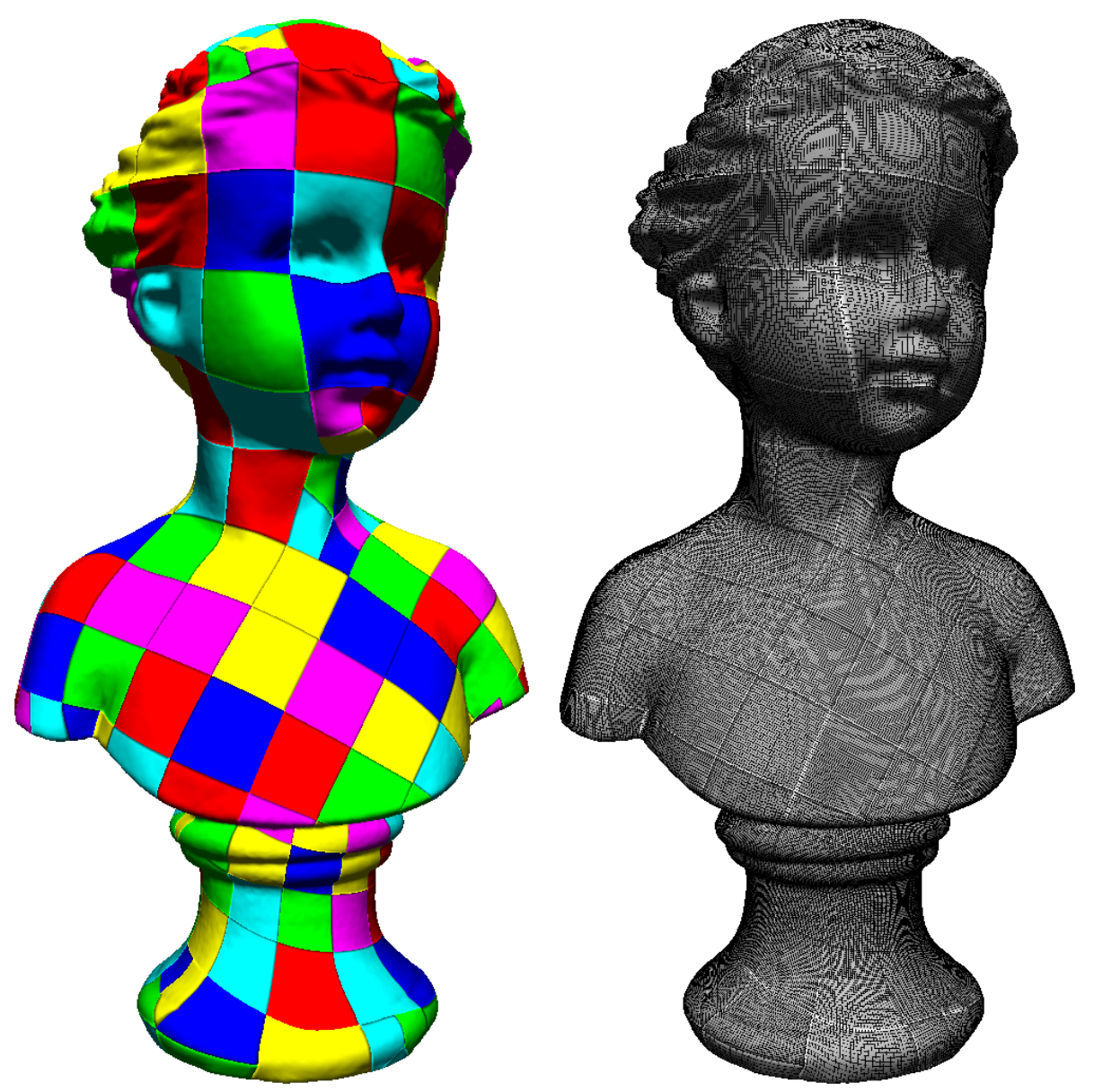

Figura 4.15: Duas visualizações da malha do modelo de um busto, que foi obtido do repositório Aim@Shape.

quadriláteros). Na visualização deste modelo foi destacada (em vermelho) a estrela de um determinado vértice.

\subsection{MF 3D}

Como foi dito anteriormente, é possível determinar o índice de arestas e faces de uma célula a partir de um método que as determina usando seus vértices incidentes. Assim, não é necessário que o usuário tenha conhecimento da ordem de indexação estabelecida para cada tipo de célula.

A Figura 4.17 representa a composição básica da MF 3D, onde sTrait3D, sVertex, sEdge, sFace e sCell3D são respectivamente os tipos perfil, vértices, arestas, faces e células da malha 3D, e $i, j$ e $k$ são respectivamente a quantidade de vértices, aresta e faces/vizinhos pertencentes à célula do tipo $s C e l l 3 D$.

Em malhas volumétricas a operação de estrela de arestas pode ser feita de modo análogo à operação de estrela de vértices em malhas 2D. Pois, como a relação de 


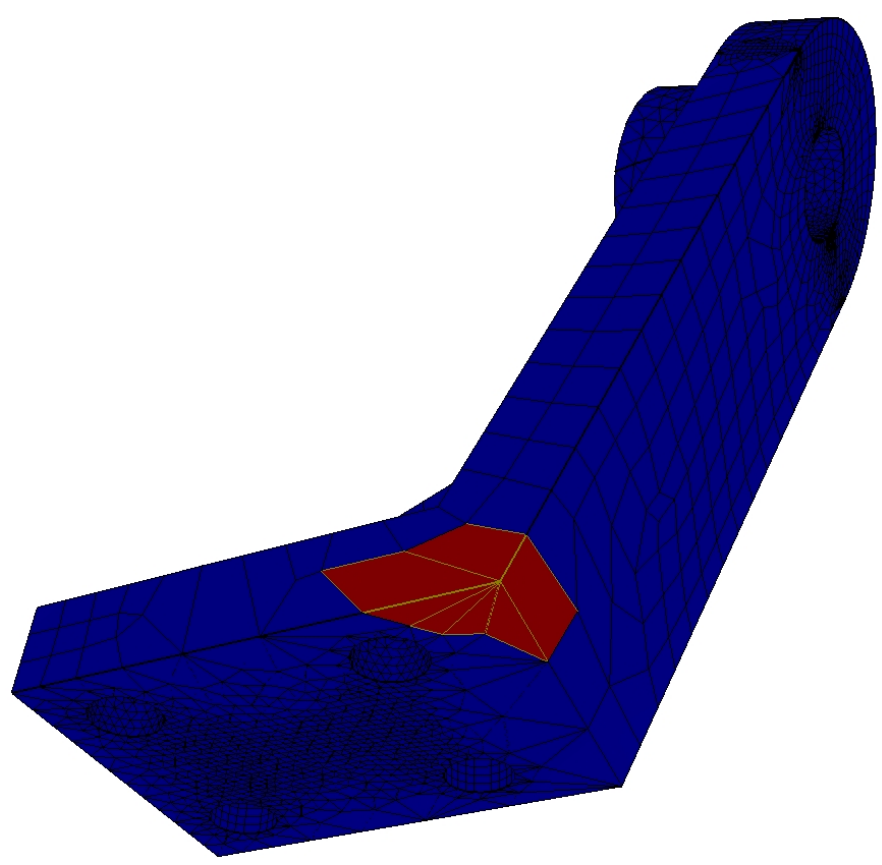

Figura 4.16: Representação da malha superficial mista de um modelo CAD obtido do repositório Aim@Shape.

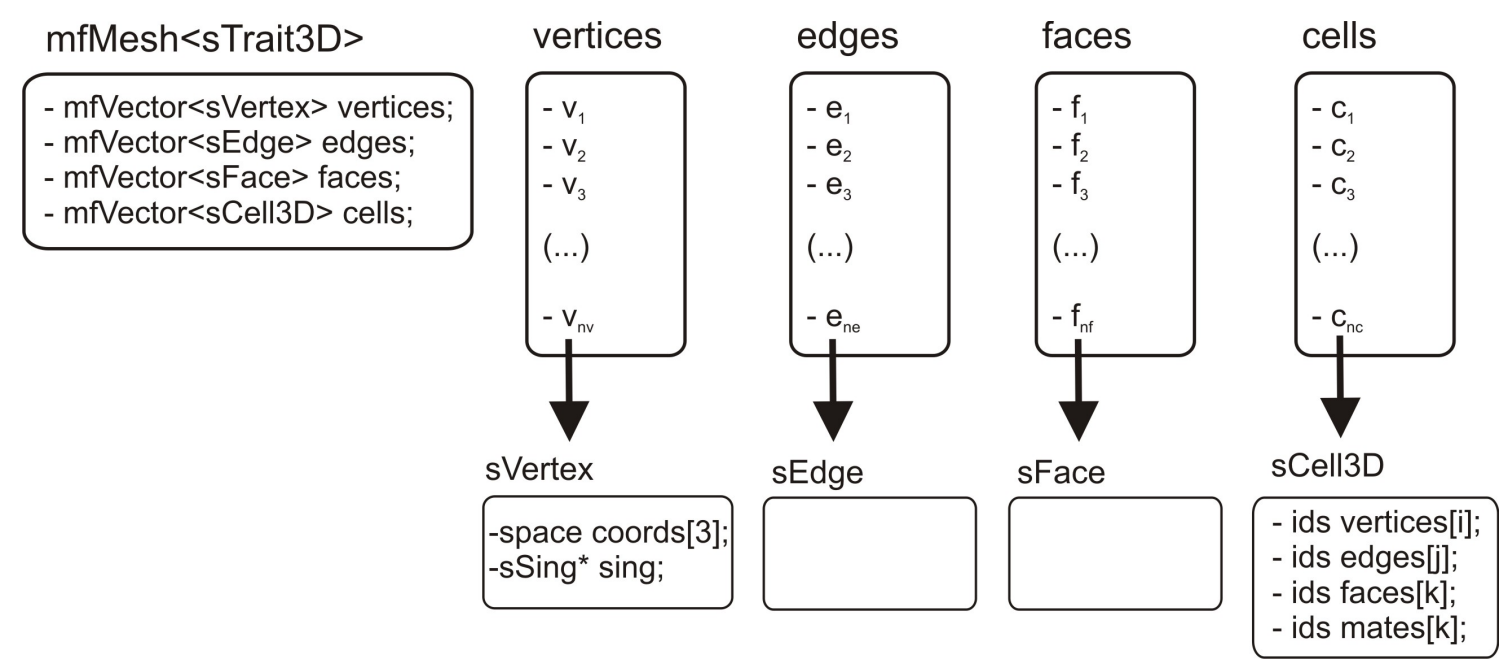

Figura 4.17: Ilustração da MF 3D básica.

vizinhança é feita por faces em comum, a busca de células incidentes à aresta em questão também pode ser feita através de um ciclo (como ilustrado na Figura 4.18).

Por outro lado, a operação da estrela de um vértice em malhas 3D é mais complexa, pois não é possível criar um único percurso que seja suficiente para percorrer todos os tipos de casos de estrela de vértices. Com isso em mente foi proposto utilizar a mesma abordagem implementada na OF. Esta abordagem se caracteriza pelo uso de dois tipos de lista: lista de células obtidas pela iteração e lista de flags que indica se 


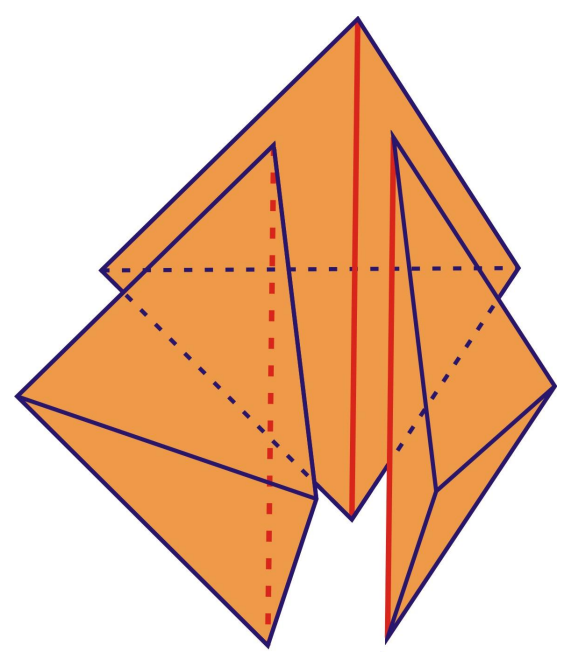

Figura 4.18: Ilustração das células resultantes da operação estrela da aresta em vermelho.

uma célula já foi visitada. O primeiro passo do iterador é obter a célula presente na lista de singularidades do vértice. Ao passo de cada iteração, uma célula da lista de células é retornada pelo iterador e também deletada dessa lista, além disso, suas células vizinhas, que contém o vértice da iteração e que não estão na lista de flags, são adicionadas às duas listas. Se o vértice for uma singularidade, o passos se repetem para todos os componentes que o contêm.

A seguir, serão apresentados os tipos de malhas volumétricas suportados pela MF de acordo com a célula que os compõem.

\subsubsection{Malhas tetraédricas}

Dentre os tipos de malhas volumétricas a serem detalhados, as malhas tetraédricas são as mais simples. Isto é evidente quando se analisa que somente as arestas da célula não podem ser indexadas por um único índice de vértice. Como ilustrado na Figura 4.19, a indexação das faces é igual ao índice de seu vértice oposto (consequentemente, a indexação dos vizinhos também é igual).

A classe de operações de manipulação de malhas tetraédricas é a mfMeshTetra. Assim como nas malhas 2D, durante a operação de adição de células, esta classe, por meio de uso da lista de singularidade dos vértices da célula sendo adicionada, verifica se já foi adicionada alguma célula que compartilha uma de suas faces.

A Figura 4.20 ilustra a representação do modelo Stanford Bunny através de seus vértices de bordo (em vermelho) e seus vértices internos (em amarelo). Esta malha foi gerada pelo método a ser apresentado no Capítulo 5, a nuvem de pontos usada foi 


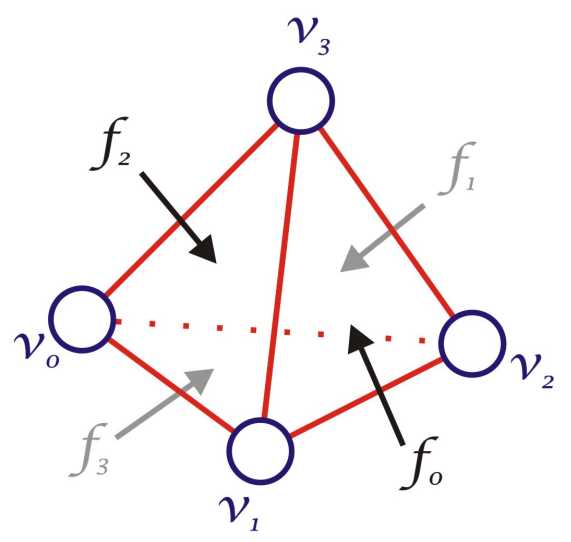

Figura 4.19: Indexação de elementos de uma célula tetraédrica.

obtida do repositório da Universidade de Stanford ${ }^{4}$. É composta por 49918 vértices e 198607 tetraedros.

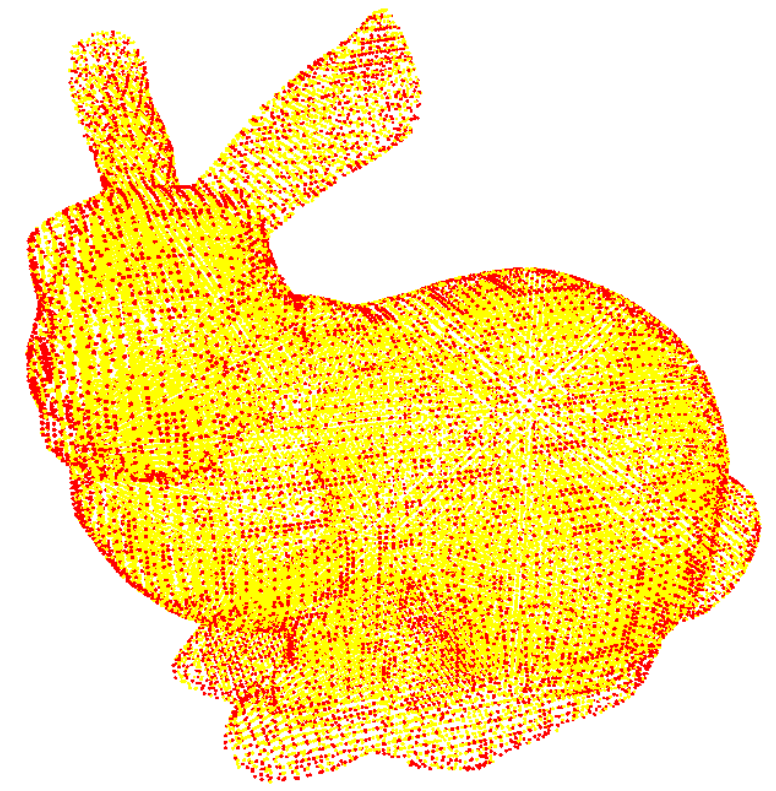

Figura 4.20: Visualização dos vértices internos (em amarelo) e de bordo (em vermelho) do modelo Stanford Bunny.

A Figura 4.21 ilustra o resultado de uma simulação numérica em uma malha tetraédrica que representa parte de um reator nuclear. Este modelo é composto por 2896 vértices e 12936 tetraedros. Foram atribuídos valores aos vértices da malha que representam o resultado obtido da simulação.

\footnotetext{
${ }^{4}$ The Stanford 3D Scanning Repository - Site: http://graphics.stanford.edu/data/3Dscanrep/
} 

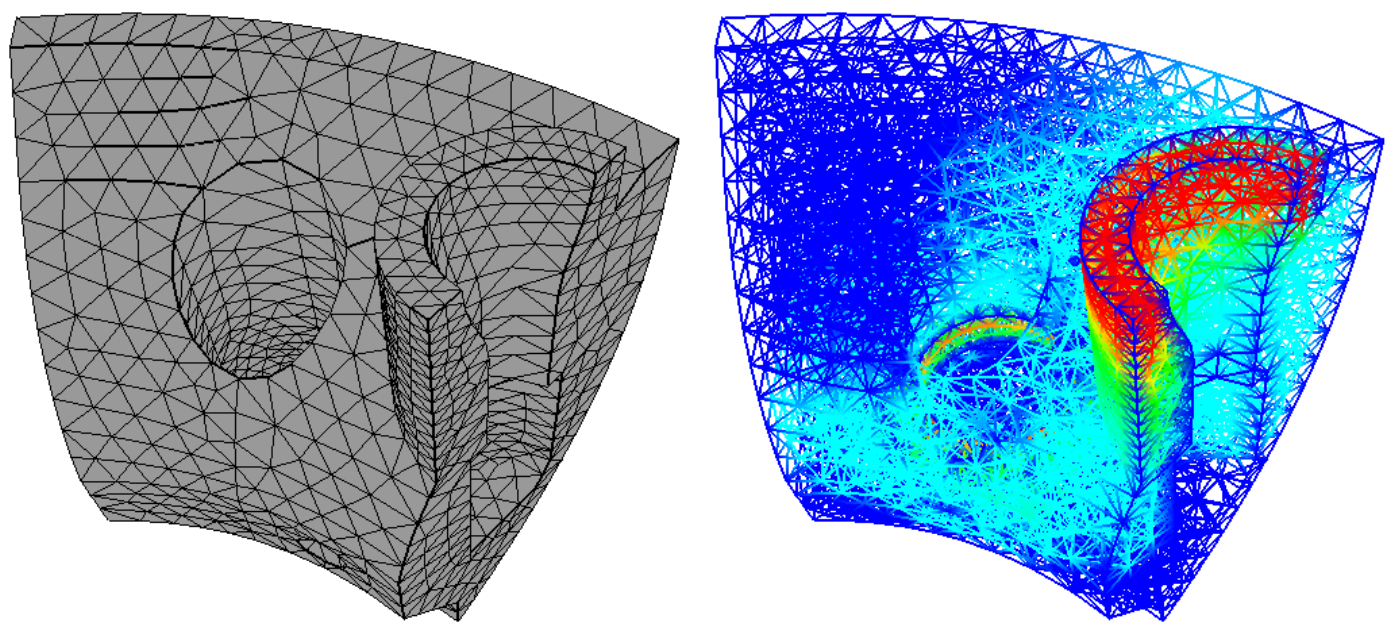

Figura 4.21: Visualização do resultado de uma simulação numérica de um modelo que representa parte de um reator nuclear. Este modelo em conjunto com os dados da simulação foi obtido do repositório Aim@Shape.

\subsubsection{Malhas hexaédricas}

Para representar as malhas formadas por hexaedros, foi necessária a implementação de uma série de métodos de mapeamento de elementos da malha. Como foi dito na Seção 4.3, devido à diferença de números de elementos de malha, os índices de faces e arestas de uma célula precisaram ser obtidos a partir da relação entre dois ou mais elementos.

A classe de operações de manipulação da malha hexaédrica é a mfMeshHexa.

Os modelos de malhas visualizados nas Figuras 4.22 e 4.23 foram obtidos do repositório de malhas hexaédricas do Instituto de Tecnologia de Georgia - EUA 5 . Tratam-se de dois modelos CAD: o Bump (Figura 4.22) composto por 1665 vértices e 1189 hexaedros, e o Fru (Figura 4.23) composto por 5124 vértices e 4360 hexaedros.

\subsubsection{Malhas prismáticas e malhas piramidais}

Assim como em malhas hexaédricas, para representar malhas prismáticas ou malhas piramidais foi necessária a implementação de uma série de métodos de mapeamento de elementos da malha. Porém, para esses dois tipos de malhas, as suas células apresentam dois tipos de faces: triangulares e quadriláteras.

Levando isso em conta e o fato que a MF somente representa complexos celulares, foi proposto que o método que obtém o índice de uma dada face da célula só precise de três vértices como parâmetro.

\footnotetext{
${ }^{5}$ Unstructured Hexahedral Meshes - Site: http://www.cc.gatech.edu/ lindstro/data/hexzip/
} 


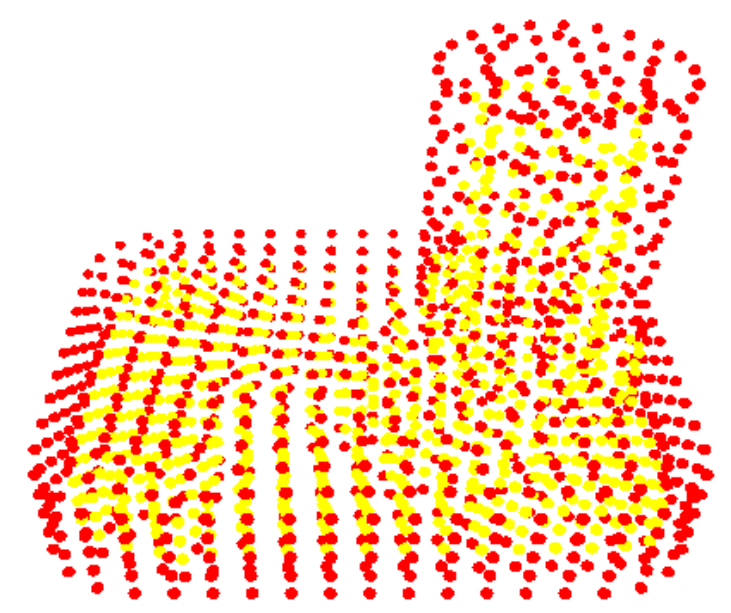

Figura 4.22: Visualização dos vértices internos (em amarelo) e de bordo (em vermelho) do modelo Bump.

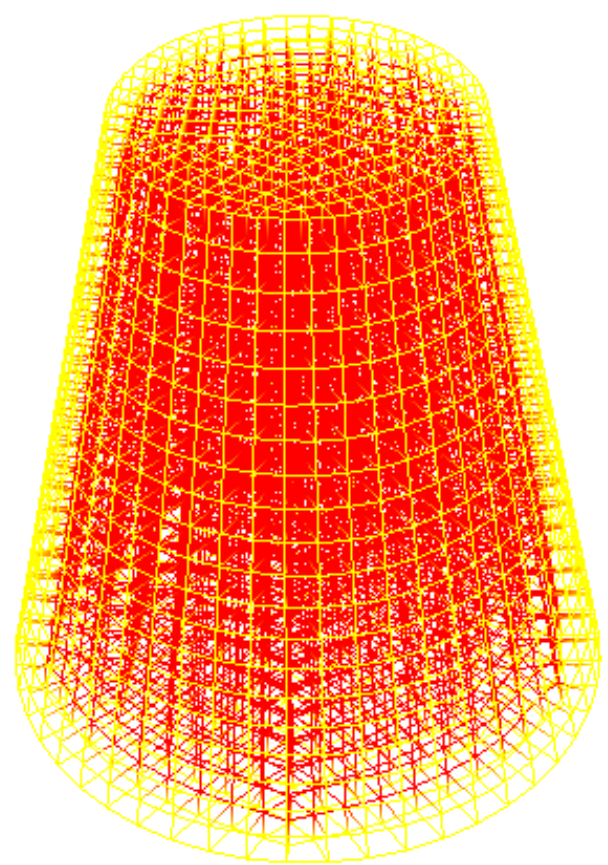

Figura 4.23: Visualização das arestas internas (em amarelo) e externas (em vermelho) do modelo Fru.

As classes de manipulação de malha prismáticas e piramidais são respectivamente a mfMeshPrism e a mfMeshPyramid.

\subsubsection{Resultados}

Além das aplicações de visualização apresentados anteriormente e das aplicações a serem apresentadas no Capítulo 6, foram feitos alguns testes comparativos de tempo entre a MF e a OF. Outro fator importante que foi analisado é o consumo de memória 
da MF.

\section{Testes comparativos de tempos com relação a OF}

Durante o desenvolvimento da ED, foram executados vários testes de desempenho e eficiência, entre os que se destacam foram os testes de comparação de tempo entre a OF e a MF. Estes testes foram executados na plataforma linux Gentoo numa máquina com processador Intel Core 2 Quad de $2.4 \mathrm{GHz}$ e 4 GB de memória RAM. Para cada teste, as operações sendo comparadas foram executadas 200 vezes e posteriormente foi calculada a média dos tempos resultantes $(\bar{x})$ e seu desvio padrão $(\sigma)$.

Para realizar esses testes, foram utilizadas as malha triangulares superficiais do elefante (Figura 4.14) e Olivier Hand (Figura 4.13), e as malhas tetraédricas que representa o reator nuclear (Figura 4.21) e Stanford Bunny (Figura 4.20). A composição dessas malhas é relacionada na Tabela 4.1.

Tabela 4.1: Relação de malhas usadas nos testes.

\begin{tabular}{|c||c|c|}
\hline Malha & Numéro de vértices & Número de células \\
\hline \hline Elefante & 2688 & 5384 \\
\hline Olivier Hand & 53054 & 105860 \\
\hline Reator Nuclear & 2896 & 12936 \\
\hline Stanford Bunny & 49918 & 198607 \\
\hline
\end{tabular}

Os primeiros testes de comparação de tempo executados foram os de carga de malha, além de comparar a OF e a MF foi feita uma outra comparação de tempo de carga usando uma versão da MF Implícita (MF sem representação explícita de arestas em malhas 2D e sem representação explícita de arestas e faces em malhas 3D). Os resultados obtidos nesses testes são apresentados na Tabela 4.2.

Os outros testes de comparação de tempo executados foram quanto a execução da estrela dos vértices de toda a malha. Seus resultados são apresentados na Tabela 4.3.

Vale salientar que a adição da representação explícita da aresta não influenciou no desempenho desta operação. Quanto a malhas triangulares, a melhora de desempenho foi devido à simplificação da operação estrela. Como foi citado na Seção 4.3, pelo fato do operador estrela (presente na MF) acessar células seguindo um ciclo, torna-se desnecessária a execução de operações de verificação e adição de células em uma lista (como ocorre na OF). Isto reduziu o custo de tempo em mais de 50\% em comparação com o tempo de execução da operação na OF. 
Tabela 4.2: Comparação de tempo (em segundos) da execução de carga de malhas pelas EDs OF, MF e MF Implícita.

\begin{tabular}{|c|c|c|c|c|c|c|}
\hline & \multicolumn{2}{|c|}{ OF } & \multicolumn{2}{c|}{ MF } & \multicolumn{2}{c|}{ MF Implícita } \\
\hline \hline Malha & $\bar{x}$ & $\sigma$ & $\bar{x}$ & $\sigma$ & $\bar{x}$ & $\sigma$ \\
\hline Elefante & $\begin{array}{c}0,07097 \\
\text { segundos }\end{array}$ & 0,003426 & $\begin{array}{c}0,071715 \\
\text { segundos }\end{array}$ & 0,004144 & $\begin{array}{c}0,069658 \\
\text { segundos }\end{array}$ & 0,001779 \\
\hline $\begin{array}{c}\text { Olivier } \\
\text { Hand }\end{array}$ & $\begin{array}{c}1,459645 \\
\text { segundos }\end{array}$ & 0,0384160 & $\begin{array}{c}1,47818 \\
\text { segundos }\end{array}$ & 0,040295 & $\begin{array}{c}1,426528 \\
\text { segundos }\end{array}$ & 0,017883 \\
\hline Reator & 0,851 & 0,012008 & $\begin{array}{c}0,81935 \\
\text { segundos }\end{array}$ & 0,012643 & $\begin{array}{c}0,84534 \\
\text { segundos }\end{array}$ & 0,011533 \\
Nuclear & segundos & & $\begin{array}{c}17,08989 \\
\text { segundos }\end{array}$ & 0,208193 & $\begin{array}{c}16,31104 \\
\text { segundos }\end{array}$ & 0,201145 \\
\hline Stanford & 16,33042 & 0,201527 & & & \\
Bunny & segundos & & & & &
\end{tabular}

Tabela 4.3: Comparação de tempo (em segundos) da execução da estrela dos vértices das malhas pelas EDs OF e MF.

\begin{tabular}{|c|c|c|c|c|}
\hline & \multicolumn{2}{|c|}{$\mathrm{OF}$} & \multicolumn{2}{|c|}{ MF } \\
\hline Malha & $\bar{x}$ & $\sigma$ & $\bar{x}$ & $\sigma$ \\
\hline Elefante & $\begin{array}{l}0,007805 \\
\text { segundos }\end{array}$ & 0,005441 & $\begin{array}{c}0,003595 \\
\text { segundos }\end{array}$ & 0,000522 \\
\hline $\begin{array}{l}\text { Olivier } \\
\text { Hand }\end{array}$ & $\begin{array}{l}0,154575 \\
\text { segundos }\end{array}$ & 0,111022 & $\begin{array}{c}0,07361 \\
\text { segundos }\end{array}$ & 0,000895 \\
\hline $\begin{array}{l}\text { Reator } \\
\text { Nuclear }\end{array}$ & $\begin{array}{c}0,04903 \\
\text { segundos }\end{array}$ & 0,001104 & $\begin{array}{c}0,04845 \\
\text { segundos }\end{array}$ & 0,001069 \\
\hline $\begin{array}{c}\text { Stanford } \\
\text { Bunny }\end{array}$ & $\begin{array}{l}0,060719 \\
\text { segundos }\end{array}$ & 0,008114 & $\begin{array}{c}0,60675 \\
\text { segundos }\end{array}$ & 0,007488 \\
\hline
\end{tabular}




\section{Consumo de memória}

Além de comparar o desempenho da MF em comparação com a OF, é importante também tratar o consumo de memória da ED.

Considerando que os identificadores são do tipo integer (32 bits) e que cada coordenada é do tipo double (64 bits) e dada a composição dos tipos de elementos da malha, tem-se, para uma malha de $n$ vértices, $m$ células e $p$ arestas, a seguinte relação de consumo de memória:

- Vértice: um vértice em $\mathbb{R}^{k}$ consome $8 * k+12$ bytes;

- Aresta: a aresta base (mfEdge) definida na MF consome 8 bytes;

- Face: a face base (mfFace) definida na MF consome 8 bytes;

- Célula 2D: a célula 2D formada por $i$ vértices, $i$ arestas e $i$ referências aos seus vizinhos consome $12 * i+8$ bytes;

- Célula 3D: a célula 3D formada por $i$ vértices, $j$ arestas, $l$ faces e $l$ referências aos seus vizinhos consome $4 * i+4 * j+8 * l+8$ bytes;

- Uma malha $2 \mathrm{D}$ no espaço $\mathbb{R}^{k}$ consome $(8 * k+12) * n+8 *(3 * m) / 2+(12 * i+8) * m$ bytes;

- Uma malha 3D consome $36 * n+8 * p+8 *(l * m) / 2+(4 * i+4 * j+8 * l+8) * m$ bytes.

Vale lembrar que a adição de oito bytes extras nos elementos é devido à herança da classe $m f B a s e$ (veja Seção 4.1.2). Além disso, para calcular esses consumos, levou-se em conta que as malhas não apresentam vértices singulares, ou seja, os vértices só armazenam um identificador de célula incidente.

Exemplificando o consumo de memória para representação de uma malha superficial (no espaço $\mathbb{R}^{3}$ ) com 2 milhões de triângulos e 1 milhão de vértices seriam necessários aproximadamente $88 \mathrm{MB}$.

\subsection{Considerações Finais}

As adaptações feitas nos conceitos implementados na ED OF permitiram que a MF pudesse estendê-la para poder representar mais tipos de malhas e elementos. Os resultados obtidos demonstraram que, mesmo com a extensão de representação explícita de arestas e faces, a MF ainda apresentou um bom desempenho de tempo em comparação com a OF.

As adaptações aumentaram o consumo de memória da malha, mas, devido à MF ser flexível, é possível diminuí-lo caso não seja necessário atribuir valores a arestas em 


\section{Mate Face}

malhas 2D ou arestas e faces em malhas 3D. Além disso, a Tabela 4.2 mostra que o desempenho de carga de malhas também melhora.

Com exceção da representação de malhas 3D mistas, todas as propostas feitas com relação à MF foram cumpridas. A representação de malhas 3D mistas apresenta alguns problemas quanto à incorporação de operações específicas para cada tipo de célula. É possível identificar cada um desses tipos, porém uma maneira eficiente de tratá-lo ainda é um desafio. Propõe-se como atividade futura a implementação desta representação, pois seu uso será bastante útil para dar sequência a outros trabalhos propostos que envolve malhas volumétricas mistas. 
Capítulo

5

\section{Geração Algébrica de Malhas Adaptativas a partir de Funções Implícitas}

Geração de malhas é um problema complexo de se resolver. Esse fato se mostra mais evidente se desejar criar uma malha a partir de um modelo geometricamente complexo. A complexidade do problema se torna maior quando se tenta gerar uma malha que precise de pouca ou nenhuma etapa de melhoramento após sua geração. Ao longo dos anos, algoritmos de geração de malhas tetraédricas tem sido proposto com alguma garantia teórica de qualidade de ângulos diedrais. Em [37], um algoritmo inovador chamado Isosurface Stuffing foi apresentado. Ele é capaz de gerar malhas com delimitação significativa de ângulos diedrais e, ao mesmo tempo, é capaz de gerar malhas tetraédricas a partir de domínios geometricamente complexos.

Neste capítulo será apresentado um método de geração de malhas baseado no uso de estênceis tetraédricos e de uma regra de warping (deslocamento) de pontos apresentados em [37] para gerar malhas com qualidade de ângulos diedrais. Para isso, propõe-se usar a triangulação $J_{1}^{a}$ proposta por Castelo et al. [14] em conjunto com o algoritmo Partição da Unidade Implícita em Multi-nível (PUI) proposto por Gois et al. [30] para gerar uma grade tetraédrica base e também gerar a aproximação da função implícita (a partir de uma nuvem de pontos). Porém, caso a superfície já tenha uma 
função implícita para representá-la, só será necessária a triangulação $J_{1}^{a}$.

O algoritmo PUI é capaz de aproximar uma função implícita a partir de uma nuvem de pontos. Esta função providenciará a posição relativa dos pontos da grade com relação à superfície e permitirá obter os pontos de corte das arestas transversais (arestas com um ponto incidente dentro da superfície e o outro ponto fora). A grade então será utilizada junto com as idéias de [37] para gerar a malha tetraédrica final.

Ao unir as idéias de ambos os trabalhos, deseja-se não somente melhorar a qualidade das faces superficiais das malhas produzidas por Gois et al. [30], mas também permitir que o método gere malhas tetraédricas. Ao usar a triangulação $J_{1}^{a}$, o método gera malhas com o interior adaptativo sem necessidade de uma estrutura auxiliar para torná-la adaptativa. Isto é uma vantagem em comparação com a malha inicial usada no algoritmo Isosurface Stuffing. Outra vantagem de se utilizar a triangulação $J_{1}^{a}$ está no fato dela usar regras algébricas, pois ela permite que regras mais simples (em comparação com as propostas em [37]) sejam utilizadas para gerar a malha final.

A Figura 5.1 apresenta uma das malhas resultantes do gerador de malhas proposto. Neste trabalho tem-se o interesse em gerar malhas com tetraedros superficiais com mesmo nível de refinamento. Já que a prova de garantia de qualidade dos ângulos diedrais dessa abordagem é menos complexa que em uma malha com superficie adaptativa. Infelizmente, devido à falta de tempo, esta prova não foi finalizada. Porém, o detalhamento desta proposta será apresentado na Seção 5.4. A prova para garantia de qualidade em superfícies adaptativas também foi proposta como continuação deste trabalho. Como será mostrado na Seção 5.4, esta prova se mostrou bastante complexa devido à diferença de tamanho entre arestas de tetraedros vizinhos de nível de refinamento diferente.

Outras características deste método são herdadas de [30], tais como:

Reconstrução com garantia topológica: com o uso da triangulação $J_{1}^{a}$ para subdividir o domínio durante a etapa da aproximação da função implícita, os seus tetraedros podem também ser usados para gerar a malha final, evitando assim casos ambíguos;

Estabilidade numérica: geralmente, a base polinomial canônica é usada para resolver os métodos de solução por mínimos-quadrados. Essa abordagem tende a gerar um sistema mal-condicionado. Ao utilizar uma base de polinômios ortogonais para resolver as aproximações, é evitado o uso de sistemas de equações, isto melhora a estabilidade além de evitar a execução de cálculos custosos;

Aproximação adaptativa das funções locais: com o uso de polinômios ortogonais, o grau dos polinômios de aproximação local pode ser eficientemente aumentado. Por 


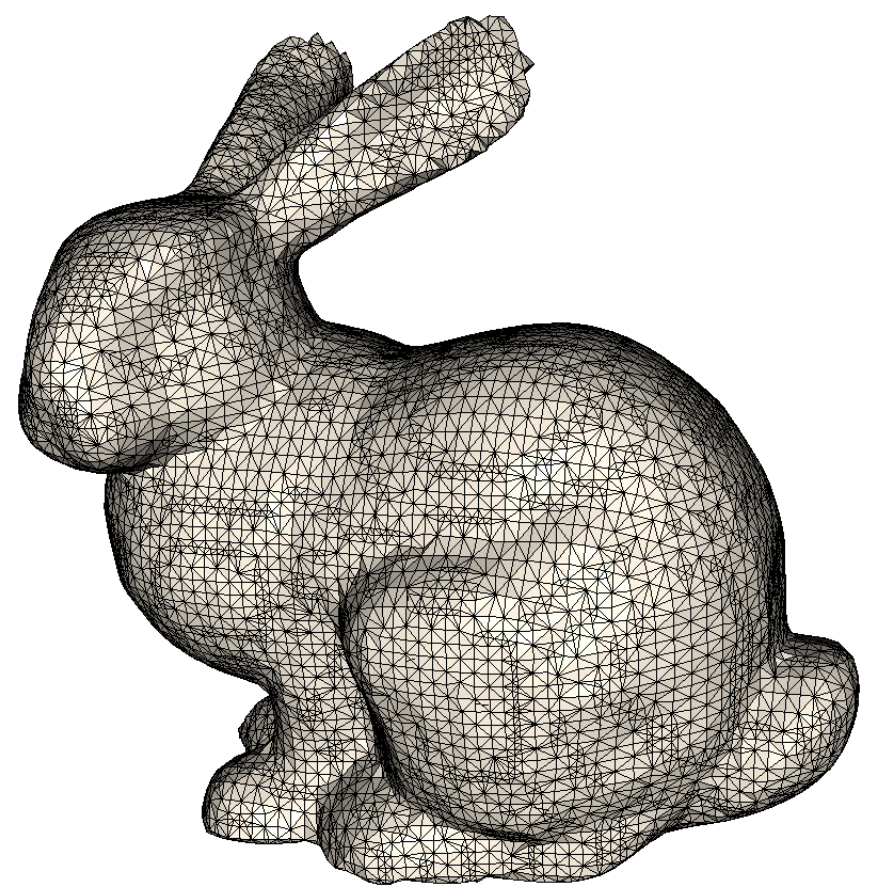

Figura 5.1: Visualização da malha do Stanford Bunny.

esta razão, o método é também adaptativo em relação às aproximações locais;

Superfícies espúrias são evitadas: em [30] foram sugeridos alguns critérios de robustez não computacionalmente custoso que evitam a geração de grande parte de superfícies espúrias e de artefatos.

\subsection{Trabalhos Relacionados}

Garantir a geração de uma malha tetraédrica com boa qualidade de ângulos diedrais é uma tarefa difícil. A necessidade de boa qualidade de ângulo se evidencia quando se analisa o sucesso do uso de malhas tetraédricas em métodos numéricos, tais como os de elementos finitos que dependem dos tamanhos desses ângulos. Ângulos muito grandes (próximos de $180^{\circ}$ ) causam erros de interpolação e fazem com que as simulações numéricas percam sua exatidão, já ângulos muito pequenos (próximos de $0^{\circ}$ ), tornam as matrizes de rigidez associadas com o método de elemento finito fatalmente malcondicionadas [57].

Trabalhos anteriores que envolveram o uso de octrees [45] ou o uso da triangulação de Delaunay $[18,56,15,40,16,53,17]$ ofereceram algumas garantias teóricas na qualidade dos menores ângulos diedrais de suas malhas. Porém, como mencionado por Labelle e Shewchuk [37], o problema desses trabalhos envolve o fato que não oferecem uma prova para delimitação de ângulos diedrais bons e às vezes apresentam 
tetraedros de má qualidade na fronteira do domínio.

O algoritmo Isosurface Stuffing (preenchimento de isosuperfícies) proposto por Labelle e Shewchuk [37] apresenta garantia de qualidade de malha teoricamente provada. Duas de suas características principais são que todos os seus ângulos diedrais são delimitados entre $8.9^{\circ}$ e $164.8^{\circ}$ (dependendo da escolha de parâmetros), e os tetraedros superficiais tem tamanhos uniformes. Este algoritmo será melhor detalhado na seção 5.1.1.

Em [30], um algoritmo robusto e adaptativo de reconstrução de superfície foi proposto. Neste trabalho, a triangulação $J_{1}^{a}$ foi empregada para construir uma malha inicial adaptativa em conjunto com o algoritmo PUI para executar a aproximação da superfície implícita. Mesmo que a qualidade dos resultados da malha superficial não tenha sido muito atraente, seus resultados mostraram que o uso da triangulação $J_{1}^{a}$ é uma alternativa promissora em comparação com a malha usada na Isosurface Stuffing. A razão para isto está no fato que a triangulação $J_{1}^{a}$ oferece algumas vantagens, tais como: a capacidade de gerar uma malha adaptativa sem a necessidade de uso de estrutura auxiliar; e suas regras algébricas (que são usadas para criar os tetraedros da triangulação) permitem a criação de uma regra de paridade mais simples que será detalhada na Seção 5.3.2.

Em [31,54], foi feita uma extensão do algoritmo que aumentou significativamente a qualidade dos triângulos de superfície em comparação com o trabalho anterior. Antes da extração da superfície, é empregado um método de deslocamento de alguns dos vértices da malha inicial afastando-os da superfície.

\subsubsection{Isosurface Stuffing}

O algoritmo de Isosurface Stuffing adota algumas idéias do algoritmo Marching Cubes [44], além disso, ele emprega o uso de estênceis para gerar a triangulação a partir da malha inicial. Para gerar essa malha inicial, o algoritmo usa a grade Body Centered Cubic (BCC), que proposta por Fuchs [28] e Naylor [47], junto com o algoritmo octree (proposto por Yerry e Shephard [63]). O uso da octree permite tornar adaptativa a malha inicial mantendo ainda a alta qualidade de malha. Uma característica muito importante da Isosurface Stuffing que permite a geração de uma malha final com boa qualidade é o uso da regra de warping (adotada do trabalho de Bern et al. [5]) e do uso estênceis tetraédricos.

Assim como o algoritmo de Marching Cubes, a Isosurface Stuffing emprega uma grade de fundo para guiar a criação da malha. A grade BCC é formada pela união de dois 
pontos de grade:

$$
\mathrm{BCC}=\mathbb{Z}^{3} \cup\left(\mathbb{Z}^{3}+\left(\frac{1}{2}, \frac{1}{2}, \frac{1}{2}\right)\right)
$$

onde $\mathbb{Z}^{3}$ são os vértices cubos da grade com coordenadas inteiras e $\mathbb{Z}^{3}+\left(\frac{1}{2}, \frac{1}{2}, \frac{1}{2}\right)$ são pontos localizados no centro destes cubos.

A triangulação resultante desses pontos é do tipo Delaunay, onde todos os tetraedros que compõem a malha inicial são idênticos. As arestas destes tetraedros têm tamanho 1 e $\sqrt{3} / 2$, além disso, os seus ângulos diedrais são de $60^{\circ}$ e de $90^{\circ}$. Esse tipo de tetraedro foi notado por Sommerville [60]. O fato que todos os tetraedros são iguais simplifica tanto a implementação quanto a prova de qualidade do algoritmo.

A Isosurface Stuffing é executada em quatro etapas: avaliação de pontos, obtenção de pontos de corte, aplicação da regra de warping, e aplicação dos estênceis. Porém, devido à semelhança entre este algoritmo e o método apresentado aqui neste capítulo, a explicação destas etapas foi omitida. Na Seção 5.3.2 será apresentada uma comparação da etapa de uso de estênceis para executar a triangulação da malha final.

\subsection{Aproximação de Superfície Implícita a Partir de Nuvem de Pontos e a Triangulação $J_{1}^{a}$}

Nesta seção serão apresentados os trabalhos que serviram de base do gerador de malhas apresentado neste capítulo. Será descrito um método de aproximação de superfícies implícitas baseado no algoritmo PUI proposto por Gois et al. [30]. E será apresentada também, a triangulação $J_{1}^{a}$ para melhor explicar a geração da malha tetraédrica inicial.

\subsubsection{Partição da Unidade Implícita em Multinível}

Caso o objeto a ser reconstruído seja definido por uma nuvem de pontos, pode-se obter uma aproximação de sua função implícita utilizando o algoritmo PUI.

Assim como os outros métodos de aproximação de funções implícitas, o algoritmo PUI é definido como o conjunto de nível zero de uma função F. Esta função (global) é definida em um domínio $\Omega$ e é obtida através de uma somatória das aproximações locais. Para este propósito, um conjunto de funções-peso não-negativas com suporte compacto é definido: $\Phi=\left\{\phi_{1}, \ldots, \phi_{n}\right\}$, onde $\sum_{i=0}^{n} \phi_{i}(x) \equiv 1, x \in \Omega$. Além disso, é definido o conjunto $\mathbb{F}=\left\{f_{1}, \ldots, f_{n}\right\}$ de funções distância locais (com sinal) $f_{i}$ em $\Omega$. Dados os conjuntos $\mathbb{F}$ e $\Phi$, a função $F: \mathbb{R}^{3} \rightarrow \mathbb{R}$ é definida como: 


$$
F(x) \equiv \sum_{i=0}^{n} f_{i}(x) \phi_{i}(x), x \in \Omega .
$$

A função de partição da unidade pode ser obtida a partir de um conjunto de um suporte compacto não-negativo e expressa como:

$$
\phi_{i}(x)=\frac{\theta_{i}(x)}{\sum_{k=1}^{n} \theta_{k}(x)}
$$

onde $\theta_{i}(x)$ é a função peso de suporte compacto. Diferentemente de [52], onde o domínio é subdividido usando uma octree, o algoritmo em [30] subdivide o domínio usando a grade da triangulação $J_{1}^{a}$ e define um suporte esférico em cada bloco desta grade.

A função implícita aproximada $F$ avaliará os pontos da grade informando assim, a posição relativa de cada ponto com respeito à superfície. Para um dado ponto $p$ da grade, diz-se que $p$ está contido na região de interesse da malha a ser gerada quando $F(p) \leq 0$.

A Figura 5.2 ilustra um exemplo bidimensional de um domínio $\Omega$ coberto por um conjunto de círculos, que suportam as funções peso $\phi_{i}$, no qual o conjunto de nível zero da função é apresentado em vermelho. Posteriormente, na Seção 5.3, será detalhado como se dá o comportamento dos blocos da triangulação $J_{1}^{a}$ (ilustrados em preto na Figura 5.2).

Vale a pena mencionar que este método requer pontos equipados consistentemente com vetores normais orientados. Para maiores detalhes sobre o algoritmo PUI, veja $[30,29]$.

\subsubsection{A Triangulação $J_{1}^{a}$}

Proposta por Castelo et al. [12,14], a triangulação $J_{1}^{a}$ é uma estrutura algebricamente definida que é capaz de ser construída em qualquer dimensão. Para acomodar aspectos locais, a triangulação $J_{1}^{a}$ lida com refinamentos naturalmente. Duas de suas características principais são a existência de um mecanismo capaz de representar unicamente cada simplexo da triangulação e a existência de regras algébricas para percorrer a estrutura. O uso dessas regras previne a estrutura de necessitar armazenar informações de conectividade dos simplexos, logo, capacitando um armazenamento mais eficiente.

A triangulação $J_{1}^{a}$ consiste em uma grade computacional formada por hipercubos (blocos) n-dimensionais no domínio $\mathbb{R}^{n}$. Cada bloco é dividido por $2^{n} n$ ! $n$-simplexos 


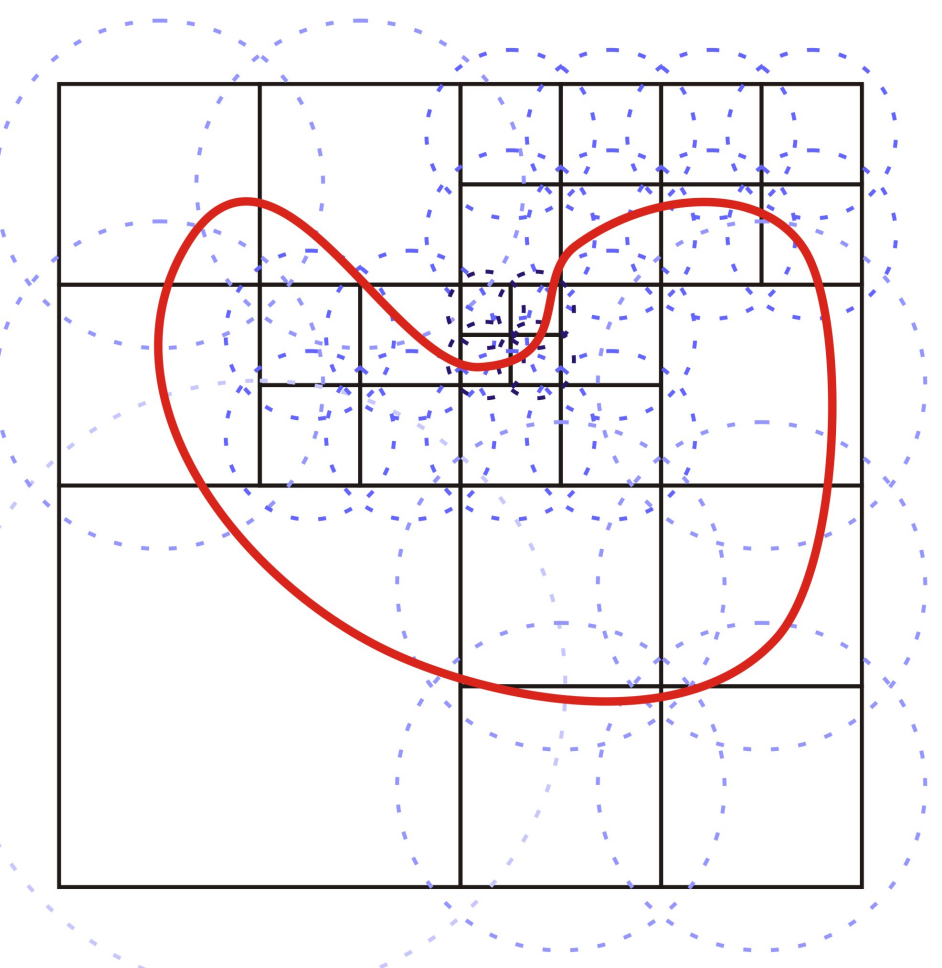

Figura 5.2: Ilustração bidimensional do comportamento do refinamento dos blocos de uma triangulação $J_{1}^{a}$ induzidos pelo critério de erro da aproximação.

que podem ser descritos algebricamente usando a sêxtupla:

$$
S=(g, r, \pi, s, t, h)
$$

Os dois primeiros elementos de $S$ definem em que bloco o simplexo está contido, sendo $g$ um vetor $n$-dimensional que indica as coordenadas do bloco em um nível de refinamento particular $r$ da grade. A Figura 5.3 ilustra, à esquerda, uma grade bidimensional da $J_{1}^{a}$ e, à direita, um bloco destacado desta grade com nível de refinamento $r=0$ (0-bloco) e $g=(3,2)$. Também na figura 5.3, pode ser notado que os blocos da grade mais escuros são de nível $r=1$ (assim chamado de 1-bloco) e, por isso, fazem parte de uma região da grade de maior resolução.

Para lidar com diferentes níveis de refinamento, a triangulação $J_{1}^{a}$ divide o bloco (que deve ser refinado) em $2^{n}$ blocos e aplica mudanças aos seus blocos vizinhos de tal modo para poder acomodar os novos blocos menores que foram criados. Então, um novo tipo de bloco é criado que será referido como bloco de transição. Por ter este bloco de transição, a triangulação $J_{1}^{a}$ obriga que não há nenhuma situação em que dois blocos 

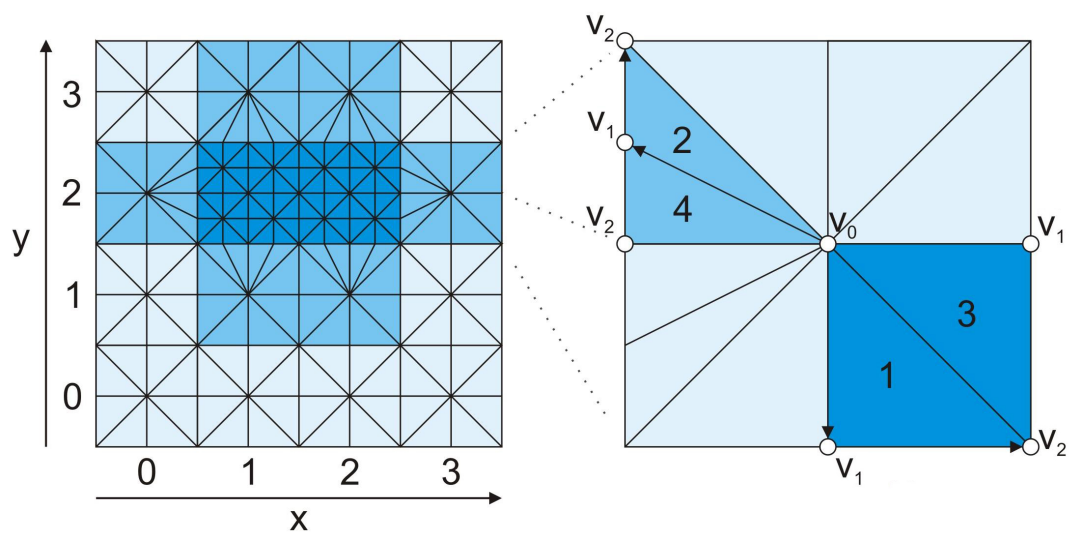

Figura 5.3: Exemplo 2D de uma grade da triangulação $J_{1}^{a}$ (esquerda) e detalhes do bloco $g=(3,2), r=0$ onde é mostrado dois percursos para traçar os simplexos do bloco (direita). Esta figura foi adaptada do trabalho [19].

vizinhos tem diferença de nível de refinamento maior que um. O nível de refinamento de um bloco de transição é determinado pelo menor nível de refinamento entre seus blocos vizinhos.

O bloco de transição tem algumas de suas faces $k$-dimensionais (onde $0<k<n$ ) refinadas para que possa acomodar seus blocos vizinhos refinados. Isto é ilustrado na Figura 5.3, onde o bloco de transição destacado somente tem sua aresta da esquerda refinada. Os blocos que não são de transição (representado pelas cores mais claras e mais escuras na figura) são referidos como sendo blocos básicos.

Para representar cada $n$-simplexo de um bloco, o primeiro fato a ser notado é que todos compartilham entre si no mínimo um mesmo vértice (o vértice central rotulado por $v_{0}$ na Figura 5.3). A partir de $v_{0}$, o próximo passo é tomado na direção positiva ou negativa de um eixo escolhido. Resultando no vértice $v_{1}$ (que está localizado no centro de uma face de dimensão $(n-1)$ ), o processo continua para os vértices $v_{2}, \ldots, v_{n}$ (que são respectivamente os centros das faces de dimensão $(n-2), \ldots, 0)$. Então, por ter obtido os vértices do simplexo, este pode ser representado pelo caminho percorrido de $v_{0}$ até $v_{n}$. Os vetores $\pi$ e s são responsáveis pela codificação deste percurso, $\pi$ armazena uma permutação de $n$ inteiros de 1 a $n$ que representam o eixo de coordenada (onde 1 se refere ao eixo $x, 2$ ao $y$, e assim por diante). O vetor $s$ representa a direção (por valores positivos ou negativos) a ser tomada no seu respectivo eixo. Na Figura 5.3, o simplexo 1 no bloco destacado é representado por $\pi=(2,1)$ e $s=(1,-1)$, que significa que o primeiro caminho a ser percorrido é ao longo do eixo y $\left(\pi_{1}=2\right)$ na direção negativa $\left(s_{\pi_{1}}=-1\right)$, e depois ao longo do eixo $x\left(\pi_{2}=1\right)$ na direção positiva $\left(s_{\pi_{2}}=1\right)$. 
Os vetores $\pi$ e $s$ armazenam informações suficientes para representar os simplexos de blocos básicos e simplexos de bloco de transição que não intersectam uma face refinada. Para os casos restantes deve-se notar que quando uma face $k$-dimensional é atingida existe mais de um centro. Por causa disto, outras informações devem ser armazenadas para representar esses simplexos. O escalar $h$ é usado para informar quantos passos foram necessários para se atingir uma face refinada, e o vetor $t$ armazena sinais extras para os eixos $\pi_{h+1} \ldots \pi_{n}$ que são usados para escolher um centro de todos as possibilidades de uma face refinada. Então, novamente na Figura 5.3, o simplexo 2 é representado por $\pi=(1,2), s=(-1,1), h=1$ e $t=(0,1)$; $h$ é igual a 1 porque somente foi necessário um passo antes de se atingir a aresta refinada e o centro escolhido para posicionar $v_{1}$ está na direção positiva do eixo $\pi_{h+1}$.

Uma maneira formal de descrever a representação de um simplexo dentro de um hipercubo (centrado na origem $(0, \ldots, 0)$ e com aresta de tamanho 2$)$ é dada pela seguinte expressão:

$$
\left\{\begin{array}{l}
v_{0}=(0, \ldots, 0) \\
v_{i}=v_{i-1}+e_{\pi_{i}} s_{\pi_{i}}, \text { for } 1 \leq i<h \\
v_{h}=v_{h-1}+e_{\pi_{h}} s_{\pi_{h}}+\frac{1}{2} \sum_{k=h+1}^{n} e_{\pi_{k}} t_{\pi_{k}} \\
v_{i}=v_{i-1}+\frac{1}{2} e_{\pi_{i}} s_{\pi_{i}}, \text { for } h<i \leq n
\end{array}\right.
$$

Onde $e_{i}$ é o vetor com valor igual a 1 na posição $i$ e igual a 0 nas demais.

Outro mecanismo importante da triangulação $J_{1}^{a}$ são as suas regra de pivotamento para percorrer a triangulação sem utilizar uma estrutura de dados topológica auxiliar. Na Figura 5.3, duas operações de pivotamento são ilustradas, onde o simplexo 1 é pivotado em relação ao vértice $v_{2}$ resultando no simplexo 3 , e o simplexo 2 é pivotado em relação ao vértice $v_{1}$ resultando no simplexo 4 . Todas as regras de pivotamento da triangulação $J_{1}^{a}$ podem ser achadas no trabalho de Castelo et al. [12,14].

Para uma descrição mais detalhada do funcionamento da triangulação $J_{1}^{a}$ ver [54].

\subsection{Geração de Malhas Adaptativas Algébricas}

Como mencionado anteriormente, o método de geração de malhas, aqui apresentado, emprega um conjunto de estênceis na malha inicial gerada pela triangulação $J_{1}^{a}$ junto com a regra de warping afim de gerar uma malha tetraédrica com adaptatividade interna e com ângulos diedrais de boa qualidade.

Desconsiderando a simetria e escala de tetraedros, a triangulação $J_{1}^{a}$ tridimensional é composta por sete tipos de tetraedros (ilustrados na Figura 5.5): os tetraedros que 
formam o bloco básico e os tetraedros que formam o bloco de transição que não atingem uma face refinada são todos do mesmo tipo (tetraedro rotulado como (1) nas Figuras 5.4 e 5.5), o resto do bloco de transição é formado pelos seis tetraedros restantes de acordo com o rótulo: os tetraedros (2) e (3) são do tipo de transição que atingem uma aresta refinada e os tetraedros (4), (5), (6) e (7) são do tipo que atingem uma face refinada.

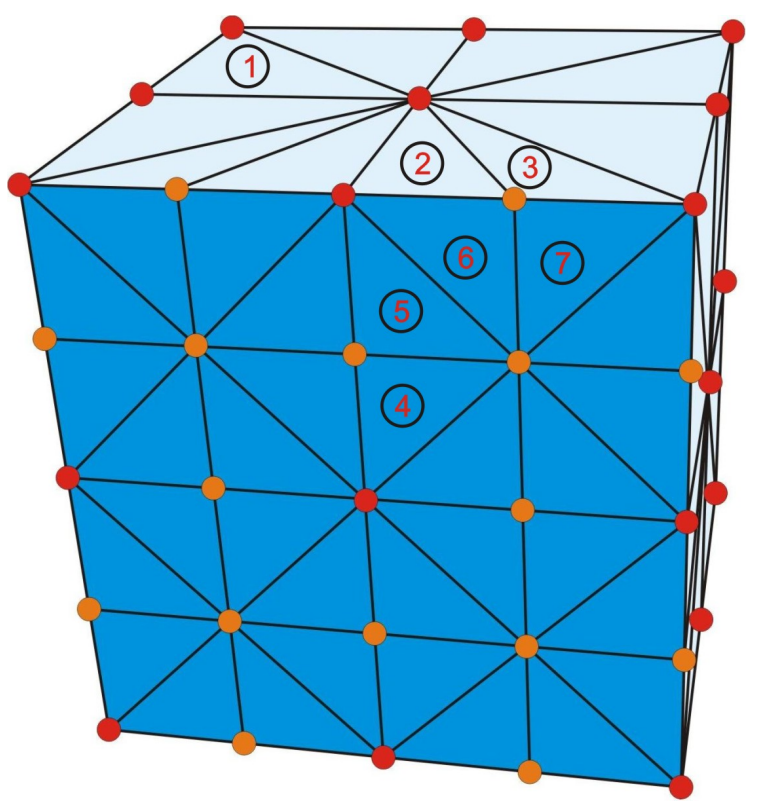

Figura 5.4: Ilustração do bloco de transição 3D onde são rotulados os tipos de tetraedros destacados na Figura 5.5.

O método é dividido em duas etapas principais: na primeira etapa a função implícita é aproximada em conjunto com a geração da malha tetraédrica inicial resultante da triangulação $J_{1}^{a}$; e a segunda etapa obtém a malha final usando os estênceis e a regra de warping.

Quando a função implícita está sendo aproximada, a triangulação $J_{1}^{a}$ subdivide o domínio em um conjunto de blocos. Para todo bloco, uma aproximação local é gerada para ajustar os dados internos ao raio de suporte circundante a este bloco. Se o critério de erro não for atingido para o bloco em questão, este bloco é então refinado ao subdividi-lo em oito blocos novos. Cada bloco novo terá sua nova aproximação calculada. Isto se repetirá até que todos os blocos satisfaçam as condições de erro e robustez ou até o nível de refinamento máximo predefinido seja atingido. Para maiores detalhes ver $[29,54]$.

Ao longo do processo de aproximação, a malha tetraédrica inicial que subdivide o domínio é criada. Depois disso, cada ponto desta malha (vértice dos tetraedros) são 


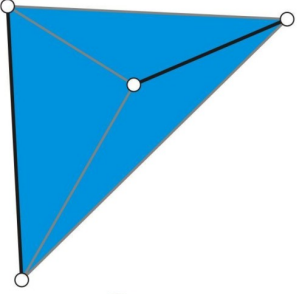

(1)

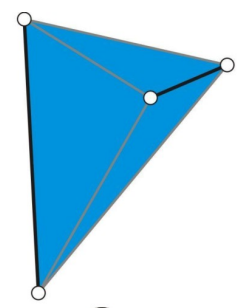

(2)

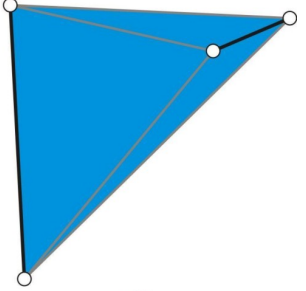

(3)

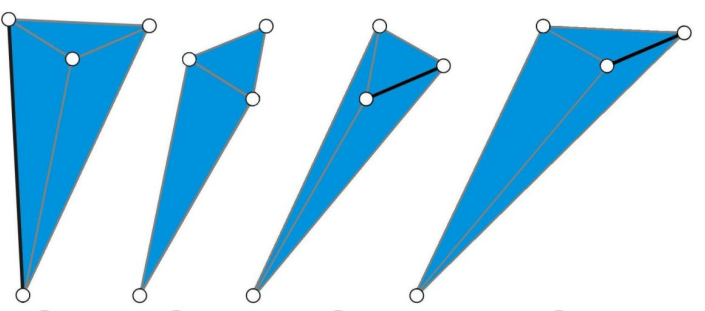

(4) (5) (6) (7)

Figura 5.5: Ilustração dos 7 tipos de tetraedros existentes na triangulação $J_{1}^{a}$ 3D. O tetraedro do canto superior esquerdo pertence ao bloco básico e os seis restantes pertencem ao bloco de transição.

avaliados usando a função implícita para determinar sua posição relativa à superfície. Posteriormente, para cada aresta transversal da grade é calculado um ponto de corte, que indica onde a aresta cruza a superfície. Devido ao requisito de se ter qualidade de ângulos, o método verifica se cada vértice vizinho tem um ou mais pontos de corte próximos demais dele, e, se for o caso, o vértice é warped (movido) para a posição de um desses pontos de corte. Finalmente, o conjunto de estênceis baseado no conjunto empregado em [37] é usado para preencher os tetraedros da grade.

A seguir, a segunda etapa é descrita com maior detalhamento. Primeiro serão apresentadas as três primeiras sub-etapas, e posteriormente a sub-etapa final.

\subsubsection{Avaliação de vértices, pontos de corte e Warping}

Dada uma malha tetraédrica formada pela triangulação $J_{1}^{a}$ e uma função implícita, o método primeiro avalia cada vértice dos tetraedros para determinar sua posição relativa e armazena esse valor. Neste estágio, os tetraedros que não contêm pelo menos um vértice com valor menor que zero são descartados. Posteriormente, para cada aresta transversal, o seu ponto de corte é calculado usando o método de regula-falsi [10].

Depois de serem obtidos todos os pontos de corte, todos os vértices $v$ da malha inicial devem ser checados para determinar se um ou mais pontos de corte $c$ estão próximos demais. Para determinar se isso acontece, o método verifica se a razão entre a distância 
de $c$ para $v$ e o tamanho da aresta onde $c$ está localizado é menor que o parâmetro $\alpha$ preestabelecido para aquela aresta. Caso seja verdade, então $c$ está próximo demais de v. Nestas condições, $v$ passa a ocupar a posição do ponto de corte mais próximo e é reavaliado. Obviamente, por $v$ ocupar a posição de um dos pontos de corte sua posição relativa à superfície será zero e seus pontos de corte adjacentes são descartados.

Foram definidos um parâmetro $\alpha$ para cada tipo de aresta. Como a superfície das malhas geradas tem o mesmo nível de refinamento, isto implica que a superfície é gerada a partir do tetraedro básico (de rótulo (1) na Figura 5.5), ou seja, são três os tipos de arestas diferentes. O parâmetro de proporção $\alpha_{1}$ foi definido para a menor aresta de comprimento $l$, o parâmetro $\alpha_{2}$ para a aresta do meio de comprimento $l \sqrt{2}$ e $\alpha_{3}$ para a maior aresta de comprimento $l \sqrt{3}$.

A execução de warping neste método é ordenada de tal modo que primeiro são verificados os vértices de valor positivo para depois serem verificados os vértices de valor negativo.

\subsubsection{Triangulação por estêncil}

Assim como o algoritmo Isosurface Stuffing, este método emprega estênceis para "preencher" os tetraedros da malha inicial. A Figura 5.6 ilustra os doze estênceis empregados, onde os menores destes representam os tetraedros da malha que não tem vértices rotulados pelo sinal + , significando que serão preenchidos por completo por um só tetraedro. Os demais oito representam situações em que tetraedros transversais serão triangulados resultando de um a três novos tetraedros.

Vale a pena mencionar que, devido ao fato de alguns estênceis resultarem em uma ou mais faces quadriláteras (os cinco estênceis inferiores da Figura 5.6), uma atenção especial deve ser dada quando for cortar essas faces. Como estas faces quadriláteras têm que ser cortadas (diagonalmente) para formar dois triângulos, as diagonais que cortam duas faces incidentes tem que ser iguais (terem os mesmos pontos extremos). A Figura 5.7 ilustra um exemplo de faces quadriláteras que precisam ter a mesma diagonal de corte.

Para escolher qual diagonal deve ser usada para corta este tipo de face, Labelle e Shewchuk [37] propuseram uma regra de paridade. Esta regra envolve rotular os dois tipos de arestas do tetraedro: arestas paralelas aos eixos de coordenadas e arestas diagonais, e os valores das coordenadas dos vértices são comparados para decidir como cortar a face quadrilateral (para maiores detalhes ver [37]).

Para o caso do método aqui apresentado, foi criada uma regra de paridade adaptada. 

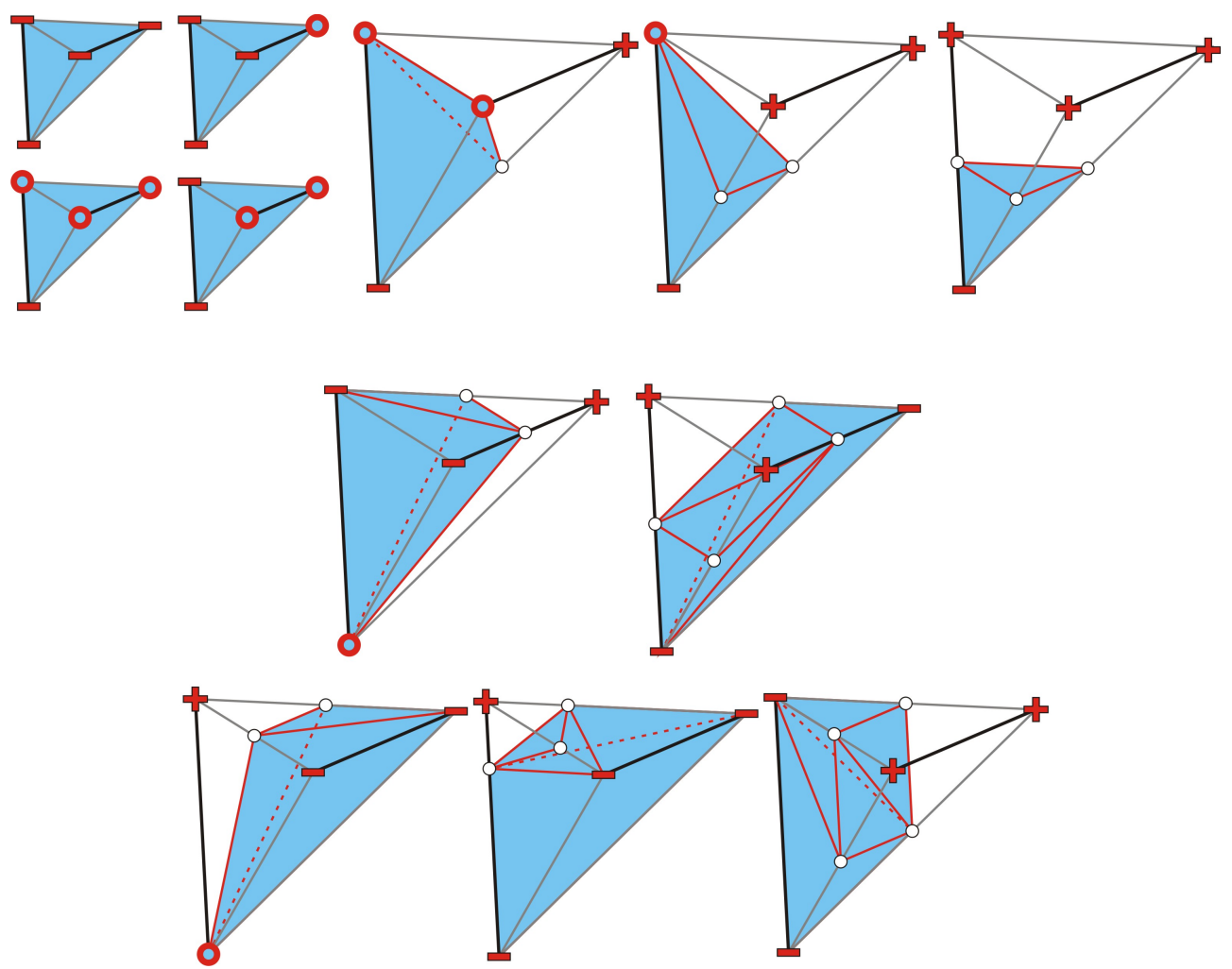

Figura 5.6: Conjunto de estênceis para gerar a triangulação dos tetraedros. Os vértices dos tetraedros são rotulados com os sinais $(0,+,-)$, os pontos de corte estão em branco e a triangulação resultante está em azul. É fácil notar que os cinco estênceis de baixo geram de dois a três tetraedros. Mesmo que a triangulação $J_{1}^{a}$ apresente sete tipos de tetraedros, o tetraedro de bloco básico foi escolhido para representar o estêncil sem qualquer perda de generalidade. Esta figura foi adaptada do trabalho [19].

Vale notar que, a aresta que forma a diagonal é composta por um vértice do tetraedro e um ponto de corte. Além disso os tetraedros provindos de blocos básicos da triangulação $J_{1}^{a}$ tem três arestas paralelas aos eixos de coordenadas, então foram escolhidas a aresta formada pelos vértices $v_{0}$ e $v_{1}$ e a aresta formada pelos vértices $v_{2}$ e $v_{3}$ para serem rotuladas como arestas pretas (como é ilustrado na Figura 5.7). A primeira parte da regra de paridade verifica se um dos pontos de corte pertencentes à face quadrilátera está localizado em uma aresta preta. Caso afirmativo, este ponto e o seu ponto oposto (com relação à face) são escolhidos para formar a diagonal. Caso contrário, deve-se verificar os vértices do tetraedro original.

Devido às características dos tetraedros da triangulação $J_{1}^{a}$, nem sempre a regra de comparação das coordenadas de vértices proposta em [37] funciona. Foi notado, em muitos casos, que o uso dessa regra não foi suficiente para garantir que as diagonais de faces incidentes se encontrem. Este problema ocorre porque algumas 


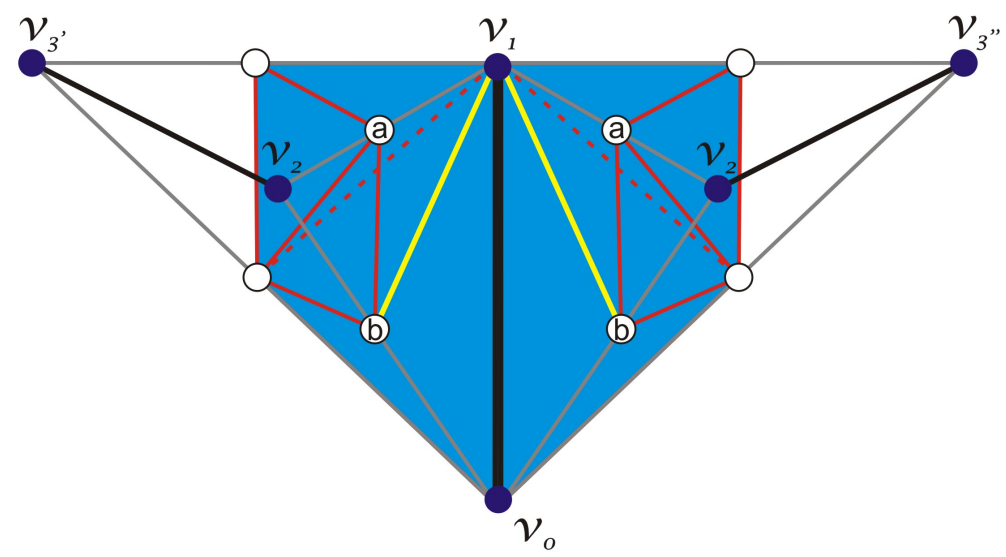

Figura 5.7: Exemplo de duas faces quadriláteras vizinhas que precisam ser cortadas por uma mesma diagonal (em amarelo). Os tetraedros à esquerda (formado por $v_{0}, v_{1}$, $v_{2}$ e $v_{3^{\prime}}$ ) e à direita (formado por $v_{0}, v_{1}, v_{2}$ e $v_{3^{\prime \prime}}$ ) foram rotacionados em sentidos opostos em relação a aresta formada por $v_{0}$ e $v_{1}$ para melhor visualizar as faces vizinhas.

faces dos tetraedros são paralelas aos planos cartesianos, isto implica que a análise por comparação de coordenadas não gera o mesmo critério para definição da diagonal para faces paralelas e não-paralelas.

Para solucionar esse problema, foi utilizada usar a ordem de percurso de vértices usadas na criação de tetraedros da triangulação $J_{1}^{a}$ [19]. Pela Figura 5.8 pode-se notar que para um dado vértice da malha inicial o seu índice em qualquer tetraedro incidente sempre será o mesmo. Então, o uso desses índices possibilita a escolha dos vértices para formarem a diagonal que corta faces incidentes sem a necessidade de comparação de suas coordenadas.

\subsection{Prova de Qualidade dos Ângulos Diedrais}

Nesta seção será apresentada a proposta da prova para analisar a qualidade dos ângulos diedrais das malhas geradas. Esta prova é dividida em duas etapas: análise de qualidade dos tetraedros da triangulação $J_{1}^{a} 3 \mathrm{D}$ e a prova de qualidade dos tetraedros gerados após o warping (utilizando os parâmetros alpha) e a triangulação por estêncil.

\section{Análise de qualidade dos tetraedros da triangulação $J_{1}^{a}$}

Seguindo os rótulos dos tetraedros na Figura 5.5, a Tabela 5.1 apresenta uma relação de qualidade de ângulos diedrais e da razão de aspecto dos tetraedros que compõem a triangulação $J_{1}^{a} 3 \mathrm{D}$. A razão de aspecto $\left(\Delta_{r a}\right)$ foi obtida seguindo a seguinte fórmula: 


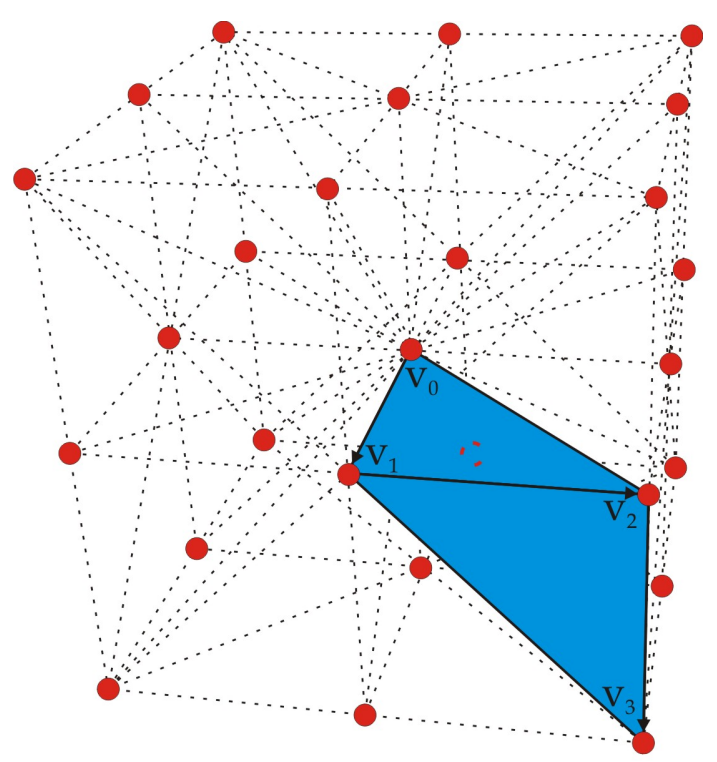

Figura 5.8: Ordem de construção dos vértices do tetraedro da triangulação $J_{1}^{a}$. Como ilustrado, o primeiro vértice localiza-se no centro do bloco; o segundo é o centro de face do bloco; o terceiro é o centro de uma aresta; e o quarto é um vértice do bloco. Esta figura foi obtida do trabalho [19].

$$
\Delta_{r a}=\frac{e_{\max }}{2 \sqrt{6} R}
$$

onde $e_{\max }$ é a medida da maior aresta, $R=3 V / A, V$ é o volume do tetraedro e $A$ é a área de sua superfície. A medida de $\Delta_{r a}=1$ refere-se a um tetraedro regular e evidentemente a melhor medida possível.

Tabela 5.1: Relação de ângulos diedrais mínimos e máximos dos tetraedros (apresentados na Figura 5.5) que compõem a triangulação $J_{1}^{a}$.

\begin{tabular}{|c||c|c|c|}
\hline Tetraedro & Ângulo mínimo & Ângulo máximo & Razão de aspecto \\
\hline \hline 1 & $45^{\circ}$ & $90^{\circ}$ & 1,70711 \\
\hline 2 & $26,57^{\circ}$ & $90^{\circ}$ & 2,03622 \\
\hline 3 & $18,43^{\circ}$ & $108,43^{\circ}$ & 2,64412 \\
\hline 4 & $45^{\circ}$ & $90^{\circ}$ & 2,01612 \\
\hline 5 & $39,23^{\circ}$ & $116,56^{\circ}$ & 2,51152 \\
\hline 6 & $35,26^{\circ}$ & $125,26^{\circ}$ & 2,91752 \\
\hline 7 & $45^{\circ}$ & $116,56^{\circ}$ & 3,14412 \\
\hline
\end{tabular}

Com esta relação de ângulos diedrais dos tetraedros, é provada a qualidade dos tetraedros internos das malhas geradas. 


\section{Qualidade de tetraedros superficiais com mesmo nível de refinamento}

A prova de qualidade dos ângulos diedrais dos tetraedros localizados na superfície da malha foi obtida através de uma simulação computacional das possíveis posições de pontos de corte em relação aos vértices da malha. Mesmo que só seja usado um número finito de estênceis, as possíveis posições dos pontos de corte podem ser infinitas. Por isso, foi implementado um programa que quebra os espaços das possíveis configurações de tetraedros em um número finito de subespaços que podem ser verificados através de um intervalo aritmético.

A análise de qualidade aqui realizada é referente aos valores dos parâmetros $\alpha$ atribuídos aos três tipos de arestas pertencentes aos tetraedros básicos da triangulação $J_{1}^{a}$.

De modo análogo à [37], para executar a análise, deve-se levar em consideração que cada aresta da malha inicial gerada pela triangulação $J_{1}^{a}$ tem um segmento central (fração entre $\alpha l$ e $(1-\alpha) l$ ) onde não ocorre warping e dois segmentos extremos onde ocorre. A figura 5.9, ilustra um asterístico que é a união dos segmentos incidentes a um dos vértices do tetraedro onde ocorre warping. Os vértices $v_{0}$ e $v_{3}$ tem astéristicos compostos por 26 segmentos e os asterísticos dos vértices $v_{1}$ e $v_{2}$ são compostos por 10 segmentos.

O asterístico mostra que para um dado tetraedro $t_{j}$ cujo vértice $v_{i}$ sofrerá warping, a posição onde $v_{i}$ será deslocado não depende somente dos pontos de corte contidos nas arestas incidentes a $v_{i}$ pertencentes à $t_{j}$. Devido à possibilidade de $v_{i}$ ser deslocado ao longo de uma aresta não pertencente $t_{j}$, a análise de qualidade deve considerar todos os possíveis segmentos dos asterísticos dos vértices de $t_{j}$.

A análise de qualidade também depende dos seguintes fatos:

- Um vértice que sofreu warping está localizado no seu asterístico e seu valor (para a escolha do estêncil) é zero;

- Um ponto de corte não pode estar localizado em uma aresta incidente a um vértice que sofreu warping;

- Dois vértices pertencentes a uma mesma aresta não podem ambos serem deslocados ao longo dessa aresta. O primeiro vértice deslocado elimina o ponto de corte;

- Um vértice não pode ser deslocado ao longo de uma aresta cujo outro vértice sofreu warping. 


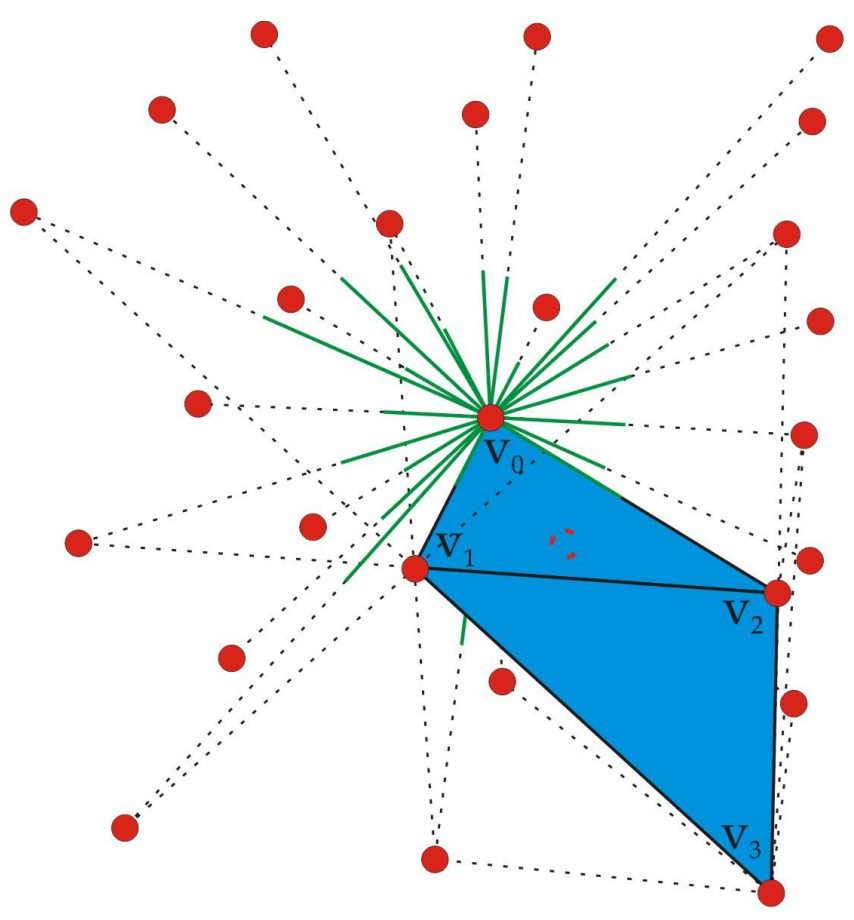

Figura 5.9: Ilustração de um asterístico do vértice $v_{0}$.

A análise de qualidade proposta segue a partir de uma configuração inicial de tetraedro básico da $J_{1}^{a}$. Para verificar a qualidade de todos os possíveis tetraedros gerados pelo conjunto de estênceis, os vértices do tetraedro inicial são deslocados ao longo de seus asterísticos e a cada deslocamento de cada vértice são calculados os ângulos diedrais dos tetraedros resultantes. São verificadas também as proporções das novas posições dos vértices em relação à aresta onde ocorreu o warping para calcular os parâmetros $\alpha$ e relacioná-los com a qualidade dos ângulos obtidos.

\section{Qualidade de superfícies adaptativas}

A prova de qualidade para superfícies adaptativas é complexa devido a uma série de obstáculos:

- Durante a execução de warping um tetraedro pequeno pode ter um de seus vértices deslocado uma distância muito grande devido a um tetraedro vizinho maior;

- Segundo Labelle e Shewchuk [37], a presença de ângulos diedrais superiores a $120^{\circ}$ é um problema, pois após a execução de warping pode produzir tetraedros de péssima qualidade;

- Novos parâmetros $\alpha$ devem ser calculados para as diferentes novas arestas 
presentes em tetraedros de blocos de transição.

Devido à nova regra de paridade, um obstáculo presente na Isosurface Stuffing não ocorre neste método. Este obstáculo é justamente devido ao fato dos tetraedros de transição em [37] terem faces paralelas aos planos cartesianos.

\subsection{Resultados}

Nesta seção serão apresentados os resultados obtidos, além de uma análise de qualidade das malhas resultantes e do consumo de tempo para gerá-las. Os testes de qualidade realizados levam em consideração os ângulos diedrais e a razão de aspecto de cada tetraedro das malhas.

A Figura 5.10 apresenta uma comparação das malhas de um modelo de um vaso geradas respectivamente sem e com uso da regra de warping. Para executar a segunda etapa apresentada na Seção 5.3 para gerar a malha ilustrada na figura 5.10 foi necessário um tempo de 42,699 segundos, onde 11,089 segundos foi o tempo necessário para executar a sub-etapa de triangulação por estêncil. A malha gerada usando warping é composta por 683k tetraedros. A Figura 5.11 ilustra uma aproximação de uma região das malhas para melhor demonstrar a diferença de qualidade. Além disso, os histogramas das Figuras 5.14 e 5.15 fazem uma análise mais qualitativa.

A Figura 5.12 ilustra a malha do modelo do Dragão Chinês com três visualizações diferentes, a Figura 5.12(d) representa a malha completa e as Figuras 5.12(a), (b) e (c) representa a malha seccionada para mostrar a adaptatividade interna.

As Figuras 5.13(a), (b), (c) e (d) tem os tetraedros das malhas coloridos seguindo o critério de qualidade: tetraedros vermelhos apresentam ângulos diedrais abaixo de $10^{\circ}$ ou acima de $164^{\circ}$, os laranjas apresentam ângulos entre $10^{\circ}$ e $18^{\circ}$, os amarelos entre $140^{\circ}$ e $164^{\circ}$, os verdes entre $126^{\circ}$ e $140^{\circ}$ e os demais são transparentes. Este último critério de cor teve este intervalo escolhido pois representa os limites inferiores e superiores dos tetraedros da triangulação $J_{1}^{a} 3 \mathrm{D}$ e facilitaria a visualização de tetraedros de qualidades inferiores. Note que para essas malhas geradas não foi gerado nenhum tetraedro de má qualidade (ângulo abaixo de $10^{\circ}$ ou acima de $164^{\circ}$ ). Com exceção da malha do coração (Figura 5.13(c)), todas as malhas apresentadas tiveram sua função implícita obtida a partir de uma nuvem de pontos. A função implícita $F$ utilizada para gerar a malha do coração foi:

$$
F(x)=\left(2 * x_{1}^{2}+x_{2}^{2}+x_{3}^{2}-1\right)^{3}-0.2 * x_{1}^{2} * x_{3}^{3}-x_{2}^{2} * x_{3}^{3}
$$



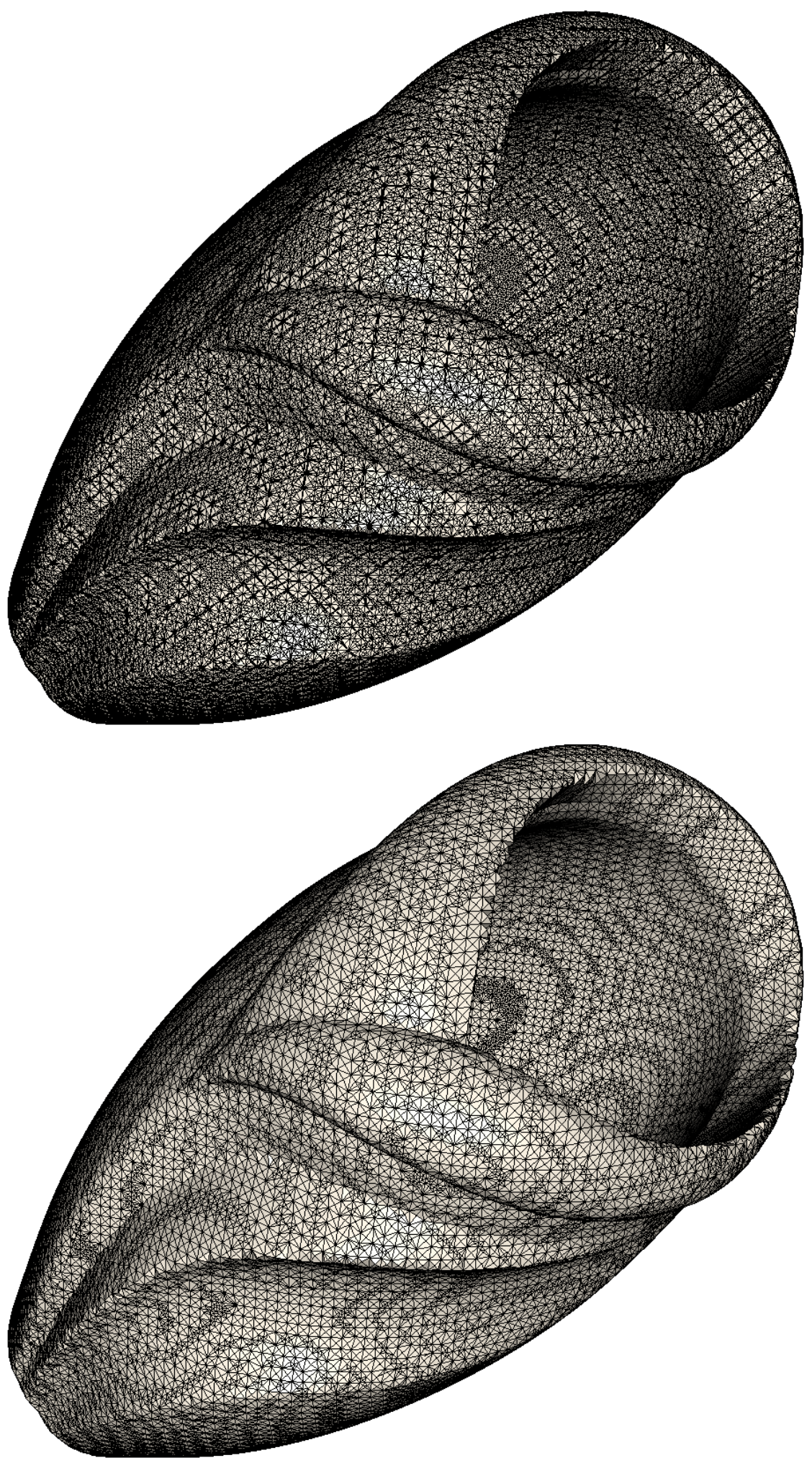

Figura 5.10: Malhas do modelo de vaso, a primeira mala foi gerada sem o uso da regra de warping e a segunda foi gerada com o uso da regra de warping. 

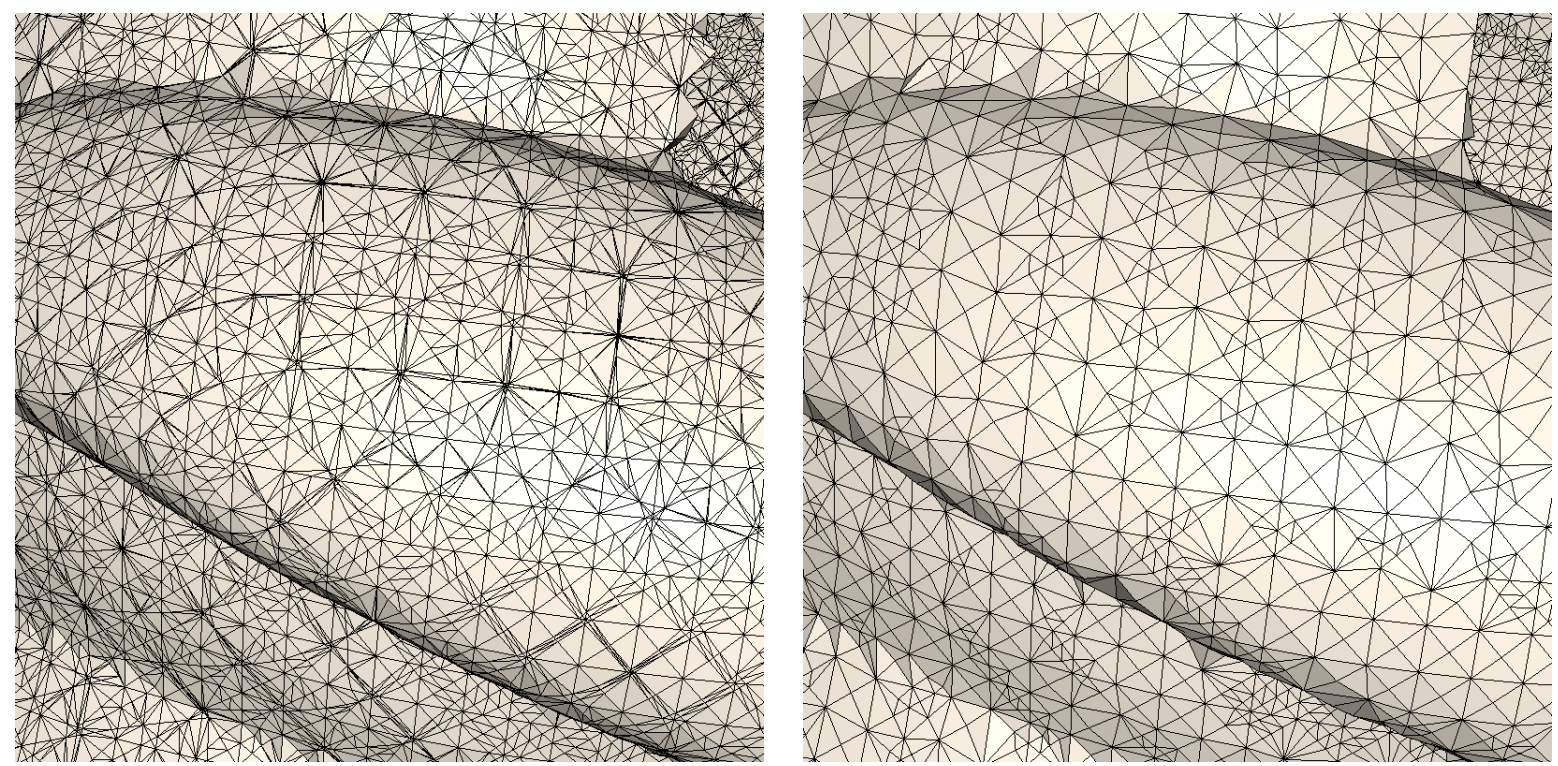

Figura 5.11: Aproximação de regiões das malhas do vaso para melhor demonstrar a diferença do resultado sem o uso de warping (à esquerda) e com o uso de warping (à direita).

onde $x$ é o vetor de coordenadas do ponto a ser avaliado por $F$.

\section{Tempo de geração de malha}

A Tabela 5.2 apresenta o tempo necessário para gerar as malhas ilustradas na Figura 5.13 de acordo com cada etapa do método proposto neste capítulo. A primeira se refere à etapa de aproximação da função implícita, da geração da triangulação $J_{1}^{a}$ com tetraedros superficiais de mesmo nível. A segunda etapa é referente à geração da malha final usando os estênceis e a regra de warping, na tabela também foi apresentado consumo de tempo da sub-etapa de triangulação por estêncil desta etapa. O tempo da execução da primeira etapa da geração da malha do coração é nulo pois esta etapa não foi necessária já que o coração já é representado por uma função implícita.

Tabela 5.2: Tempo de geração das malhas ilustradas na Figura 5.13 de acordo com a etapa. A unidade de tempo é dada em segundos.

\begin{tabular}{|c||c|c|c|}
\hline Malha & $1^{\text {a }}$ Etapa & 2 $^{\text {a Etapa }}$ & Triangulação por estêncil \\
\hline \hline Duas Esferas & $48,451 \mathrm{~s}$ & $1,799 \mathrm{~s}$ & $0,293 \mathrm{~s}$ \\
\hline Elipse & $30,592 \mathrm{~s}$ & $1,368 \mathrm{~s}$ & $0,277 \mathrm{~s}$ \\
\hline Coração & - & $0,206 \mathrm{~s}$ & $0,001 \mathrm{~s}$ \\
\hline Witch Hat & $1914,61 \mathrm{~s}$ & $11,935 \mathrm{~s}$ & $2,817 \mathrm{~s}$ \\
\hline
\end{tabular}


Geração Algébrica de Malhas Adaptativas a partir de Funções Implícitas
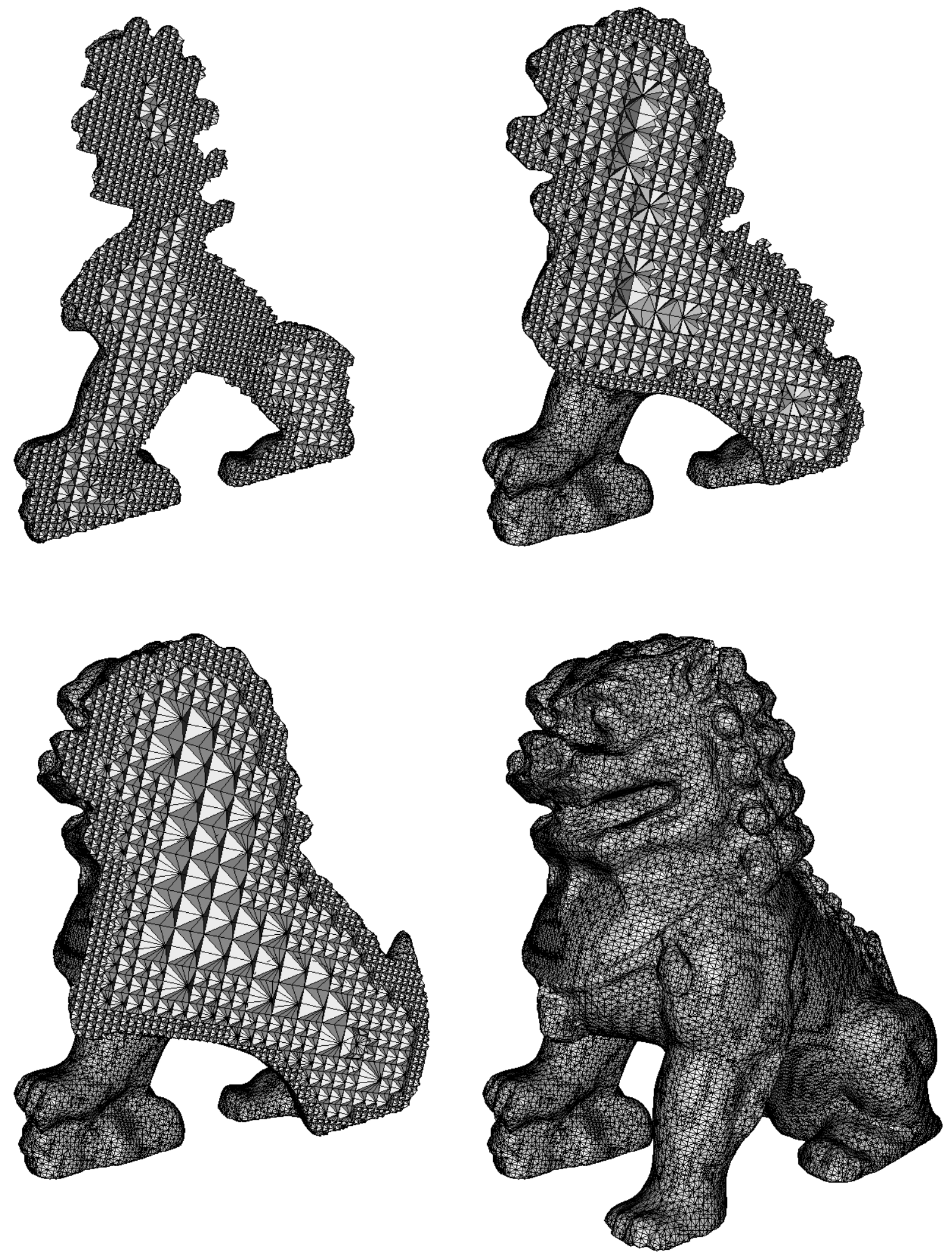

Figura 5.12: Malha do Dragão Chinês composta por 1053k tetraedros. 


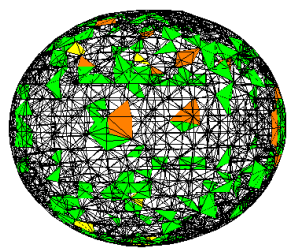

(a) Duas Esferas - 29k tetraedros

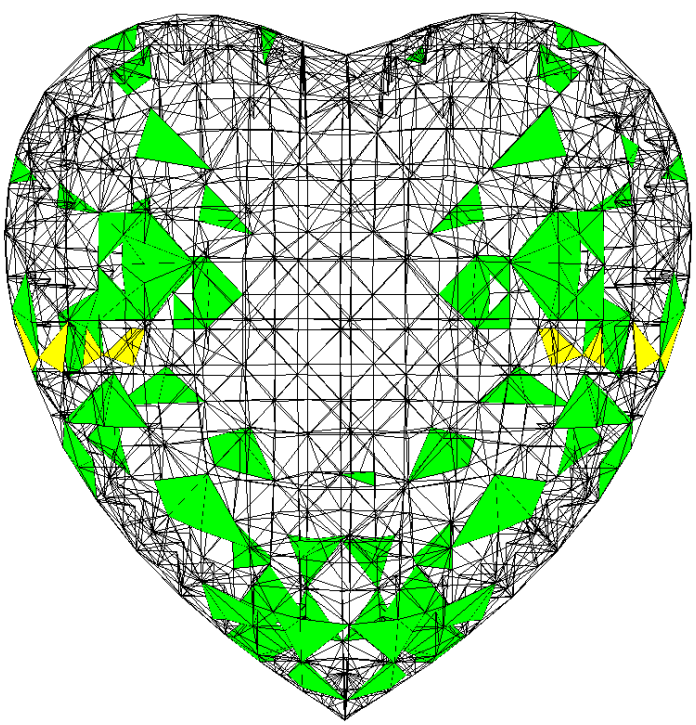

(c) Coração - 8k tetraedros

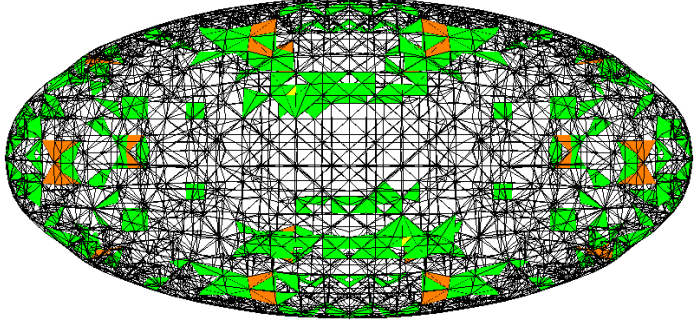

(b) Elipse - 25k tetraedros

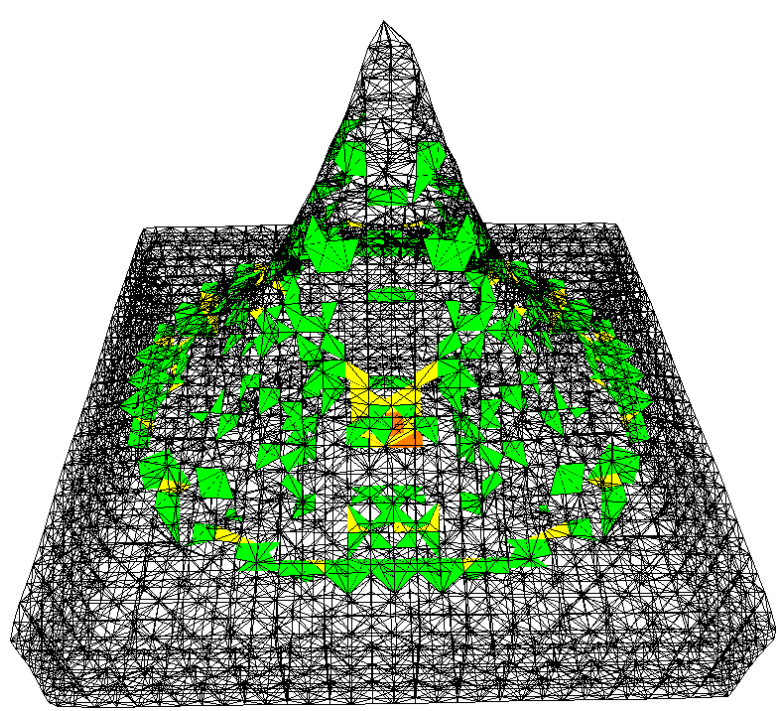

(d) Witch Hat - 54k tetraedros

Figura 5.13: Ilustração da relação de qualidade de tetraedros de algumas malhas geradas pelo método proposto.

\section{Análise de qualidade}

As Figuras 5.14, 5.15, 5.16, 5.17, 5.18, 5.19, 5.20 and 5.21 ilustram os histogramas dos ângulos diedrais e das razões de aspecto das malhas geradas. As colunas em laranja nos histogramas de ângulos diedrais e as colunas em vermelho nos histogramas de razão de aspecto tiveram seus tamanhos diminuídos para melhor visualizar as colunas em azul.

\subsection{Considerações Finais}

Neste capítulo foi apresentado um método de geração de malhas baseado no uso de estênceis tetraédricos e de uma regra de warping de pontos com objetivo de gerar 


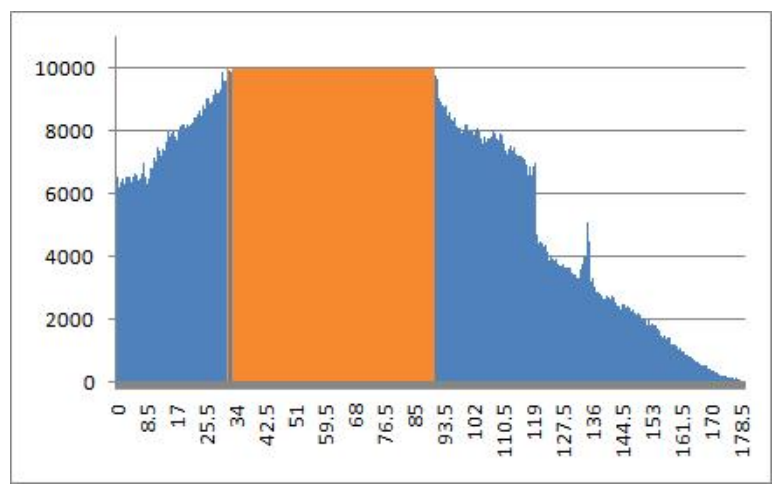

(a) Ângulo diedral

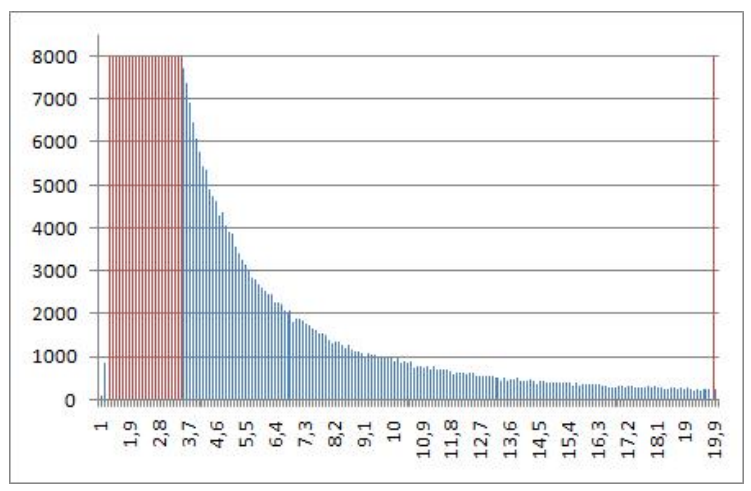

(b) Razão de aspecto

Figura 5.14: Vaso sem warping, esta malha apresentou razão de aspecto médio de 3,61 com desvio padrão de 4,1706 e pior elemento com valor acima de 20.

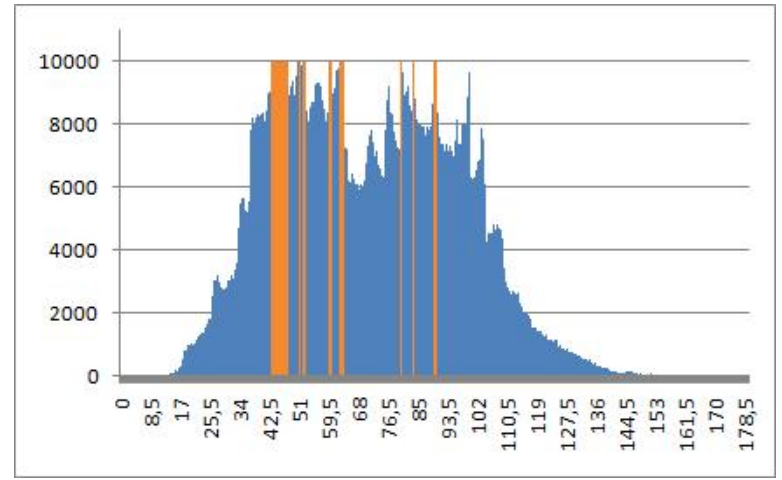

(a) Ângulo diedral

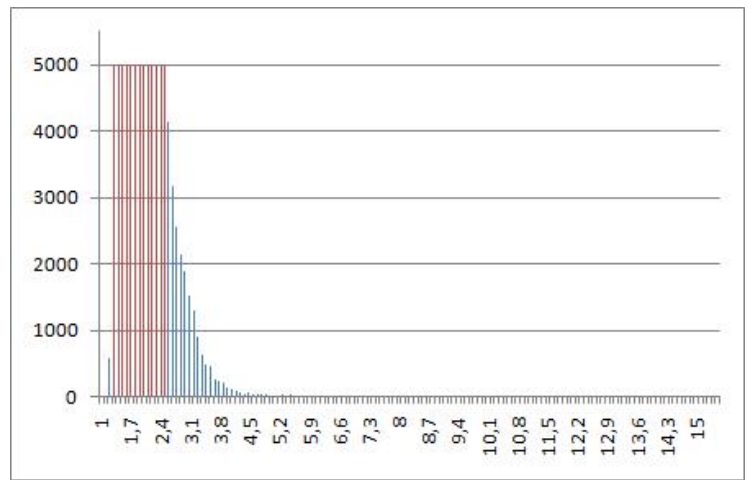

(b) Razão de aspecto

Figura 5.15: Vaso com warping, esta malha apresentou razão de aspecto médio de 1,77 com desvio padrão de 0,2904 e pior elemento com valor de 15,5.

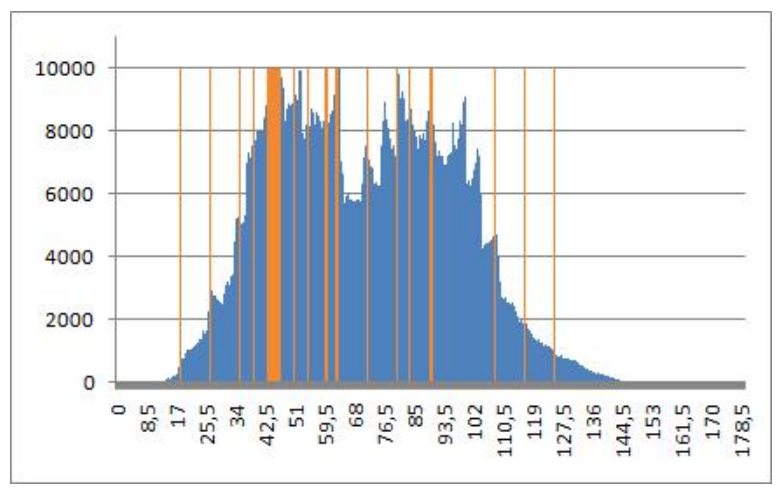

(a) Ângulo diedral

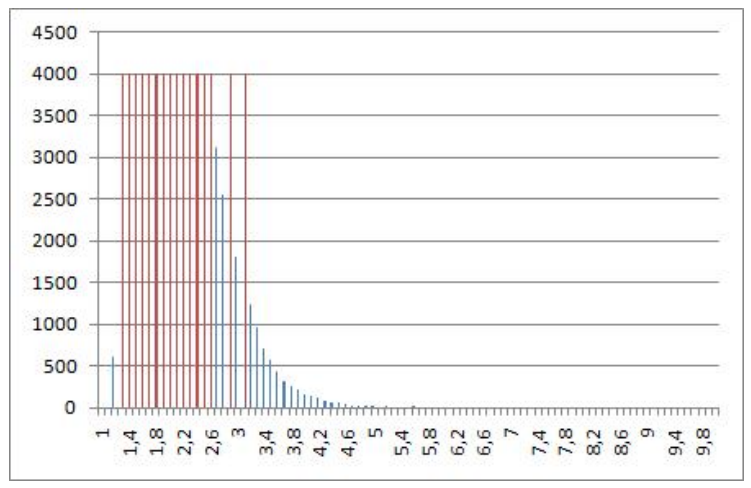

(b) Razão de aspecto

Figura 5.16: Dragão chinês, esta malha apresentou razão de aspecto médio de 1,84 com desvio padrão de 0,36899 e pior elemento com valor de 19,9. 
Geração Algébrica de Malhas Adaptativas a partir de Funções Implícitas

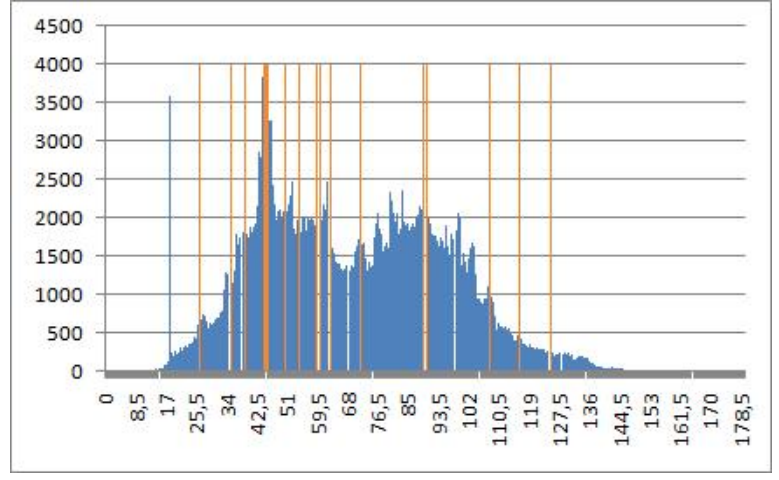

(a) Ângulo diedral

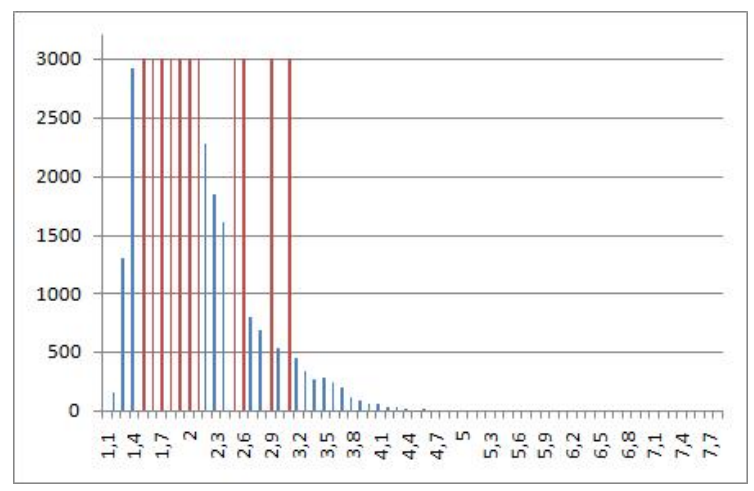

(b) Razão de aspecto

Figura 5.17: Stanford Bunny, esta malha apresentou razão de aspecto médio de 1,86 com desvio padrão de 0,4032 e pior elemento com valor de 19,9.

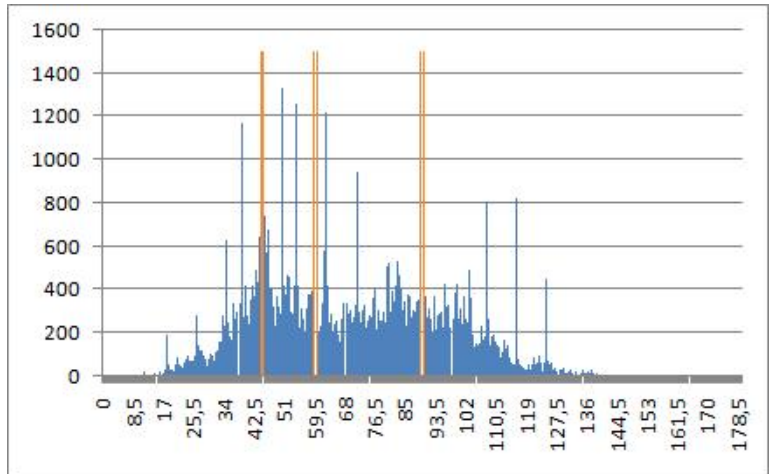

(a) Ângulo diedral

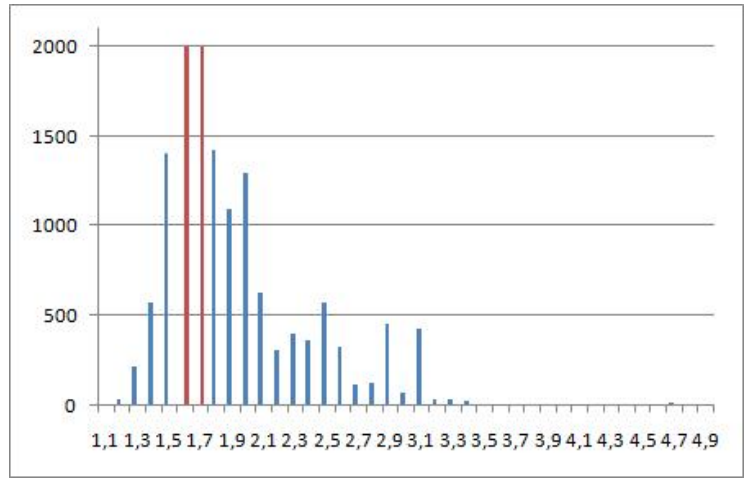

(b) Razão de aspecto

Figura 5.18: Duas Esferas, esta malha apresentou razão de aspecto médio de 1,8197 com desvio padrão de 0,3544 e pior elemento com valor de 4,9.

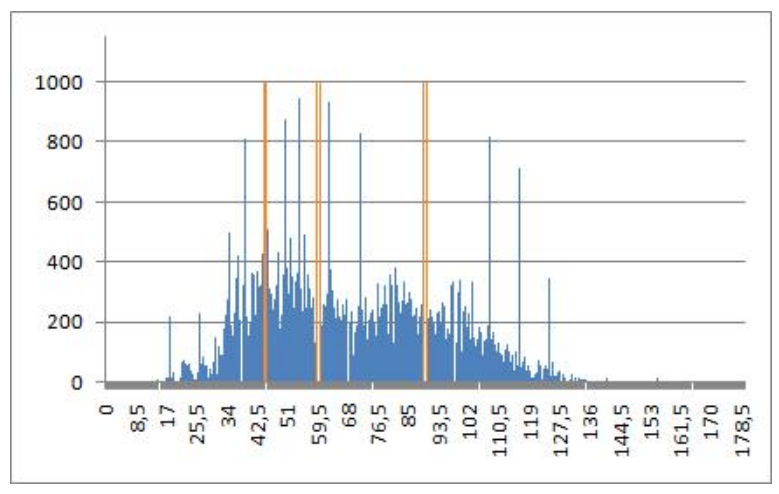

(a) Ângulo diedral

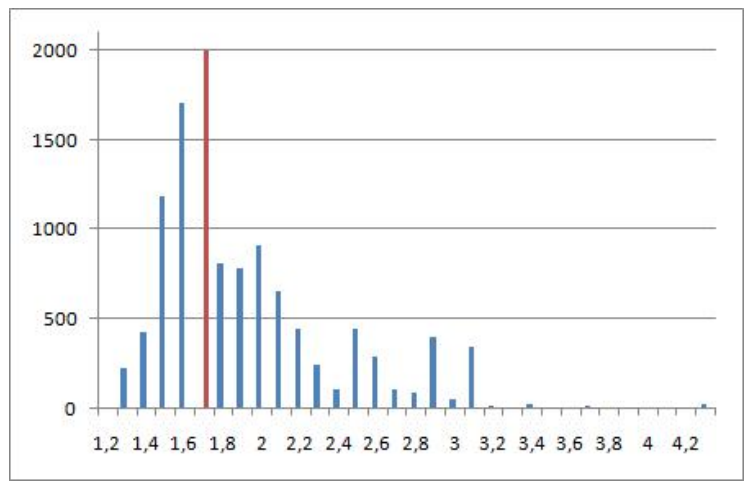

(b) Razão de aspecto

Figura 5.19: Elipse, esta malha apresentou razão de aspecto médio de 1,8019 com desvio padrão de 0,3277 e pior elemento com valor de 4,3. 


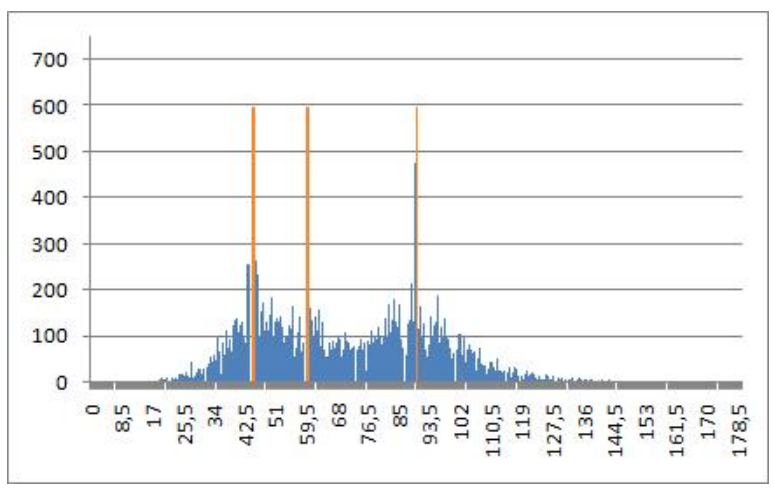

(a) Ângulo diedral

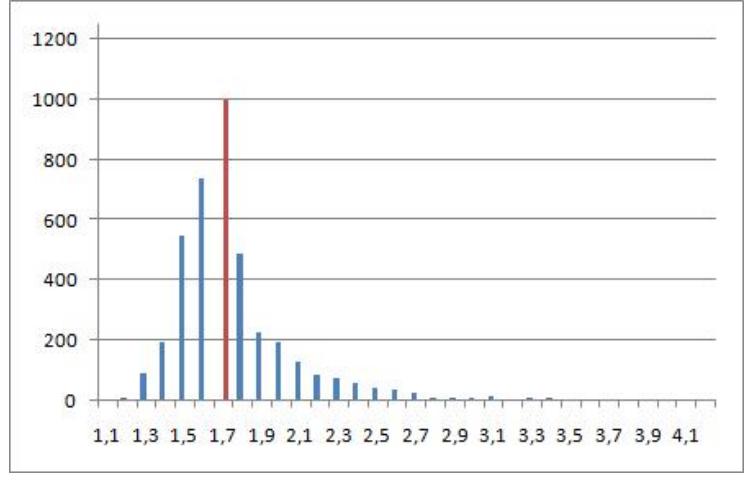

(b) Razão de aspecto

Figura 5.20: Coração, esta malha apresentou razão de aspecto médio de 1,7293 com desvio padrão de 0,2272 e pior elemento com valor de 4,2.

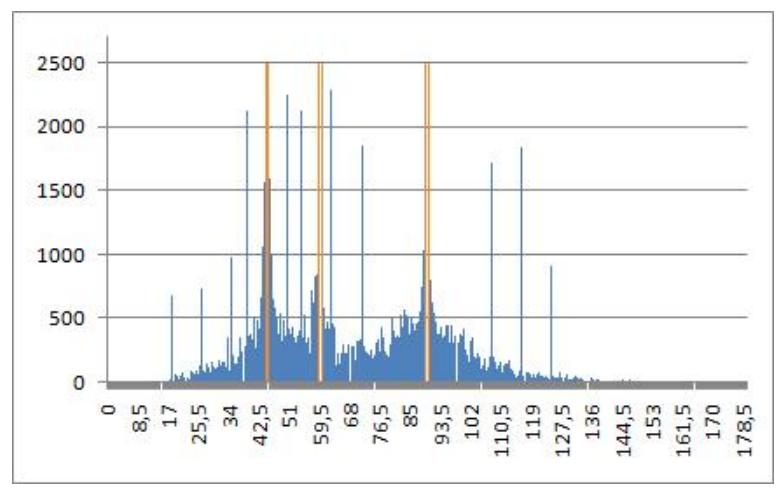

(a) Ângulo diedral

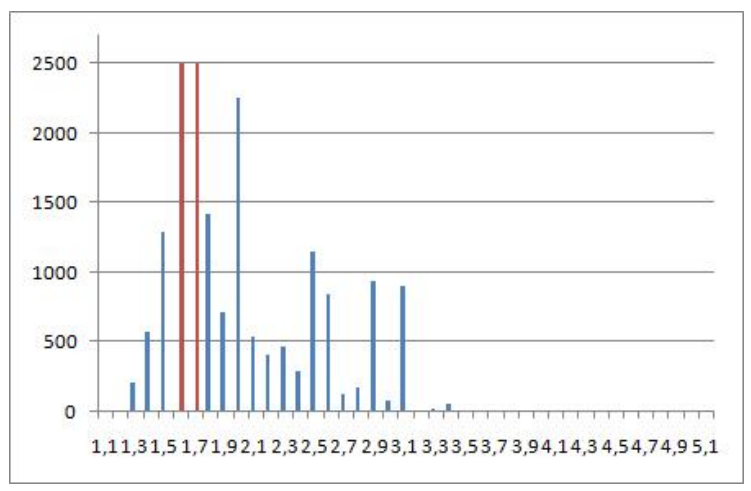

(b) Razão de aspecto

Figura 5.21: Witch Hat, esta malha apresentou razão de aspecto médio de 1,807 com desvio padrão de 0,33128 e pior elemento com valor de 5,1.

malhas com boa qualidade de ângulos diedrais. O uso da triangulação $J_{1}^{a}$ permitiu uma nova abordagem com relação ao algoritmo de Isosurface Stuffing. A partir dela foi possível gerar uma malha adaptativa inicial sem necessitar de uma estrutura auxiliar. Além disso, a triangulação $J_{1}^{a}$ permitiu o uso de regras mais simples para gerar a malha final.

Os resultados obtidos são de boa qualidade, mesmo que em alguns casos ainda existam ângulos diedrais muito grandes ou muito pequenos. Isso ocorre porque ainda não foi possível concluir a prova da garantia de qualidade dos ângulos. Como foi dito anteriormente, a partir desta prova é possível determinar os valores dos parâmetros $\alpha$ responsáveis pela qualidade desses ângulos.

Quanto ao tempo necessário para gerar as malhas nota-se que o tempo para executar a segunda etapa é bem inferior ao tempo necessário para executar a primeira. Esse fato 
ocorre devido à execução de duas operações durante a primeira etapa: refinar todos os tetraedros superficiais da malha para que estes fiquem no mesmo nível de refinamento e obtenção dos vértices de tetraedros para gerar a malha final. Vale salientar que este último fator não é uma deficiência da triangulação $J_{1}^{a}$ e sim uma deficiência originada durante a expansão do trabalho de proposto por Gois et al. [30]. Uma solução já foi proposta e será implementada em trabalhos futuros.

Além de solucionar o problema de custo de tempo da primeira etapa do método, propõe-se como atividade futura mais duas atividades: a finalização da prova da garantia de qualidade para tetraedros superficiais de mesmo nível e realizar a prova da garantia de qualidade para superfícies adaptativas. Após finalizar a primeira prova, serão propostas novas regras para realizar a segunda prova. A primeira regra prioriza a execução da regra de warping em tetraedros menores e a segunda servirá para evitar a presença de tetraedros de péssima qualidade. Além disso os novos parâmetros $\alpha$ devem ser calculados. 


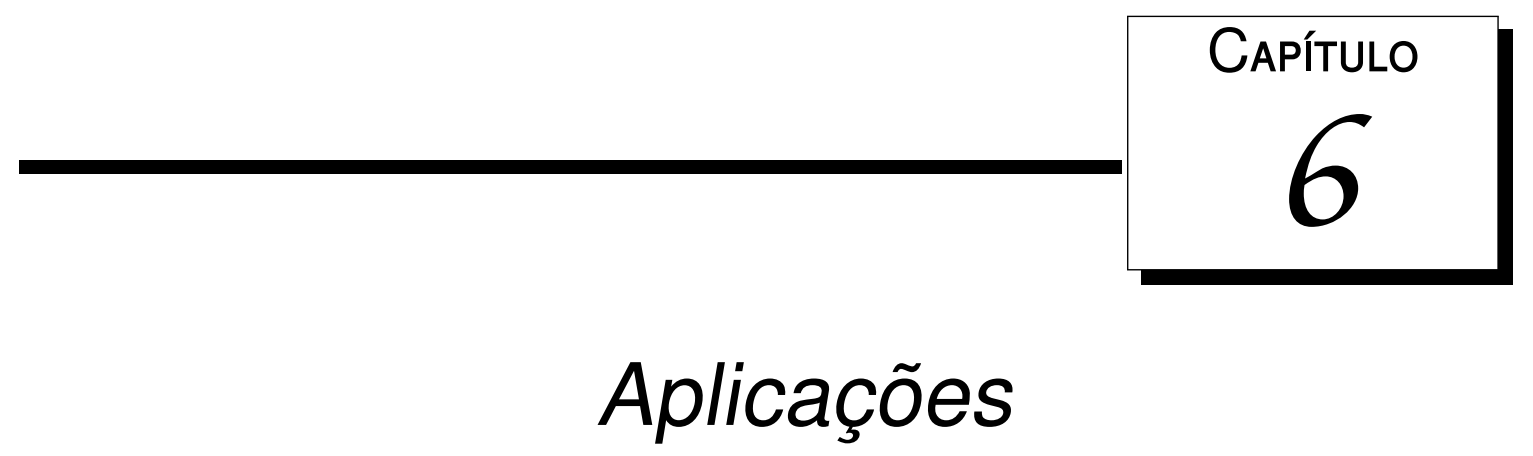

Neste capítulo são apresentadas as aplicações de movimento de malhas elásticas que foram implementadas usando a estrutura MF. Essas malhas seguem a estratégia de analogia com molas para malhas.

Primeiramente será apresentada a abordagem adotada para resolver o sistema de equações que regem a malha elástica. Este tipo de abordagem foi baseado no trabalho de Soares [58]. Posteriormente serão apresentadas as duas aplicações implementadas e seus resultados.

Nestas aplicações foi utilizada a mola do tipo semi-torcional para movimentar os vértices de tal forma que se conformem à nova descrição da malha sempre que for alterado o domínio onde a malha está definida, mantendo ou melhorando a qualidade da malha.

A primeira aplicação envolve o movimento de uma malha triangular plana que representa a parte externa do aerofólio (corte da asa de um avião). A segunda aplicação envolve o movimento de uma malha mista plana que representa uma mão com buraco circular nela.

\subsection{Execução de malha dinâmica}

O sistema de equações lineares que rege a malha elástica pode ser resolvido de várias maneiras. Para as aplicações apresentadas neste capítulo foi considerada a solução iterativa pelo método de Gauss-Seidel modificado onde o novo deslocamento 


\section{Aplicações}

do vértice $v_{i}\left(\delta_{i}^{\text {new }}\right)$ depende dos deslocamentos calculados anteriormente $\left(\delta^{\text {old }}\right)$. Por exemplo, no caso de uso de molas semi-torcionais, o valor de $\delta_{i}^{\text {new }}$ é obtido por:

$$
\delta_{i}^{\text {new }}=\frac{\sum_{v_{w} \in L\left(v_{i}\right)} \alpha_{i w} \delta_{w}^{\text {old }}}{\sum_{v_{w} \in L\left(v_{i}\right)} \alpha_{i w}}
$$

onde $w$ são os índices dos vértices obtidos de acordo com a conectividade da malha. Pode-se observar que $\delta_{i}^{\text {new }}$ é obtido pela média dos deslocamentos vizinhos ponderada pelos coeficientes de rigidez das molas. Vale lembrar que, uma vez que os vértices são deslocados, os coeficientes de molas torcionais que compõem o coeficiente de mola semi-torcional $(\alpha)$ devem ser atualizados após cada iteração. Esta atualização diferencia o método aqui proposto do método de Gauss-Seidel.

O Algoritmo 6.1 descreve os passos da execução de movimento de malha onde foram usadas molas semi-torcionais e a solução do sistema pelo método de Gauss-Seidel modificado. Vale notar que o algoritmo não desloca de fato os vértices, e sim atualiza os vetores de deslocamento que lhes foram atribuídos. O critério de parada escolhido identifica se ainda existe algum deslocamento de vértice maior que a tolerância de convergência pré-estabelecida.

\section{Algoritmo 6.1}

Entrada: Sejam $M$ a malha a ser deslocada, $\partial M$ o conjunto de vértices na fronteira de $M$, $C_{1}^{e}$ e $C_{2}^{e}$ os coeficientes de molas torcionais da aresta $e \in M$ que compõem o coeficiente semi-torcional $\alpha_{e}$ e $\epsilon$ a tolerância de convergência do método numérico.

1. $\delta_{w} \leftarrow 0$ para todo $v_{w} \in M$ tal que $v_{w} \notin \partial M$

2. faça

3. $\quad$ para cada $v_{i} \in M$ tal que $v_{i} \notin \partial M$ faça

4. $\quad$ calcule $\delta_{i}^{\text {new }} / *$ por meio da Equação $6.1 * /$

5. $\quad$ para cada $e_{i} \in M$ faça

6. $\quad$ atualize $C_{1}^{e_{i}}$ e $C_{2}^{e_{i}}$

7. enquanto $\max _{v_{w} \in M}\left(\delta_{i}^{\text {new }}\right) \geq \epsilon$

\subsubsection{Vértices ativos}

Pelo Algoritmo 6.1 pode-se notar que os vértice internos são processados em um laço aninhado. Consequentemente, pode ocorrer desperdício de processamento, principalmente no final da execução onde poucos vértices ainda estão sendo deslocados. Segundo Soares [58], a sequência em que os vértices são visitados também influencia 


\section{Aplicações}

na convergência do método numérico utilizado, por isso, foi proposta uma ordem de processamento em que os vértices são iterados em camadas (de forma semelhante a cascas de cebola) começando da fronteira até o interior da malha.

Outra contribuição de [58] foi o uso de um mecanismo baseado em vértices ativos para melhorar o desempenho computacional, controlar a sequência de processamento dos vértices e também controlar o critério de parada. Este mecanismo rotula os vértices da seguinte maneira:

- ativo: o vértice pode ser processado;

- inativo: o vértice não está sendo processado;

- fixo: o vértice não pode ser processado.

Cada vértice só pode possuir um único rótulo. Os conjuntos de vértices ativos e inativos têm seus elementos dispostos em uma sequência dada pela ordem de entrada dos elementos.

Em uma etapa de pré-processamento, todos os vértices da malha são rotulados de acordo com o seguinte procedimento:

1. Rotular todos os vértices que terão o deslocamento inicial não nulo e os vértices que não devem ser deslocados como fixos;

2. Rotular todos os vértices que são vizinhos aos vértices fixos como ativos;

3. Rotular como inativos todos os vértices que ainda não foram rotulados.

Apenas os vértices ativos podem ser iterados. Durante a execução vértices ativos e inativos tem seus rótulos alternados. Um vértice ativo se torna inativo quando seu deslocamento for insignificante (menor que uma tolerância $\epsilon$ ). Porém, se seu movimento for significativo, além de permanecer ativo, todos os vértices inativos vizinhos se tornam ativos. Após um vértice ativo ser processado, ele é removido do início da sequência de processamento dos vértices ativos.

\subsubsection{Passos de iteração}

As Aplicações I e II utilizam o mecanismo de vértices ativos adaptando assim o Algoritmo 6.1 para torná-lo mais eficiente. A execução dessas aplicações segue os passos do Algoritmo 6.2. 


\section{Aplicações}

\section{Algoritmo 6.2}

Entrada: Seja $V$ o conjunto de vértices rotulados como fixos da malha $M, n$ o número de passos de deslocamento de $v_{i} \in V$ e $d x_{i}$ o deslocamento desse vértice $v_{i}$ para cada passo.

1. $\delta_{i} \leftarrow 0$ para todo $v_{i} \in V$

2. $\quad$ para $\mathrm{j} \leftarrow 1$ até $\mathrm{n}$ faça

3. $\quad$ para todo $v_{i} \in V$ faça

4. $\quad \delta_{i} \leftarrow \delta_{i}+d x_{i}$

5. $\quad$ execute o Algoritmo 6.1 utilizando o mecanismo de vértices ativos

\subsection{Aplicação I - Movimento de malha triangular plana}

Nesta aplicação, a malha em questão representa a região externa de um aerofólio (Figura 6.1). Esta malha é composta por 8323 vértices e 16232 triângulos.

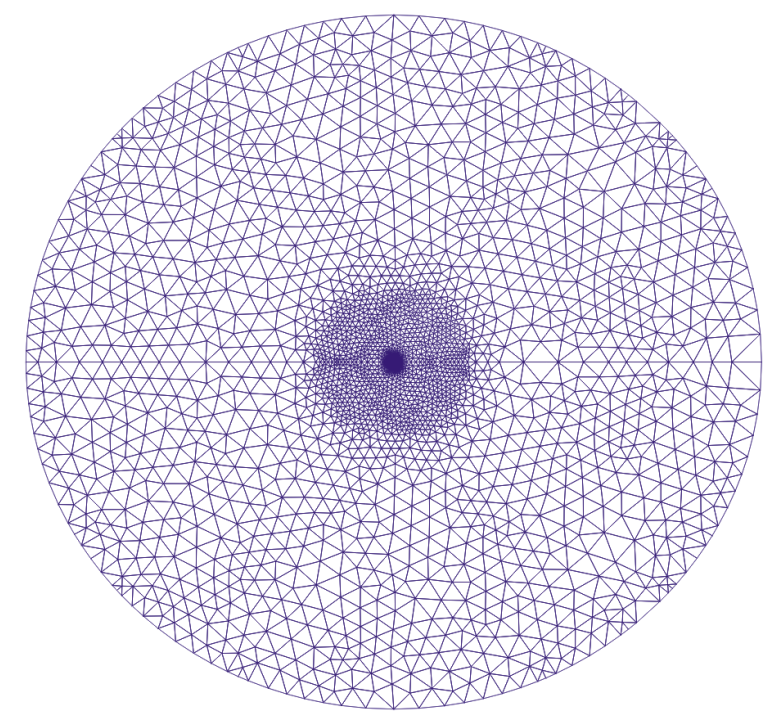

Figura 6.1: Malha que representa a parte externa do aerofólio. O bordo interno da malha (que representa o aerofólio) está localizado no centro da malha.

O deslocamento dos vértices pertencentes ao bordo interno da malha é igual para todos os vértices e incrementado a cada passo da aplicação.

A Figura 6.2(a) ilustra uma aproximação da região do aerofólio onde o movimento de malha causa mais efeito. As Figuras 6.2(b) a (e) ilustram os resultados da execução do movimento de malha e a Figura 6.2(f) ilustra a comparação da malha original com o resultado obtido no $60^{\circ}$ passo. 


\section{Aplicações}

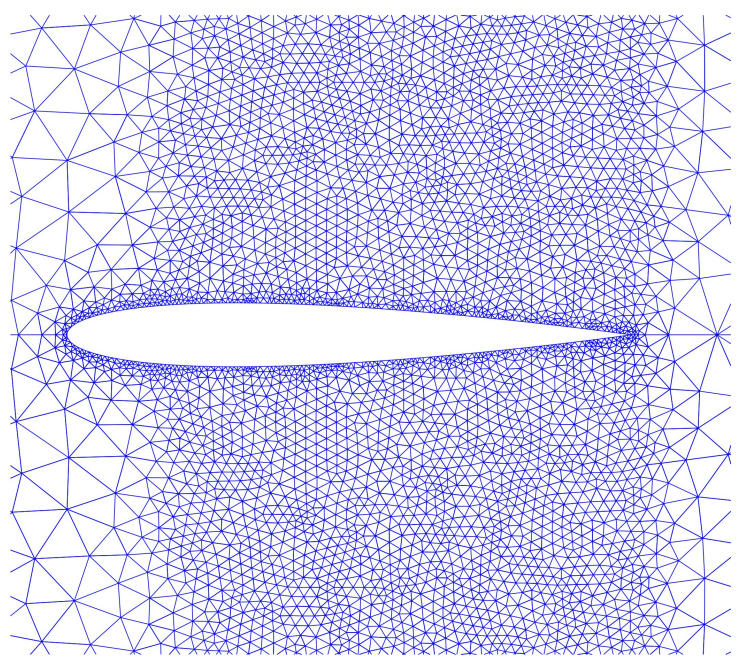

(a) Malha original

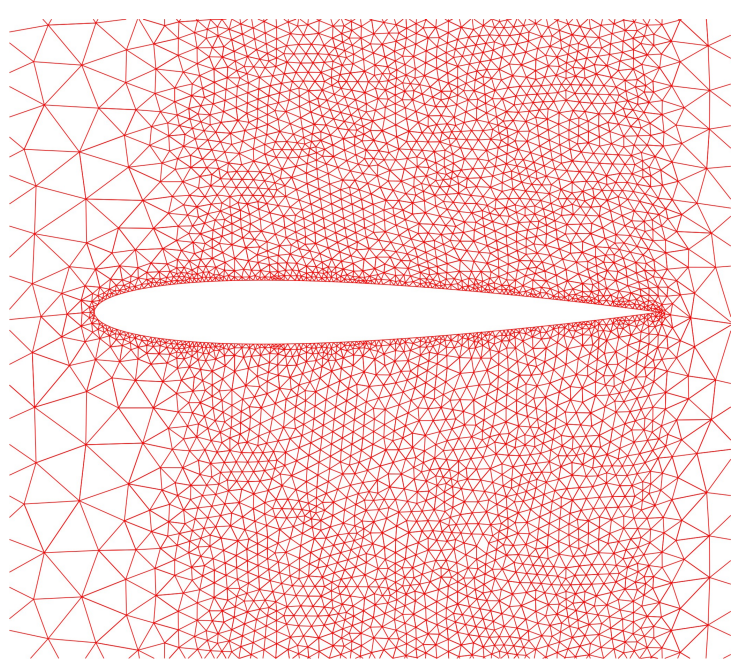

(c) Passo 20

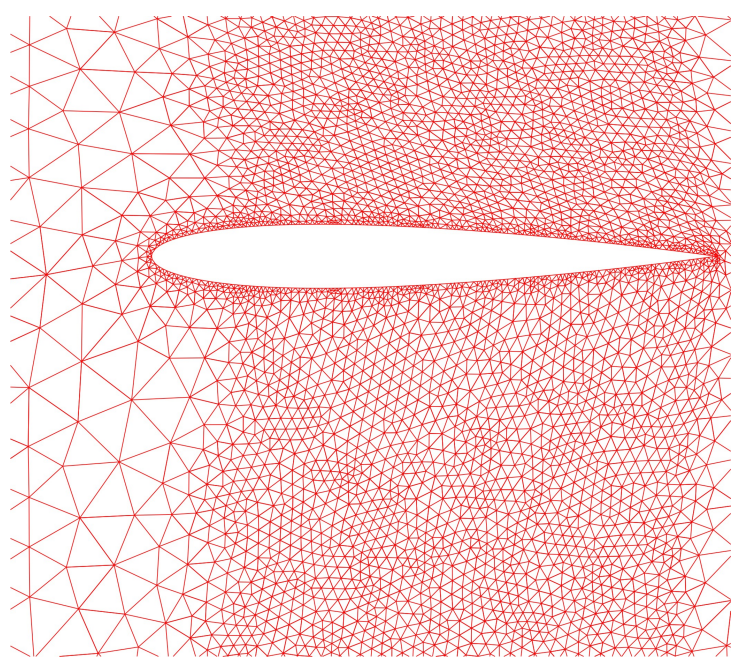

(e) Passo 60

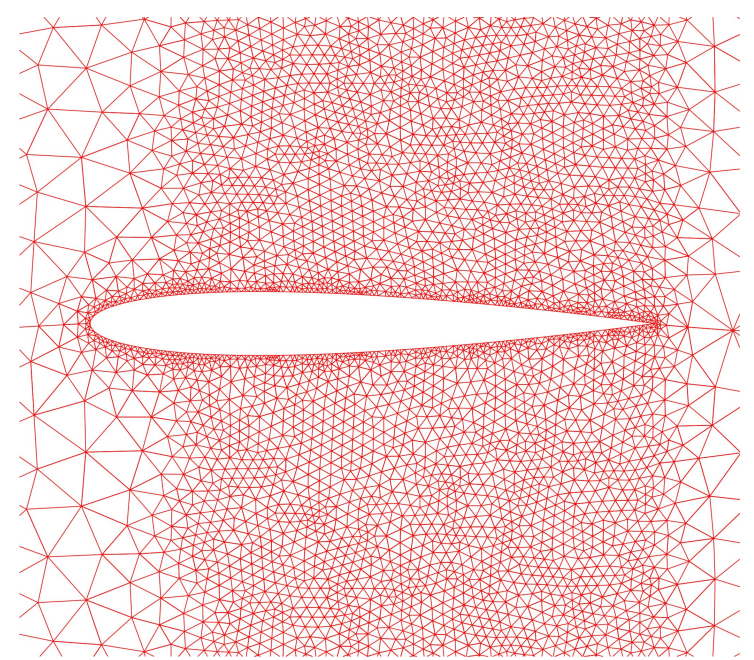

(b) Passo 10

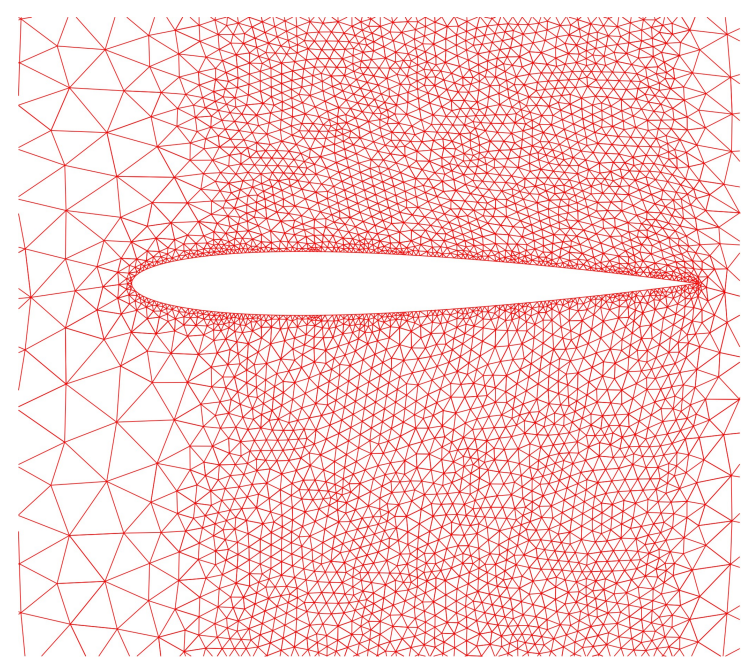

(d) Passo 40

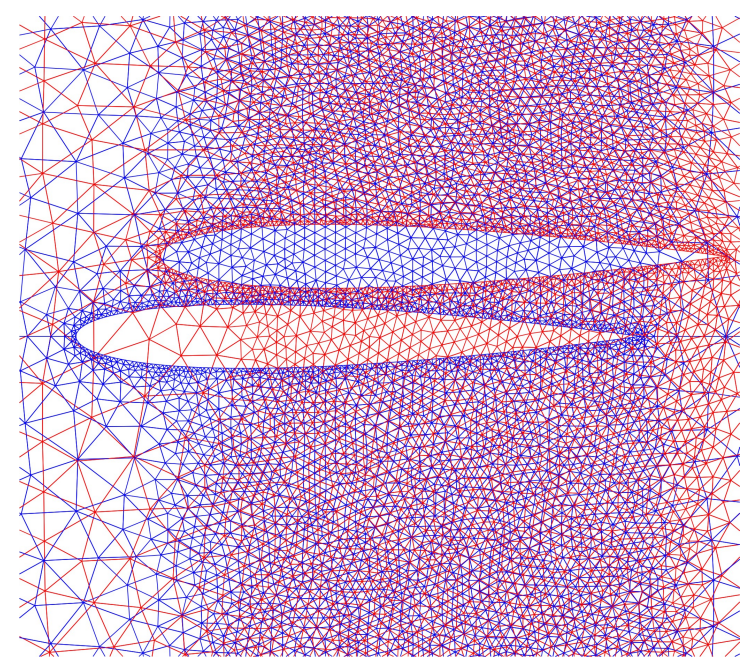

(f) Comparação com a malha original

Figura 6.2: Execução do passos da Aplicação I e comparação entre a malha original e o resultado final. 


\section{Aplicações}

Para mostrar a qualidade da malha resultante após o último passo, as Figuras 6.3(a) e (b) apresentam uma aproximação das regiões da malha consideradas mais críticas por poderem produzir triângulos de qualidade ruins.

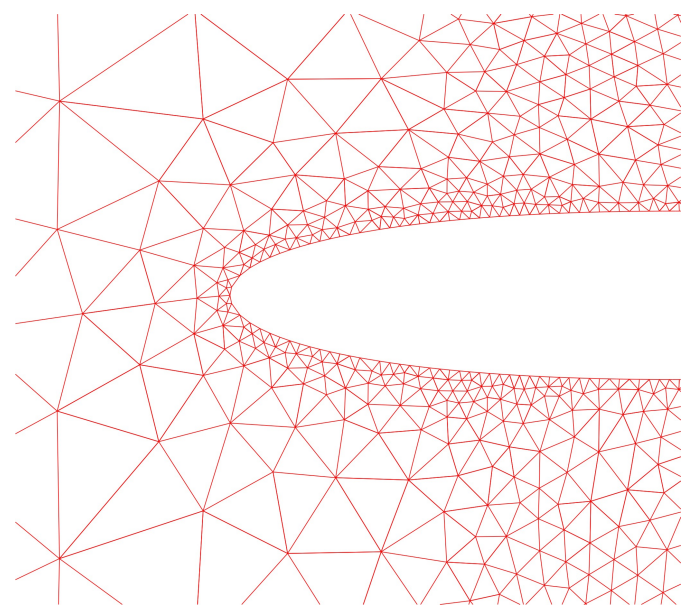

(a) Aproximação da região à esquerda

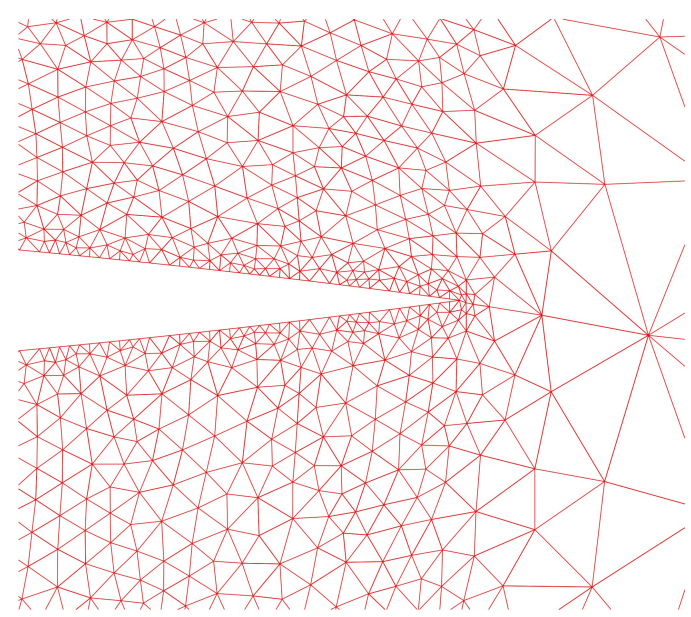

(b) Aproximação da região à direita

Figura 6.3: Aproximação das regiões consideradas mais críticas após 60 passos.

\subsection{Aplicação II - Movimento de malha mista plana}

A segunda aplicação envolve movimento de uma malha mista plana que representa uma mão com um círculo "retirado" dela (Figura 6.4). O movimento desta malha é executado em 60 passos e os vértices do bordo internos (o círculo) são deslocados conforme o raio do círculo é aumentado.

A Figura 6.5(a) ilustra uma aproximação da região do círculo onde o movimento de malha causa mais efeito. As Figuras 6.5(b) a (e) ilustram os resultados da execução do movimento de malha e a Figura 6.5(f) ilustra a comparação da malha original com o resultado obtido no $60^{\circ}$ passo. 


\section{Aplicações}

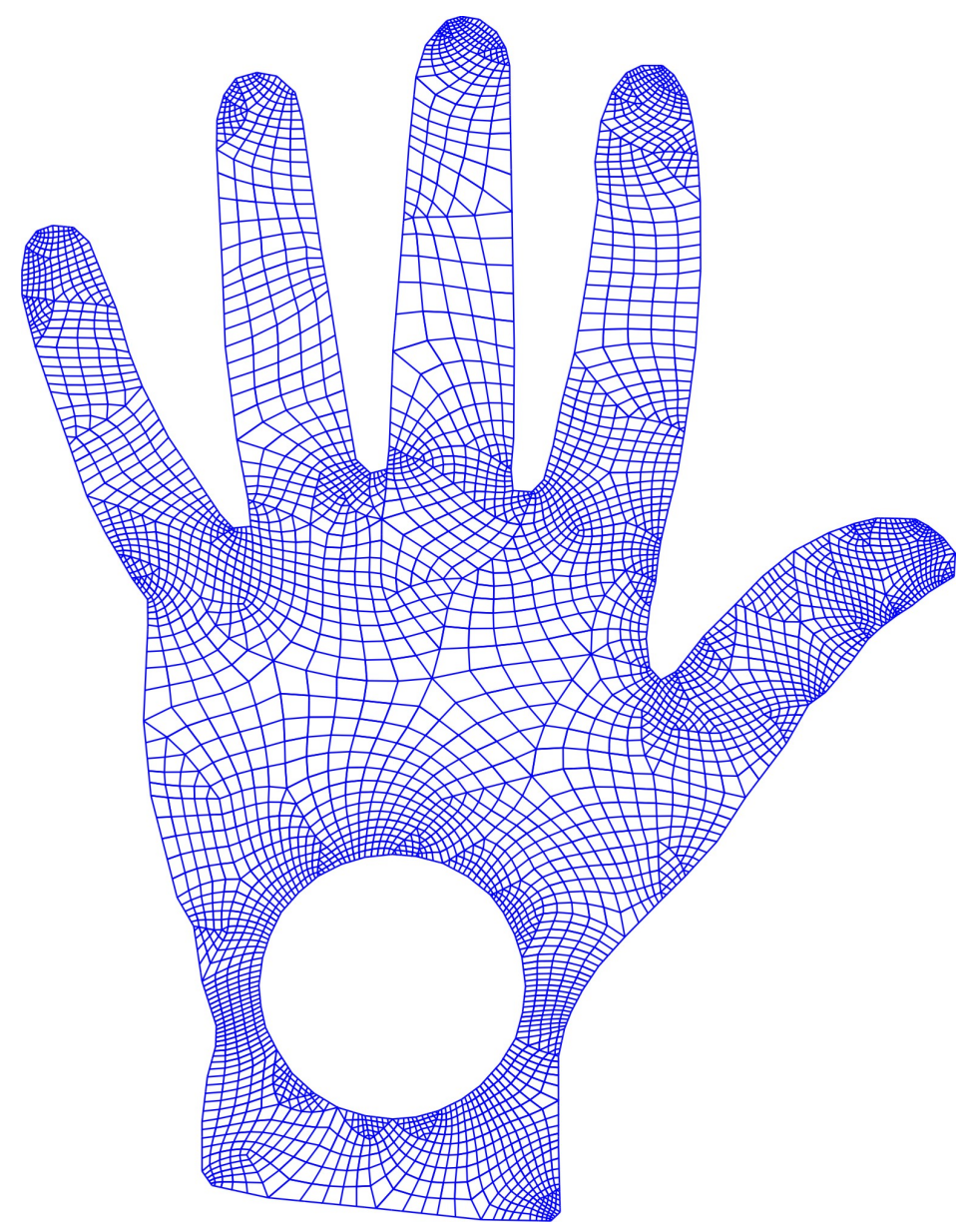

Figura 6.4: Malha da mão original formada por 6207 vértices e 4345 células. Esta malha foi gerada pelo algoritmo de geração de malhas proposto por Mario Augusto de Souza Liziér. 


\section{Aplicações}

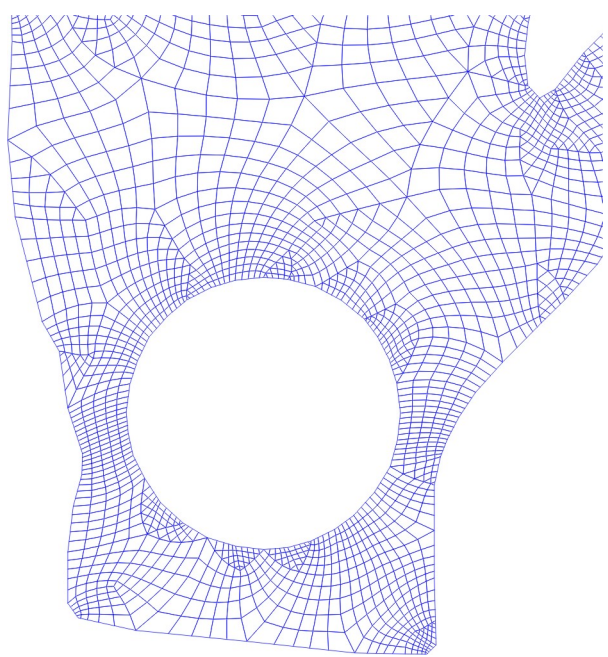

(a) Malha original

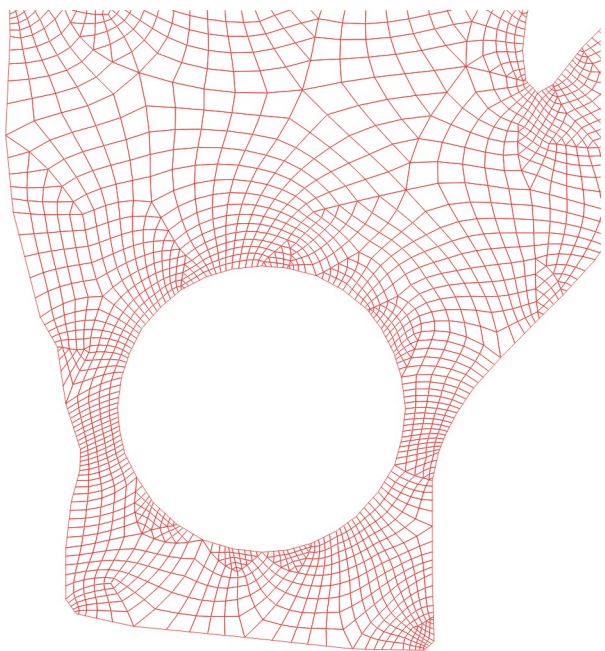

(c) Passo 20

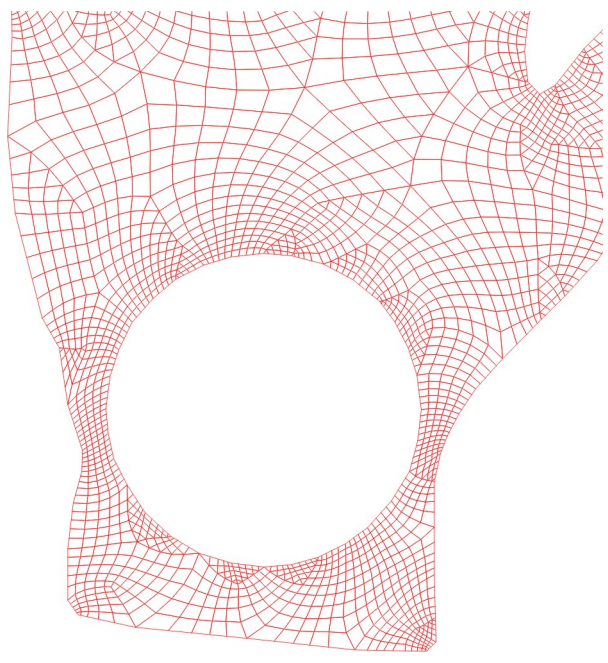

(e) Passo 60

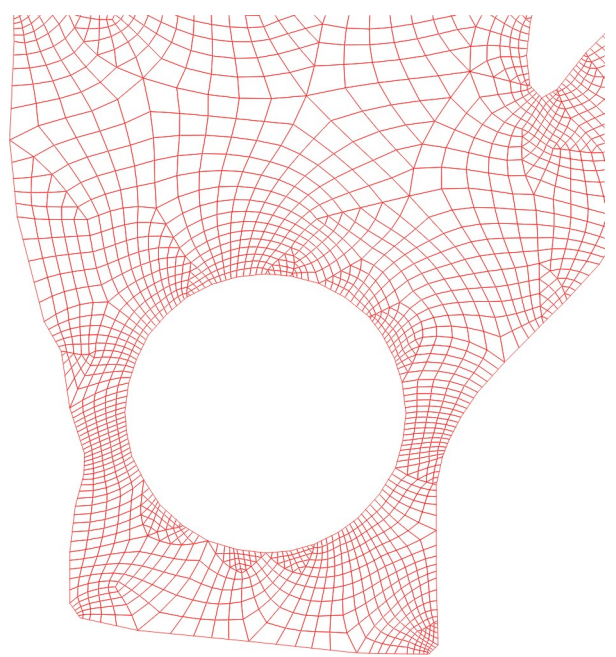

(b) Passo 10

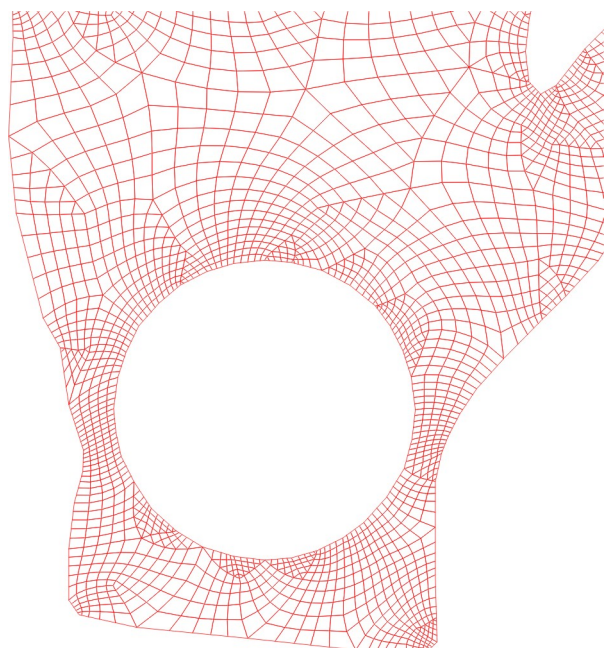

(d) Passo 40

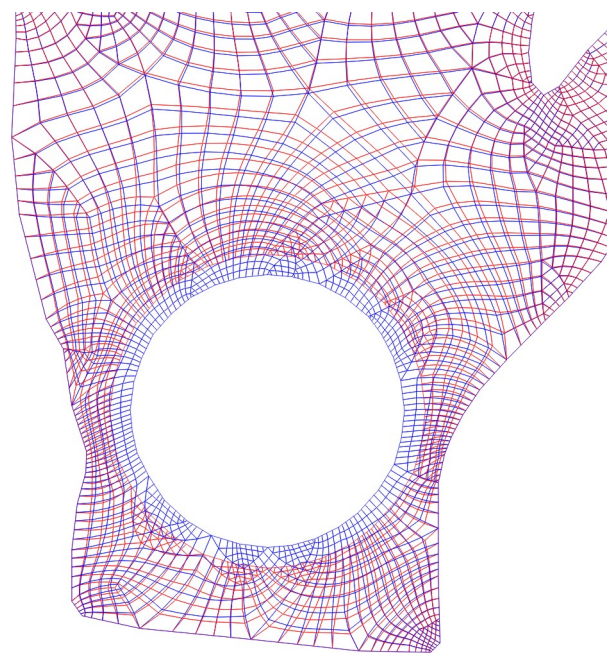

(f) Comparação com a malha original

Figura 6.5: Execução do passos da Aplicação II e comparação entre a malha original e o resultado final. 


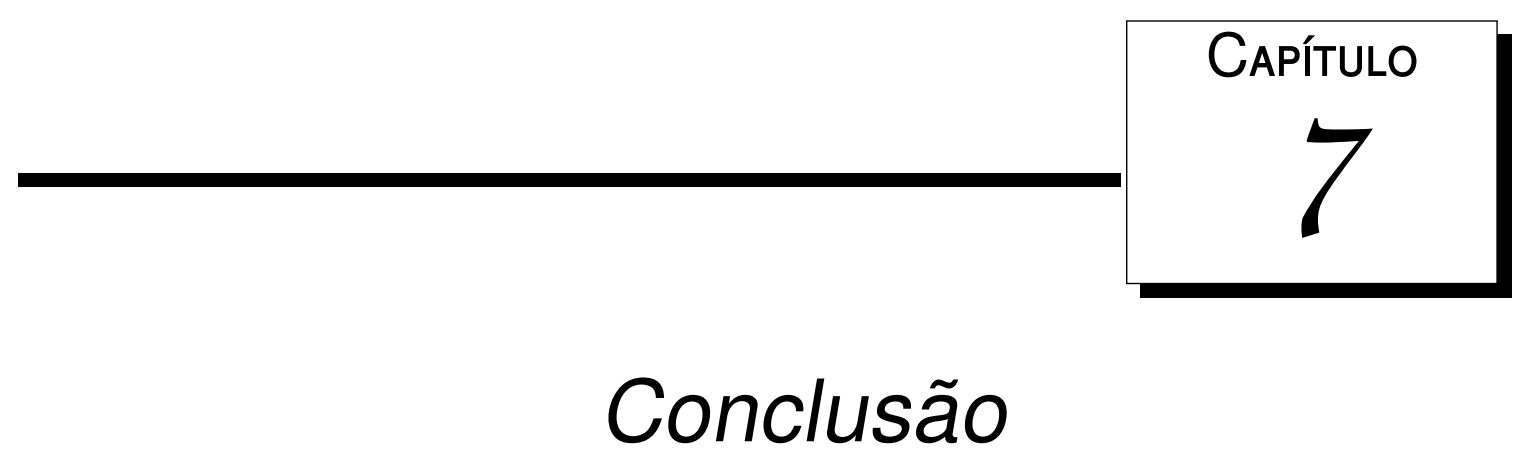

Nesta dissertação foram apresentados dois trabalhos que serviram de foco principal neste projeto de mestrado: o desenvolvimento de uma ED topológica para a representação de malhas $2 \mathrm{D}$ e 3D e o desenvolvimento de um método de geração de malhas tetraédricas.

A ED desenvolvida foi a estrutura Mate Face (MF). Esta é capaz de representar implicitamente malhas bidimensionais (triangulares, quadriláteras ou mistas) e malhas tridimensionais (tetraédricas, hexaédricas, prismáticas ou piramidais). Os focos principais deste trabalho foram tornar essa ED flexível quanto aos tipos de malhas que ela representa e torná-la fácil de se utilizar sem que o usuário precise de um conhecimento aprofundado sobre o funcionamento interno da estrutura.

A estrutura MF estende a estrutura $\mathrm{OF}$, porém foi necessária uma série de adaptações para possibilitar a representação de células não-simpliciais e permitir a representação explícita das arestas e faces (sendo esta última somente em malhas 3D). Esta última característica permite a atribuição de valores a esses componentes de maneira mais simples. Em aplicações onde não é necessária atribuição de valores a esses componentes, é possível reduzir o consumo de memória nas representações implícitas. Isto é possível devido à flexibilidade da estrutura MF.

Foram implementadas algumas aplicações para testar a funcionalidade e eficiência da estrutura MF, entre elas se destacam as aplicações de movimento de malhas elásticas. Estas aplicações demonstraram um bom comportamento da estrutura tanto 
na aplicação envolvendo malhas triangulares quanto na aplicação envolvendo malhas mistas.

O método de geração de malhas implementado foi baseado no algoritmo de Isosurface Stuffing proposto por Labelle e Shewchuk [37]. O principal objetivo desse método é gerar malhas tetraédricas com adaptatividade interna que apresentam boa qualidade de ângulos diedrais.

Os resultados obtidos apresentam a grande maioria dos tetraedros com boa qualidade, porém devido ao fato que ainda não foi possível finalizar a prova da garantia de qualidade dos ângulos diedrais, existem alguns casos de tetraedros com ângulos muito pequenos ou muito grandes. Acredita-se que após a finalização desta prova poderão ser obtidos os parâmetros $\alpha$ necessários para a garantia de qualidade. Além disso, será proposta a prova de garantia de qualidade para malhas com superfícies adaptativas.

Vale mencionar que a estrutura MF é utilizada durante a segunda etapa do gerador de malhas. O uso dessa estrutura serviu para facilitar a implementação das operações executadas durante a segunda etapa. Além disso serviu também para novamente testar a funcionalidade da estrutura, já que foram necessárias operações envolvendo vizinhanças de elementos (estrelas de vértices) e atribuição de valores a arestas.

\subsection{Trabalhos Futuros}

Propõe-se como trabalhos futuros as seguintes atividades:

- Substituição da ED OF pela estrutura MF no sistema CyberMed para apoiar a expansão desse sistema. A estrutura OF foi usada nesse sistema para representação de malhas triangulares [20]. Com a expansão do CyberMed, será necessário o uso de outros tipos de malhas além das triangulares, para isso pretende-se empregar a estrutura MF;

- Resolver o problema de representação de malhas volumétricas mistas. A possibilidade de representar malhas volumétricas será útil para dar sequência a outros trabalhos que envolvem malhas 3D mistas;

- Desenvolvimento de aplicações envolvendo movimento de malhas volumétricas elásticas. Para tal propósito, pretende-se seguir a estratégia de analogia com molas altura [58] para evitar que as células presentes na malha se tornem inválidas;

- Além de finalizar a prova da garantia de qualidade da geração de malhas com 
Conclusão

tetraedros superficiais de mesmo nível de refinamento, desenvolver uma prova de qualidade envolvendo malhas tetraédrica com superfície adaptativas. Esta prova é mais complexa devido ao fato que os tetraedros são de tamanhos diferentes, logo o cálculo dos parâmetros $\alpha$ exige um maior cuidado. 
Conclusão 


\section{Referências Bibliográficas}

[1] Andrea L. Ames, David R. Nadeau, and John L. Moreland. VRML 2.0 Sourcebook. Wiley, segunda edição, 1996.

[2] J. T. Batina. Unsteady euler airfoil solutions using unstructured dynamic meshes. AIAA Journal, 28(8):1381-1388, 1990.

[3] B. G. Baumgart. A polyhedron representation for computer vision. In AFIS National Computer Conference, volume 44, pages 589-596, 1975.

[4] M. W. Bealland and M. Shephard. A general topology-based mesh data structure. In Int. J. for Numerical Methods in Engineering, volume 40, pages 1573-1596, 1997.

[5] M. Bern, D. Eppstein, and J. Gilbert. Provably good mesh generation. J. Comput. Syst. Sci., 48(3):384-409, 1994.

[6] F. J. Blom. Considerations on the spring analogy. International Journal for Numerical Methods in Fluids, 32(6), 2000.

[7] J. D. Boissonnat, O. Devillers, M. Teillaud, and M. Yvinec. Triangulations in cgal. In In 16th Annu. ACM Sympos. Comput. Geom. ACM, 2000.

[8] F. J. Bossen and P. S. Heckbert. A pliant method for anisotropic mesh generation. In In 5th Intl. Meshing Roundtable, pages 63-74, 1996.

[9] C. L. Bottasso, O. Klass, and M. S. Shephard. Data structures and mesh modication tools for unstructured multigrid adaptive techniques. In Engineering with Computers, volume 14, pages 234-247. Springer London, 1998.

[10] R. L. Burden and J. D. Faires. Numerical Analysis. PWS Publishing Co, USA, quarta edição, 1989. 


\section{Referências Bibliográficas}

[11] S. Campagna, L. Kobbelt, and H. Seidel. Directed edges: A scalable representation for triangle meshes. In Journal of Graphics Tools, volume 3, pages 1-11, 1998.

[12] A. Castelo. Aproximação adaptativa de variedades implícias com aplicações na modelagem implícita e em equações algébrico-diferenciais. Tese de doutorado, Pontíficia Universidade Católica do Rio de Janeiro - PUC-RIO, 1992.

[13] A. Castelo, H. Lopes, and G. Tavares. Handlebody representation for surfaces and morse operations. In Curves and Surfaces in Computer Vision and Graphics III, pages 270-283, 1992.

[14] A. Castelo, L. G. Nonato, M. Siqueira, R. Minghim, and G. Tavares. The j1a triangulation: An adaptive triangulation in any dimension. Computer $\mathcal{E}$ Graphics, 30(5):737-753, 2006.

[15] S.-W. Cheng, T. K. Dey, H. Edelsbrunner, M. A. Facello, and S.-H. Teng. Sliver exudation. J. ACM, 47(5):883-904, 2000.

[16] S.-W. Cheng and T. K. Dey. Quality meshing with weighted delaunay refinement. In SODA '02: Proceedings of the thirteenth annual ACM-SIAM symposium on Discrete algorithms, pages 137-146. Society for Industrial and Applied Mathematics, 2002.

[17] S.-W. Cheng, T. K. Dey., E.A. Ramos, and T. Ray. Quality meshing for polyhedra with small angles. In Proceedings of the twentieth annual symposium on Computational geometry, pages 290-299. ACM, 2004.

[18] L. P. Chew. Guaranteed-quality delaunay meshing in 3d (short version). In Proceedings of the thirteenth annual symposium on Computational geometry, pages 391-393. ACM, 1997.

[19] I. L. L. da Cunha, A. De Lacassa, V. Polizelli-Junior, J. P. Gois, L. G. Nonato, and A. C. Filho. Adaptive algebraic mesh generation from implicit functions. In Iberian Latin American Congress On Computational Methods in Engineering, 2008.

[20] I. L. L. da Cunha, R. M. Moraes, and L. dos S. Machado. Cybview - uma classe para visualização interativa e estereoscópica para sistemas de realidade virtual. In Workshop de Iniciação Científica - WIC-SIBGRAPI 2006, 2006.

[21] C. Degand and C. Farhat. A three-dimensional torsional spring analogy method for unstructured dynamic meshes. Computers and Structures, 80:305-316, 2002. 
[22] D. P. Dobkin and M. J. Laszlo. Primitives for the manipulation of three-dimensional subdivisions. Algorithmica, 4:3-32, 1989.

[23] H Doi and J. J. Alonso. Fluid/structure coupled aeroelastic computations for transonic flows in turbomachinery. In ASME Turbo Expo 2002, 2002.

[24] L. dos S. Machado, S. F. Campos, I. L. L. da Cunha, and R. M. Moraes. Cybermed: realidade virtual para ensino médico. IFMBE Proceedings, 5:573-576, 2004.

[25] L. dos S. Machado, R. M. Moraes, D. F. L. Souza, L. C. Souza, and I. L. L. da Cunha. A framework for development of virtual reality-based training simulator. Studies in Health Technology and Informatics, 142:174-176, 2009.

[26] C. Farhat, C. Degand, B. Koobus, and M. Lesoinne. An improved method of spring analogy dynamic unstructured fluid meshes. AIAA Paper, 1998.

[27] L. De Floriani and A. Hui. A scalable data structure for three-dimensional nonmanifold objects. In Symposium on Geometry Processing, pages 72-82. ACM, 2003.

[28] A. Fuchs. Automatic grid generation with almost regular delaunay tetrahedra. In Seventh International Meshing Roundtable, pages 133-148, 1998.

[29] J. P. Gois. Minimos-quadrados e aproximação de superfície de pontos: novas perspectivas e aplicações. Tese de doutorado, Universidade de São Paulo, 2008.

[30] J. P. Gois, V. Polizelli-Junior, T. Etiene, E. Tejada, A. Castelo, T. Ertl, and L. G. Nonato. Robust and adaptive surface reconstruction using partition of unity implicits. In SIBGRAPI '07: Proceedings of the XX Brazilian Symposium on Computer Graphics and Image Processing, pages 95-104. IEEE Computer Society, 2007.

[31] J. P. Gois, V. Polizelli-Junior, T. Etiene, E. Tejada, A. Castelo, T. Ertl, and L. G. Nonato. Two-fold adaptive partition of unity implicits. The Visual Computer, 24(12):1013-1023, 2008.

[32] L. J. Guibas and J. Stolfi. Primitives for the manipulation of general subdivisions and the computation of voronoi diagrams. Transactions On Graphics, 4:74-123, 1985.

[33] L. Kettner. Using generic programming for designing a data structure for polyhedral surfaces. Computational Geometry - Theory and Applications, 13:65-90, 1999. 


\section{Referências Bibliográficas}

[34] Kitware Inc. The VTK User's Guide - Version 4.4. Kitware Inc., 2004.

[35] W. R. Kruger, R. Heinrich, and M. Spieck. Fluid-structure coupling using cfd and multibody simulation methods. In ICAS 2002 Congress, 2002, 2002.

[36] W. Kwok, K. Haghighi, and E. Kang. An efficient data structure for the advancingfront triangular mesh generation technique. In Communications in Numerical Methods in Engineering, volume 11, pages 465-473, 1995.

[37] F. Labelle and J. R. Shewchuk. Isosurface stuffing: fast tetrahedral meshes with good dihedral angles. ACM Trans. Graph., 26(3):57, 2007.

[38] M. Lage, T. Lewiner, H. Lopes, and L. Velho. CHF: A scalable topological data-structure for tetrahedral meshes. In SIBGRAPI '05: Proceedings of the XVIII Brazilian Symposium on Computer Graphics and Image Processing, pages 349-356. IEEE Computer Society, 2005.

[39] M. Lage. Scalable topological data structures for 2 and 3-manifolds. Dissertação de mestrado, Pontíficia Universidade Católica do Rio de Janeiro - PUC-RIO, 2006.

[40] X.-Y. Li and S.-H. Teng. Generating well-shaped delaunay meshes in 3d. In SODA '01: Proceedings of the twelfth annual ACM-SIAM symposium on Discrete algorithms, pages 28-37. Society for Industrial and Applied Mathematics, 2001.

[41] M. Liziér. Geração de malhas a partir de imagens com textura. Qualificação de doutorado, Universidade de São Paulo, 2006.

[42] H. Lopes. Algorithms to Build and Unbuild 2 and 3 dimensional manifolds. Tese de doutorado, Pontíficia Universidade Católica do Rio de Janeiro - PUC-RIO, 1996.

[43] H. Lopes and G. Tavares. Structural operators for modeling 3-manifolds. In Solid modeling and applications, pages 10-18. ACM, 1997.

[44] W. E. Lorensen and H. E. Cline. Marching cubes: A high resolution 3d surface construction algorithm. SIGGRAPH Comput. Graph., 21(4):163-169, 1987.

[45] S. A. Mitchell and S. A. Vavasis. Quality mesh generation in higher dimensions. SIAM J. Comput., 29(4):1334-1370, 2000.

[46] M. Mäntylä. An Introduction to Solid Modeling. Computer Science Press, 1988. 


\section{Referências Bibliográficas}

[47] D. J. Naylor. Filling space with tetrahedra. International Journal for Numerical Methods in Engineering, 44(10):1383-1395, 1999.

[48] G. M. Nielson. Volume modeling. In Volume Graphics, pages 29-48. SpringerVerlag, 2000.

[49] L. G. Nonato, A. Castelo, M. Oliveira, and M. A. S. Liziér. Topological approach for detecting objects from images. volume 5300, pages 62-73. SPIE, 2004.

[50] L. G. Nonato, A. Castelo, J. E. P. P. de Campos, H. H. Biscaro, and R. Minghim. Topological tetrahedron characterization with application in volume reconstruction. International Journal of Shape Modeling, 11(2):189-215, 2005.

[51] L. G. Nonato, M. A. S. Liziér, J. Batista, M. Oliveira, and A. Castelo Filho. Topological triangle characterization with application to object detection from images. Image and Vision Computing, 26:1081-1093, 2008.

[52] Y. Ohtake, A. Belyaev, M. Alexa, G. Turk, and H.-P. Seidel. Multi-level partition of unity implicits. ACM Trans. Graph., 22(3):463-470, 2003.

[53] S. E. Pav and N. J. Walkington. Robust Three Dimensional Delaunay. In In 13th International Meshing Roundtable, pages 145-156, 2004.

[54] V. Polizelli-Junior. Métodos implícitos para a reconstrução de superfície a partir de nuvens de pontos. Dissertação de mestrado, Universidade de São Paulo, 2008.

[55] J. Rossignac, A. Safonova, and A. Szymczak. 3d compression made simple: Edgebreaker on a corner table. In Shape Modeling International Conference, pages 278-283, 2001.

[56] J. R. Shewchuk. Tetrahedral mesh generation by Delaunay refinement. In Proceedings of the fourteenth annual symposium on Computational geometry, pages 86-95. ACM, 1998.

[57] J. R. Shewchuk. What is a good linear element? interpolation, conditioning, and quality measures. In In 11th International Meshing Roundtable, pages 115-126, 2002.

[58] I. P. Soares. Movimento de malhas e remalhamento de malhas superficiais. Tese de doutorado, Instituto de Ciências Matemáticas e de Computação - ICMC/USP-São Carlos, 2007. 


\section{Referências Bibliográficas}

[59] I. P. Soares, L. G. Nonato, A. Castelo Filho, and J. A. Cuminato. Malha elástica restrita à forma. In In Proceedings of XXV CILAMCE - Iberian Latin American Congress on Computational Methods, 2004.

[60] D. M. Y. Sommerville. Space-filling tetrahedra in euclidean space. In Proceedings of the Edinburgh Mathematical Society, volume 41, pages 46-57, 1923.

[61] D. F. Souza, I. L. L. da Cunha, L. C. Souza, R. M. Moraes, and L. dos S. Machado. Development of a VR simulator using free tools: A case study. In Proceedings of IX Symposium on Virtual and Augmented Reality, 2007.

[62] A. Vieira, L. Velho, H. Lopes, G. Tavares, and T. Lewiner. Fast stellar mesh simplification. In Proceedings of the XVI Brazilian Symposium on Computer Graphics and Image Processing, pages 27-34. IEEE Press, 2003.

[63] M. A. Yerry and M. S. Shephard. Automatic three-dimensional mesh generation by the modified-octree technique. International Journal for Numerical Methods in Engineering, 20(11):1965-1990, 1984.

[64] D. Zeng and C. R. Ethier. A semi-torcional spring analogy model for updating unstructured meshes. In 9th Anual Conference of the CFD Sopciety of Canada, page 113, 2001. 
APÊNDICE $\mathcal{A}$

\section{Códigos Exemplos}

Neste apêndice, são apresentados os trechos de códigos exemplos que auxiliaram no entendimento do funcionamento da MF.

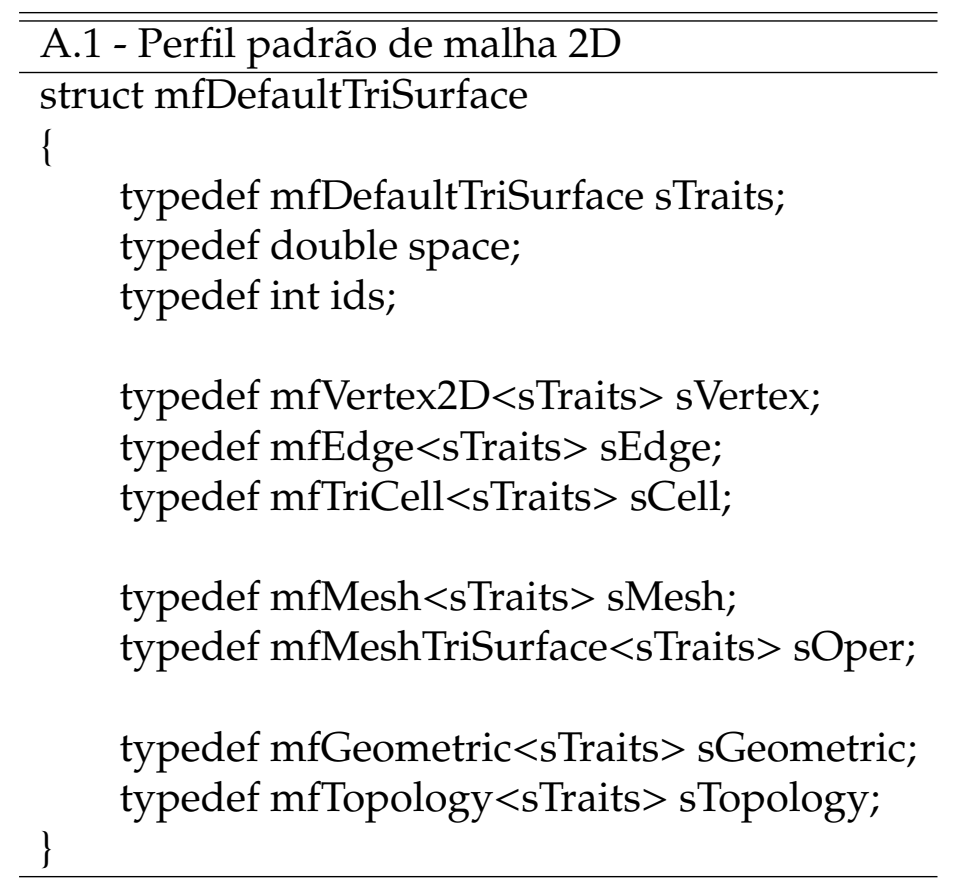



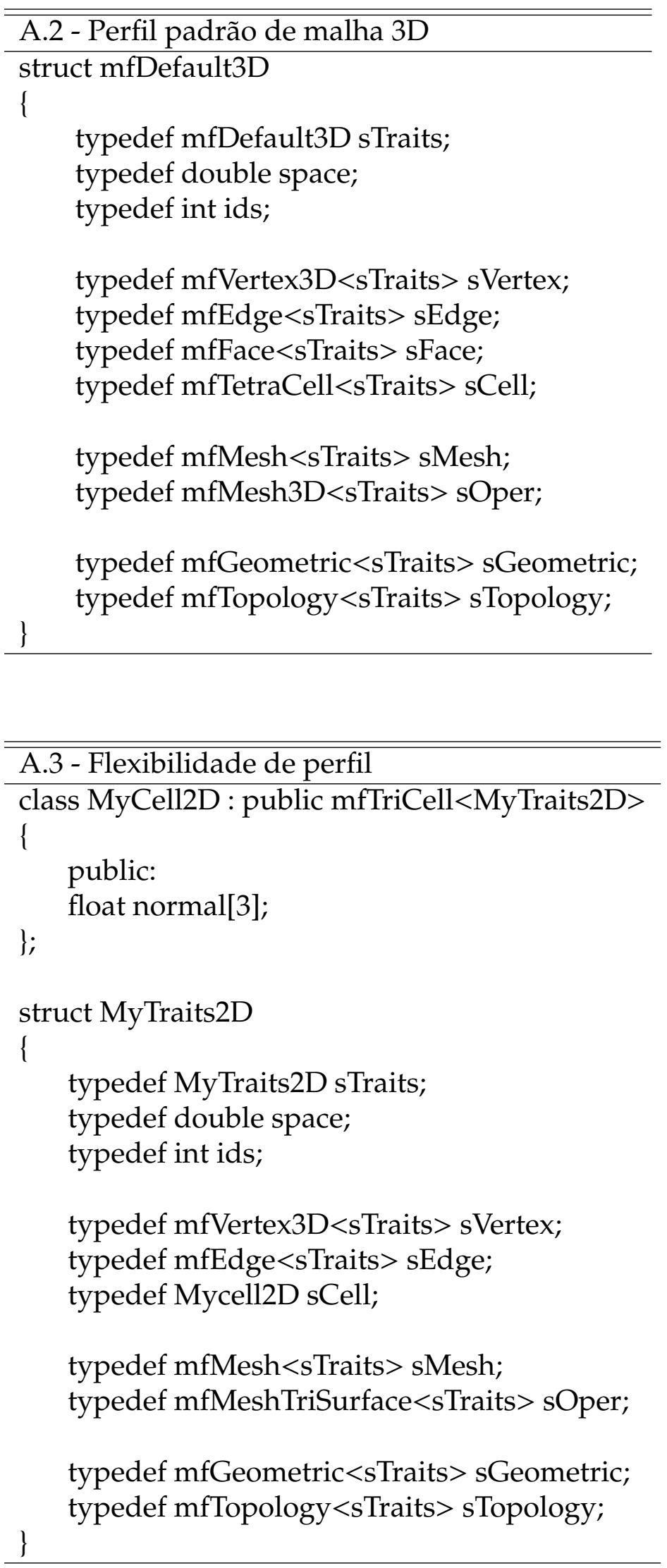


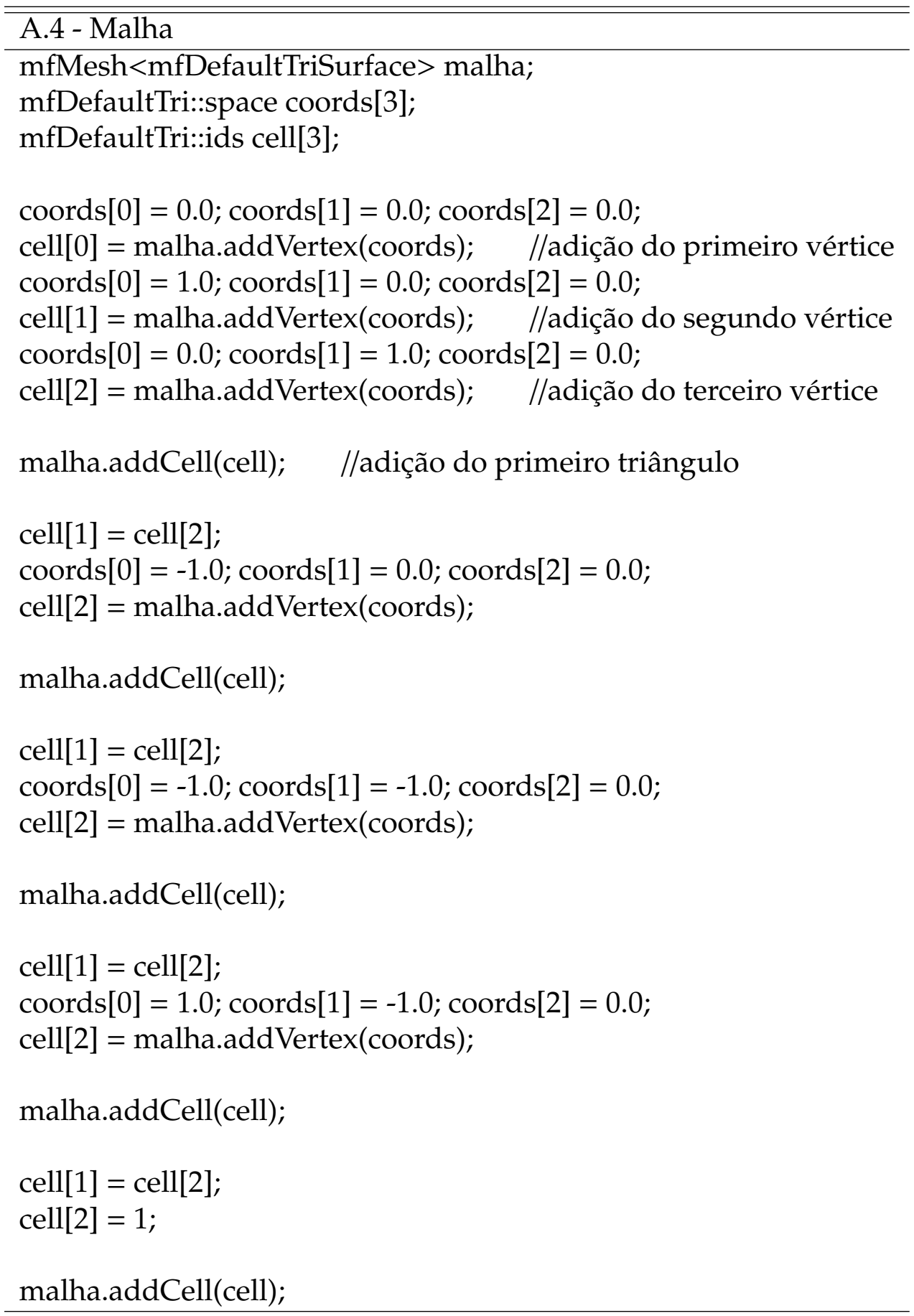



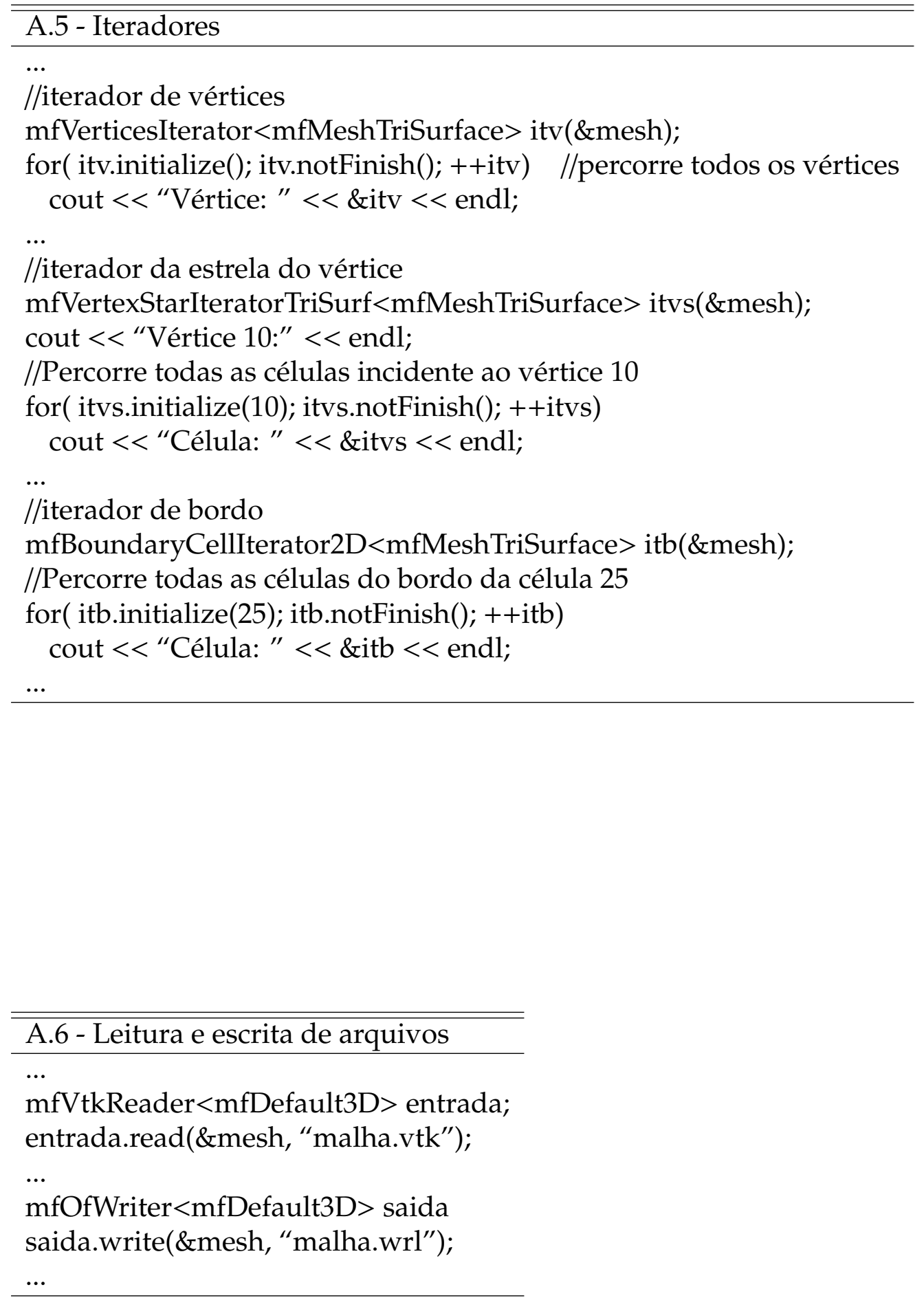